Gilcinea Rangel Pesenti

\title{
Medição remota como estratégia de monitoramento de baterias estacionárias: Estudo de caso em uma subestação de energia elétrica
}

Dissertação de Mestrado

Dissertação apresentada como requisito parcial para obtenção do grau de Mestre pelo Programa de PósGraduação em Metrologia da PUC-Rio. Área de concentração: Metrologia para Qualidade e Inovação.

Orientador: Prof. Mauricio Nogueira Frota

Rio de Janeiro 
Gilcinea Rangel Pesenti

\section{Medição remota como estratégia de monitoramento de baterias estacionárias: Estudo de caso em uma subestação de energia elétrica}

Dissertação apresentada como requisito parcial para obtenção do título de Mestre em Metrologia pelo Programa de Pós-Graduação em Metrologia da PUC-Rio. Aprovada pela Comissão Examinadora abaixo assinada.

Prof. Mauricio Nogueira Frota

Presidente / Orientador Programa de Pós-Graduação em Metrologia (PUC-Rio)

Profa. Elisabeth Costa Monteiro Programa de Pós Graduação em Metrologia (PUC-Rio)

Dr. José Antonio Donizete Rossi CPqD

Prof. Jose Eugenio Leal Coordenador Setorial de Pós-Graduação do Centro Técnico Científico (PUC-Rio) 
Todos os direitos reservados. É proibida a reprodução total ou parcial do trabalho sem autorização da universidade, do autor e do orientador.

\section{Gilcinea Rangel Pesenti}

Graduada em Bacharel e Licenciatura em Química, possui MBA em Gerenciamento de Projetos pela Fundação Getulio Vargas (FGV) e Pós-graduação em Análise de Sistemas. Tem 24 anos de experiência profissional trabalhados em concessionária de energia elétrica, com atuação em gerência de projetos, avaliação industrial de fornecedores, avaliação empresarial de fornecedores, avaliação de responsabilidade social, diligenciamentos e inspeções de materiais. Participa de revisões de Normas Brasileiras (ABNT). Atualmente é responsável técnica do laboratório de química de uma concessionária de energia elétrica. Autora de trabalhos apresentados em eventos técnico-científicos no Brasil e no exterior.

Ficha Catalográfica

Pesenti, Gilcinea Rangel
Medição remota como estratégia de
monitoramento de baterias estacionárias: estudo de caso
em uma subestação de energia elétrica / Gilcinea Rangel
Pesenti ; orientador: Mauricio Nogueira Frota. - 2012.
83 f. : il. (color.); $30 \mathrm{~cm}$
Dissertação (mestrado) - Pontifícia Universidade
Católica do Rio de Janeiro, Programa de Pós-Graduação
em Metrologia (Área de concentração: Metrologia para a
Qualidade e Inovação), 2012 .
Inclui bibliografia
1. Metrologia - Teses. 2. Medição remota. 3.
Monitoramento de baterias. 4. Sistema de energia. 5.
Subestações. I. Frota, Maurício Nogueira. II. Pontifícia
Universidade Católica do Rio de Janeiro. Programa de
Pós-Graduação em Metrologia para a Qualidade e
Inovação. III. Título.

CDD 389.1 
Dedico esta dissertação à minha amada filha Luana, que me dá força para superar todas as dificuldades da vida. 


\section{Agradecimentos}

Primeiramente, agradeço a todos que de alguma forma, passaram pela minha vida e contribuíram para a construção de quem sou hoje.

Especialmente, algumas pessoas, ajudaram diretamente e indiretamente para que este trabalho fosse concluído, onde presto minha sincera homenagem:

Ao professor Maurício, que para mim foi uma imensa honra e orgulho tê-lo como orientador e aos demais professores da metrologia da PUC-Rio, que foram tão importantes na minha vida acadêmica.

À pesquisadora Maria de Fátima Rosolem, ao Pesquisador Raul Beck e aos demais colegas do $\mathrm{CPqD}$, que muito contribuíram para esta realização.

Aos meus pais, meu marido Ivan, minha tia Luiza, minha sobrinha Karine e a toda família que, de forma especial e carinhosa me deram força e coragem, me apoiando nos momentos de dificuldades.

Aos amigos José Daniel, Maria Helena e Ângela pelo incentivo e pelo apoio constante.

Ao José Tenório e demais colegas de trabalho da Light que acreditaram no meu projeto e me incentivaram a ir em frente.

À banca examinadora, composta por Dr. José Antonio Donizete Rossi e Dra. Elisabeth Costa Monteiro, pelos comentários e sugestões apresentadas com o objetivo de valorizar o trabalho. 


\section{Resumo}

Pesenti, Gilcinea Rangel; Frota, Mauricio Nogueira. Medição remota como estratégia de monitoramento de baterias estacionárias: Estudo de caso em uma subestação de energia elétrica. Rio de Janeiro, 2012. 83p. Dissertação de Mestrado - Programa de Pós-Graduação em Metrologia (Área de concentração: Metrologia para Qualidade e Inovação), Pontifícia Universidade Católica do Rio de Janeiro.

A presente dissertação tem por objetivo geral validar em condições reais de operação, a técnica (desenvolvida em ambiente laboratorial) de monitoramento remoto de baterias estacionárias e como objetivos específicos identificar as limitações das tecnologias convencionais de monitoramento de baterias estacionárias, avaliar a confiabilidade do método de monitoramento remoto proposto e justificar a alternativa tecnológica proposta à luz do impacto econômico que dela decorrem. $\mathrm{O}$ desenvolvimento deste tema de dissertação de mestrado foi motivado pelas contribuições que poderá produzir para a Light e demais empresas dos setores elétricos, óleo e gás, bancário, de telecomunicações, entre outros setores que utilizam baterias estacionárias. A Light e o CPqD realizaram o projeto de P\&D Light-Aneel 033/2008. Este projeto teve como objetivo o aumento da confiabilidade dos serviços auxiliares das subestações e redução dos custos de manutenção. Para tal efeito, foi desenvolvido um sistema automatizado de monitoramento e gestão individual e remota de todos os elementos que compõe o banco de baterias. A pesquisa de mestrado avaliou, quantitativamente, a confiabilidade da medição remota realizada na subestação Baependi da Light, na cidade do Rio de Janeiro. A metodologia aplicada na presente dissertação consiste em estudos estatísticos (Testes de hipóteses paramétricos e não paramétricos) para comparação de resultados de tensão elétrica e impedância obtidos em condições reais de operação (Medições SIMBAGEBAT) em relação ao equipamento portátil de medição. A pesquisa validou aos níveis de significância de 90\%,95\% e 99\%, a metodologia empregada para avaliação remota de baterias para os ensaios de impedância e tensão elétrica e identificou a repetitividade da metodologia da avaliação remota. O resultado da pesquisa foi fundamental para provar a credibilidade do sistema de monitoramento remoto de baterias. A utilização desse sistema ora validado contribuirá para o aumento da confiabilidade dos equipamentos que utilizam sistema de backup, além de redução dos custos de manutenção preventiva.

\section{Palavras-chave}

Metrologia; medição remota; monitoramento de baterias; sistema de backup; subestações. 


\section{Abstract}

Pesenti, Gilcinea Rangel; Frota, Mauricio Nogueira (Advisor). Remote measurement as strategy to monitor stationary batteries: case study in an eletric power substation. Rio de Janeiro, 2012. 83p. MSc. Dissertation - Programa de Pós-Graduação em Metrologia (Área de concentração: Metrologia para Qualidade e Inovação), Pontifícia Universidade Católica do Rio de Janeiro.

The present work has the general objective of validating, under real operation conditions, the technique (developed in a laboratorial environment) of remote monitoring of stationery batteries. The development of this $\mathrm{MsC}$ dissertation theme was motivated by the contributions that it is expected to give to the Light S.E.S.A. and other companies of the Electric Sector, Oil and Gas, Bank, IT and many others which use stationary batteries in their DC energy supply. Light and $\mathrm{CPqD}$ developed together a Research and Development Project named R\&D Light-ANEEL 033/2008. This project had as its main objective to increase the reliability of the ancillary services of substations and to reduce their maintenance costs. To reach this target, was developed an automated monitoring system and a remote individual management of all elements that form the batteries bank. The MSc research evaluated, quantitatively, the reliability of the remote metering, performed to the Light's Baependi substation, which is located in the south zone of Rio de Janeiro City. The methodology applied in this dissertation consists of statistical studies (Hypothesis testing parametric and nonparametric), for comparison of voltage and impedance results obtained in actual operating conditions (Measurements SIMBA-GEBAT) compared to portable measurement. The research has validated, to the significance levels of $90 \%, 95 \%$ and $99 \%$, the methodology used to the remote evaluation of batteries relatively to the impedance and voltage essays, and has also identified the repetitivity of the remote evaluation methodology. The research results were fundamental to prove the credibility of the remote monitoring system of batteries. The use of this system will contribute to increase the reliability of the equipments which use backup systems, besides promoting a cost reduction of the predictive maintenance.

\section{Keywords}

Metrology; remote measurement; batteries monitoring; backup system; substation. 


\section{Sumário}

1 Introdução 15

1.1. Baterias: conceitos, definições e legislação aplicável 16

$\begin{array}{ll}\text { 1.1.1. Conceitos Básicos } & 17\end{array}$

1.1.2. Documentos normativos e regulatórios 18

1.2. Contextualização da pesquisa 18

1.3. Caracterização do problema da pesquisa 20

1.4. Motivação 20

1.5. Objetivos 21

1.6. Metodologia 21

1.7. Estrutura da dissertação 22

2 Baterias estacionárias $\quad 24$

2.1. Bateria chumbo-ácida: estado-da-arte 25

2.1.1. Bateria chumbo-ácida ventilada 25

2.1.2. Bateria chumbo-ácida regulada por válvula 27

2.2. Bateria: fonte auxiliar de energia na subestação 30

2.3. Bateria: métodos de avaliação de desempenho 31

3 Monitoramento remoto de baterias 35

3.1. Funcionalidades do protótipo 35

3.2. Definição dos parâmetros monitoráveis 36

3.3. Instalação e teste de campo 36

4 Validação da medição remota em ambiente real de operação:

$\begin{array}{ll}\text { Procedimentos experimentais e resultados } & 38\end{array}$

4.1. Procedimentos de ensaio para validação das medições 38

4.2. Calibração do equipamento portátil 38

4.3. Análises estatísticas dos dados $\quad 40$

4.3.1. Análise estatística da medição de impedância 41

4.3.1.1. Teste Kolmogorov-Smirnov (K-S) 42 
4.3.1.2. Teste de significância para duas variâncias

4.3.1.3. Independência nas medições das amostras 54

4.3.1.4. Teste de significância para a igualdade de duas médias 54

4.3.2. Análise estatística da medição da tensão elétrica 56

4.3.2.1. Teste Kolmogorov-Smirnov (K-S) 58

4.3.2.2. Teste de significância para duas variâncias 67

4.3.2.3. Teste de significância para a igualdade de duas médias $\quad 69$

5 Conclusões $\quad 71$

$\begin{array}{ll}\text { Referências bibliográficas } & 73\end{array}$

Anexo 1 - Certificado de calibração shunt de 60 a / 60 mv 75

$\begin{array}{ll}\text { Anexo } 2 \text { - Tabela Distribuição D } & 78\end{array}$

Anexo 3- Tabela de Distribuição F para 1- $\alpha=90 \%$

Anexo 4 - Tabela de Distribuição F para: $1-\alpha=95 \%$

Anexo 5 - Tabela de Distribuição F para: 1- $\alpha=99 \%$

Anexo 6 - Tabela Distribuição Normal (Área $0 \mathrm{a}+\infty$ ) 82

Anexo 7 - Tabela Distribuição Normal (Área - $\infty$ a 0) 83 


\section{Lista de figuras}

Figura 1 - Desenho da pesquisa 22

Figura 2 - Sistema de baterias estacionárias 31

Figura 3 - Curva de descarga de uma bateria chumbo-ácida ventilada

Figura 4 - Arquitetura do sistema de monitoramento remoto 36

Figura 5 - Unidade de Medida do protótipo do sistema 37

Figura 6 - Unidade de Controle do protótipo do sistema 37

Figura 7 - Sistema de baterias estacionárias localizado na subestação Baependi $\quad 37$

Figura 8 - Ensaio para validação das medições 39

Figura 9 - Histograma de frequência: medições de impedância SIMBA-GEBAT 44

Figura 10 - Frequência absoluta da amostra acumulada vs Frequência esperada acumulada

Figura 11 - Histograma de frequência: Medidas de impedância obtidas utilizando o equipamento portátil

Figura 12 - Frequência absoluta da amostra acumulada vs Frequência esperada acumulada

Figura 13 - Histograma de frequência: Medições da tensão elétrica do SIMBAT-GEBAT

Figura 14 - Frequência absoluta da amostra acumulada vs Frequência esperada acumulada

Figura 15 - Histograma de frequência: Medidas da tensão Elétrica do Equipamento Portátil

Figura 16 - Frequência absoluta da amostra acumulada vs Frequência esperada acumulada 


\section{Lista de tabelas}

Tabela 1 - Expectativa de vida útil das baterias chumbo-ácida VRLA 29

Tabela 2 - Valores obtidos nas medições de resistência elétrica $\quad 40$

Tabela 3 - Medições de Impedância SIMBA-GEBAT (Medidas 1) 41

Tabela 4 - Medições de Impedância do Equipamento Portátil (Medidas 2)

Tabela 5 - Estatística descritiva 43

Tabela 6 - Intervalo do histograma 43

Tabela 7 - Tabela de frequência absoluta $\quad 44$

Tabela 8 - Cálculo da frequência esperada 45

Tabela 9 - Cálculo da estatística D 45

Tabela 10 - Estatística descritiva 47

Tabela 11 - Intervalo do histograma 48

Tabela 12 - Tabela de frequência absoluta $\quad 49$

Tabela 13 - Cálculo da frequência esperada 50

Tabela 14 - Cálculo da frequência esperada $\quad 50$

Tabela 15 - Medidas da tensão elétrica SIMBA-GEBAT (Medidas 1) 57

Tabela 16 - Medida da tensão elétrica do Equipamento Portátil (Medidas 2) 57

Tabela 17 - Estatística descritiva $\quad 58$

Tabela 18 - Intervalo do histograma $\quad 59$

Tabela 19 - Tabela de frequência absoluta $\quad 60$

Tabela 20 - Cálculo da frequência esperada $\quad 60$

Tabela 21 - Cálculo da estatística D 61

Tabela 22 - Estatística descritiva 63

Tabela 23 - Intervalo do histograma 63

Tabela 24 - Tabela de frequência absoluta 64

Tabela 25 - Cálculo da frequência esperada 65

Tabela 26 - Cálculo da estatística D 65 


\section{Abreviaturas e Termos}

$\left|f_{a}-e_{a}\right|$
$1-\alpha$
$A$

ABNT

$\mathrm{Ah}$

$\mathrm{Ah} / \mathrm{kg}$

$\mathrm{Ah} / \mathrm{l}$

Anatel

Aneel

C

$\mathrm{CPqD}$

$\mathrm{Cr}$

D

$\mathrm{D}_{\max }$

$\mathrm{E}$

E.C.

$\mathrm{e}_{\mathrm{a}}$

$\mathrm{e}_{\mathrm{i}}$

EUA

$\mathrm{F}$

$f_{a}$

$\mathrm{F}_{\text {cal }}$

$\mathrm{f}_{\mathrm{i}}$

GEBAT

GSM

$\mathrm{H}_{1}$

$\mathrm{H}_{2}$

$\mathrm{H}_{2} \mathrm{O}$

$\mathrm{H}_{2} \mathrm{SO}_{4}$

Ho

HW

i

INMETRO

$\mathrm{k}$

$\mathrm{kg}$

K-S

1

MBA

$\mathrm{ml}$
Módulo da diferença entre a Frequência absoluta da amostra acumulada e a Frequência esperada acumulada

Nível de confiança

ampère

Associação Brasileira de Normas Técnicas

ampère-hora

ampère-hora/kilograma

ampère-hora/litro

Agência Nacional de Telecomunicações

Agência Nacional de Energia Elétrica

Capacidade específica

Centro de Pesquisa e Desenvolvimento em Telecomunicações

Capacidade real da bateria

Distribuição de probabilidade D

Estatística do teste Kolmogorov-Smirnov

Tensão elétrica

Energia específica

Frequência esperada acumulada

Frequência esperada

Estados Unidos de América

Distribuição F-Snedecor

Frequência absoluta da amostra acumulada

Estatística do teste de igualdade entre duas variâncias

Frequência absoluta da amostra

Gestão de Bateria

Global System for Mobile

Hipótese alternativa

Hidrogênio

Água

Ácido sulfúrico

Hipótese nula

Hardware

Corrente

Instituto Nacional de Metrologia, Qualidade e Tecnologia

Fator de abrangência

Quilograma

Kolmogorov-Smirnov

litro

Master of Business Administration

mililitro 


\begin{tabular}{|c|c|}
\hline $\mathrm{mOhm}$ & $\mathrm{ohm}$ \\
\hline MSc. & ter of Science \\
\hline $\mathrm{mV}$ & milivolt \\
\hline $\mathrm{N}$ & Número do intervalo adotado \\
\hline $\mathrm{n}$ & Tamanho da amostra \\
\hline NBR & Norma Brasileira \\
\hline $\mathrm{O}_{2}$ & Oxigênio gasoso \\
\hline $\mathrm{P}$ & Potência específica \\
\hline$P \& D$ & Pesquisa \& Desenvolvimento \\
\hline $\mathrm{Pb}$ & Chumbo \\
\hline $\mathrm{PbO}_{2}$ & Peróxido de chumbo \\
\hline $\mathrm{PbSO}_{4}$ & Sulfato de chumbo \\
\hline PósMQI & $\begin{array}{l}\text { Programa de Pós-graduação em Metrologia, Qualidade, } \\
\text { Inovação e Sustentabilidade }\end{array}$ \\
\hline PUC-Rio & Pontifícia Universidade Católica do Rio de Janeiro \\
\hline RA & Região de aceitação \\
\hline $\mathrm{RC}$ & Região Critica \\
\hline$s^{2}$ & Variância amostral \\
\hline Sc & Desvio padrão amostral conjunto \\
\hline SIMBA-GEBAT & Sistema de Monitoração Remota de Bateria \\
\hline SW & Software \\
\hline $\mathrm{t}$ & Tempo \\
\hline$t_{\text {cal }}$ & Estatística do teste de igualdade entre duas médias \\
\hline $\mathrm{UC}$ & Unidade de Controle \\
\hline UM & Unidade de Medição \\
\hline UPS & Uninterruptible Power Supply \\
\hline V & Volt \\
\hline VIM & $\begin{array}{l}\text { Vocabulário Internacional de Termos Fundamentais e } \\
\text { Gerais de Metrologia }\end{array}$ \\
\hline VRLA & Valve Regulated Lead Acid \\
\hline $\mathrm{W} / \mathrm{kg}$ & watt/quilograma \\
\hline Wh & watt-hora \\
\hline $\mathrm{Wh} / \mathrm{kg}$ & watt-hora/quilograma \\
\hline $\mathrm{Wh} / 1$ & watt-hora/litro \\
\hline $\mathrm{Wm}$ & Energia específica mássica \\
\hline Wv & Energia específica volumétrica \\
\hline $\mathrm{X}$ & Valor da medição \\
\hline$\overline{\mathbf{x}}$ & Média amostral \\
\hline Z & $\begin{array}{l}\text { Valor da variável da distribuição Normal de } \\
\text { Probabilidade }\end{array}$ \\
\hline $\mathrm{Z} \sim \mathrm{N}(0,1)$ & $\begin{array}{l}\text { Distribuição normal de probabilidade com média zero e } \\
\text { variância um }\end{array}$ \\
\hline$\alpha$ & Nível de significância \\
\hline$\mu$ & Média populacional \\
\hline$\sigma$ & Desvio padrão populacional \\
\hline$\sigma^{2}$ & Variância populacional \\
\hline$\varphi$ & Grau de liberdade \\
\hline
\end{tabular}


“Aqueles que passam por nós, não vão sós, não nos deixam sós. Deixam um pouco de si, levam um pouco de nós' Antoine de Saint-Exupéry 


\section{1 \\ Introdução}

A geração, a transmissão e a distribuição de energia elétrica são de extrema importância no mundo atual e na vida das pessoas. Estes sistemas não são perfeitos e estão sujeitos a falhas de operação. No entanto, várias aplicações de grande porte (e.g.: data center, centrais telefônicas, subestações de energia, controle de tráfego metroviário, sistemas de emergência de plataformas de petróleo) exigem alto grau de confiabilidade e não podem deixar de operar caso haja uma falha na energia comercial. Nesses casos, a opção por outra fonte backup de energia faz-se necessário como estratégia de suprir esta falta de energia durante o período da falha, que pode durar minutos ou mesmo horas.

O acumulador elétrico, também denominado bateria, é a fonte de energia mais utilizada nessas aplicações. Este é um dos poucos dispositivos que consegue armazenar energia por grandes períodos de tempo e disponibilizá-la quando solicitado.

Em uma subestação de energia elétrica o uso da bateria é de vital importância na confiabilidade dos chamados serviços auxiliares. É a bateria que assegura que todo o comando e o controle dos componentes eletrônicos se mantêm em operação durante uma falha da energia comercial. A falta de atuação da bateria pode provocar grandes prejuízos em uma subestação de energia elétrica. A tecnologia de bateria mais utilizada nas aplicações de sistemas de backup de grande porte é a bateria chumbo-ácida estacionária. A vida útil projetada desta tecnologia para esta aplicação é de dez anos, considerando as condições operacionais. Para garantir esta durabilidade e confiabilidade do sistema, o usuário deve periodicamente realizar manutenções na bateria. Na realização da manutenção os seguintes parâmetros devem ser verificados: inspeção visual; medições de densidade (bateria ventilada); tensão elétrica, temperatura; corrente de flutuação. No entanto, somente estes parâmetros não indicam com precisão o grau de degradação da bateria. Comumente, o ensaio tradicional para avaliar esta degradação é o ensaio de capacidade. Este é um ensaio invasivo já que a sua 
realização requer a retirada da bateria de operação. É longo e necessita de acompanhamento por profissional qualificado [1-4].

A introdução da telefonia móvel em nível mundial e o crescimento da área de telecomunicações, na virada da década de 80, passaram a requerer métodos mais rápidos, mais eficazes e menos invasivos para se avaliar o grau de degradação da bateria chumbo-ácida. Vários grupos de pesquisas, principalmente nos EUA, se dedicaram a este tema e concluíram que a degradação da bateria chumbo-ácida deve-se à variação de sua resistência interna, impactando na sua durabilidade. Foi com base nessa constatação que a resistência interna da bateria passou a ser considerada a propriedade crítica para se avaliar, de forma permanente, o grau de degradação das baterias chumbo-ácidas estacionárias.

Fundamentado nesse preceito, foram desenvolvidos e industrializados alguns equipamentos manuais que permitem medir a resistência interna da bateria por meio da sua condutância ou impedância. Esses equipamentos foram introduzidos no Brasil a partir de 2002 e têm sido muito utilizados por empresas de telecomunicações e dos setores de energia, notadamente o elétrico e o petrolífero [5-9].

Com o objetivo de otimizar os custos de operação e manutenção e contornar a escassez de mão de obra qualificada, as empresas vêm investindo em soluções que visam a automação e o monitoramento a distância de seus equipamentos [10$11]$.

\section{1.}

\section{Baterias: conceitos, definições e legislação aplicável}

Aderente ao jargão internacional, esta dissertação de mestrado, faz uso dos conceitos técnicos tal qual definidos no Vocabulário Internacional de Termos Fundamentais e Gerais de Metrologia (VIM) [12], complementados por denominações técnicas específicas utilizadas por profissionais de sistemas de monitoramento de baterias estacionárias. 


\subsection{1.}

\section{Conceitos Básicos}

Uma bateria recarregável é um dispositivo que armazena energia elétrica na forma de compostos ativos eletroquimicamente (energia química) e, vice-versa, transforma energia química em elétrica. Ou seja, é um dispositivo capaz de armazenar e gerar energia elétrica mediante reações eletroquímicas de oxidação (perda de elétrons) e redução (ganho de elétrons). Nessas reações, a transferência dos elétrons ocorre no circuito elétrico, o que gera a corrente elétrica. Quando a bateria é utilizada, isto é, na descarga, a energia química armazenada nos eletrodos se transforma direta e espontaneamente em energia elétrica.

Fisicamente a unidade básica de uma bateria é uma célula ou elemento. A associação de dois ou mais elementos, em série ou em paralelo, ou ambos, constitui uma bateria. Cada célula eletroquímica é formada por dois eletrodos (placas positiva e negativa) separados por um eletrólito (meio condutor). O eletrodo positivo (cátodo) é constituído pelo material ativo que possui maior potencial de oxirredução (redox). Por outro lado, o eletrodo negativo (anodo) é constituído pelo material ativo com menor potencial redox. O eletrólito pode ser líquido, sólido ou gasoso.

Durante o processo de descarga, a energia química armazenada nos eletrodos se transforma diretamente e espontaneamente em energia elétrica (através das reações de oxidação/redução dos materiais ativos das placas). Durante o processo de carga, faz-se necessário fornecer energia elétrica para transformar os materiais gerados na descarga nos produtos eletroquimicamente ativos originais. O desempenho de uma bateria depende das características de fabricação de seus elementos [13]. Os parâmetros eletroquímicos mais utilizados para caracterizar uma célula e bateria são:

- Tensão elétrica (E): representa o potencial, ou força eletromotriz, de uma célula eletroquímica, dada pela diferença entre os potenciais de oxidação e redução dos materiais ativos dos cátodos e ânodos. Unidade de medida: Volt (V).

- Capacidade específica (C): é a quantidade total de corrente por unidade de tempo que uma célula ou bateria é capaz de fornecer. Unidade de medida: ampère-hora (Ah). Para comparar baterias utiliza-se o valor de capacidade normalizado em massa $(\mathrm{Ah} / \mathrm{kg})$ ou volume $(\mathrm{Ah} / \mathrm{l})$.

- Energia específica (E.C.): Indica a quantidade de energia elétrica que uma célula ou bateria pode armazenar. Unidade de medida: $\mathrm{Wh}$. 
- Energia específica mássica (Wm): Wm=E.C./(peso da bateria). Unidade de medida: $\mathrm{Wh} / \mathrm{kg}$

- Energia específica volumétrica (Wv): Wv=E.C./(volume da bateria). Unidade de medida: $\mathrm{Wh} / \mathrm{l}$

- Potência específica $(\mathbf{P})$ : reflete a capacidade de uma bateria para fornecer altas taxas de corrente. Unidade de medida: W/kg (mássica) ou W/l (volumétrica).

- Ciclos de vida: é o número de ciclos de carga/descarga que a bateria pode realizar até que sua capacidade se reduza ao valor percentual limite (especificado por tecnologia) em relação ao valor nominal.

\subsection{2.}

\section{Documentos normativos e regulatórios}

As normas aplicáveis e de interesse ao desenvolvimento da presente dissertação são: NBR 14198 e NBR 14206, referente à terminologia de baterias chumbo-ácidas ventiladas e reguladas por válvula.

A legislação vigente no Brasil aplicável às baterias chumbo-ácidas estacionárias fundamenta-se no seguinte acervo legal e normativo [14]:

- Resolução Anatel 570: norma para certificação e homologação de acumuladores chumbo-ácidos estacionários regulados por válvula;

- Resolução Anatel 597: norma para certificação e homologação de acumuladores chumbo-ácidos estacionários ventilados;

- ABNT NBR 14197: acumulador chumbo-ácido estacionário ventilado especificação;

- ABNT NBR 14199: acumulador chumbo-ácido estacionário ventilado - método de ensaio;

- ABNT NBR 14204: acumulador chumbo-ácido estacionário regulado por válvula especificação;

- ABNT NBR 14205: acumulador chumbo-ácido estacionário regulado por válvula método de ensaio.

\section{2.}

\section{Contextualização da pesquisa}

Com o objetivo de implantar soluções mais eficazes para avaliar e monitorar a integridade de baterias utilizadas em suas subestações, a Light desenvolveu projetos de P\&D em parceria com o Centro de Pesquisa e Desenvolvimento em Telecomunicações (CPqD). Em 2001, desenvolveu o projeto de P\&D referência Light-Aneel 3105/01 [1], que teve por objetivo implantar a metodologia de ensaio 
de condutância e impedância para avaliação das baterias em operação nas subestações da Light.

A metodologia desenvolvida em parceria com o CPqD mostrou ser eficiente no acompanhamento do estado de degradação de baterias. Como contribuição do P\&D ao setor elétrico, a solução proposta passou a ser adotada por empresas do setor elétrico.

Após a implementação desta metodologia como ferramenta de manutenção das baterias de suas subestações, a Light sentiu a necessidade de dispor de um sistema, capaz de realizar a gestão das medições de condutância, impedância, tensão elétrica de flutuação, densidade e teste de capacidade. E, também, de ser capaz de gerar relatórios e possibilitar a extração de um maior número de informações que venham a auxiliar a concessionária em suas operações de manutenção corretiva e preditiva das baterias.

Foi com esse propósito que o $\mathrm{CPqD}$ e a Light desenvolveram o projeto de P\&D complementar, referência Light-Aneel 019/2006 [2], visando disponibilizar um sistema de gestão da operação e manutenção de baterias chumbo-ácidas ventiladas e reguladas por válvulas, instaladas em subestações da Light. Como produto deste P\&D foi desenvolvido o software de gestão de baterias (GEBAT). Por meio de medições da condutância ou impedância dos elementos da bateria tornou-se possível projetar uma estimativa do estado de degradação da bateria para os próximos dois anos.

Em continuidade a este segundo projeto, a Light e o CPqD desenvolveram o projeto de P\&D Light-Aneel 033/2008 [4]. Projeto que teve por objetivo aumentar a confiabilidade dos serviços auxiliares das subestações e reduzir os custos associados de manutenção. Para atingir este propósito, o projeto de P\&D desenvolveu um sistema automatizado e remoto de monitoramento e gestão individual de todos os elementos que compõem o banco de baterias. O sistema está constituído de dois hardwares e um software, no qual é possível obter em tempo real e de forma automática os resultados de impedância, corrente, tensão elétrica de flutuação, temperatura, nível de eletrólito em cada elemento ou monobloco da bateria [11]. Toda a informação de gestão e avaliação das medições do sistema de monitoramento remoto foi implementada no software de gestão de baterias desenvolvido no projeto P\&D Light-Aneel 019/2006 [2]. 
Fazendo uso dos resultados desses P\&D a presente pesquisa de mestrado se desenvolveu conforme caracterizado na seção a seguir.

\section{3.}

\section{Caracterização do problema da pesquisa}

Nos últimos 15 anos observa-se um esforço por parte de fabricantes e usuários de baterias estacionárias para implantar metodologias de avaliação do estado de degradação da bateria, sem a necessidade de desconectá-las dos equipamentos consumidores. A presente pesquisa de mestrado atende a este propósito, complementando iniciativas que resultaram das atividades de pesquisa e desenvolvimento acima caracterizadas. Assim, facilitando a realização de ensaios que fazem uso de equipamentos comerciais portáteis para medir a condutância, impedância ou resistência interna de baterias, o trabalho desenvolveu e validou metrologicamente um protótipo de medição e monitoramento remoto de baterias do tipo estacionárias.

A presente dissertação responde as seguintes questões:

- Quais as razões que levam à alternativa tecnológica proposta?

- Quais são os benefícios e a confiabilidade do método de monitoramento remoto proposto?

- Qual o impacto econômico resultante da introdução da alternativa tecnológica proposta?

Como estudo de caso, a pesquisa de mestrado avaliou, quantitativamente, a confiabilidade da medição remota realizada na subestação Baependi da Light, na cidade do Rio de Janeiro.

\section{4 . Motivação}

O desenvolvimento deste tema de dissertação de mestrado foi motivado pelas contribuições que poderá produzir para a Light e demais empresas dos setores elétricos, petrolíferos, bancários, de telecomunicações, entre outros setores que utilizam baterias estacionárias. Dentre os benefícios destacam-se: 
- avanço do conhecimento no Brasil, no que tange ao monitoramento remoto de baterias estacionárias;

- ganho de eficácia do monitoramento remoto das baterias estacionárias:

- aprimoramento da solução de hardware (HW) e software (SW);

- avaliação metrológica das medições ôhmicas em baterias;

- fomento de projetos de inovação voltados às necessidades da concessionária.

\section{5.}

Objetivos

A presente dissertação tem por objetivo geral validar em condições reais de operação, a técnica (desenvolvida em ambiente laboratorial) de monitoramento remoto de baterias estacionárias.

Em termos específicos, a dissertação busca:

- Identificar as limitações das tecnologias convencionais de monitoramento de baterias estacionárias e discutir as vantagens da alternativa tecnológica proposta no âmbito do P\&D Light-Aneel 033/2008 [4];

- Avaliar a confiabilidade do método de monitoramento remoto proposto, validando-o em condições normais de operação;

- Justificar a alternativa tecnológica proposta à luz do impacto econômico que dela decorrem.

\section{6. \\ Metodologia}

A presente pesquisa é classificada de acordo com a taxionomia de Vergara (2005) [15]. Assim, quanto aos fins, é descritiva (expõe características de determinado fenômeno, estabelece correlações entre variáveis e define sua natureza); aplicada (fundamentalmente motivada pela necessidade de resolver problemas concretos, mais imediatos ou não). Quanto aos meios de investigação, classifica-se como: bibliográfica, documental e experimental. No que concerne à natureza da pesquisa, tem característica predominantemente quantitativa.

O seu desenvolvimento foi estruturado segundo as seguintes fases:

- Fase 1 - Exploratória: pesquisa bibliográfica e documental como base teórica da dissertação;

- Fase 2 - Pesquisa de Campo: medições em condições normais de operação, cálculo de incerteza e avaliação de impactos econômicos; 
- Fase 3 - Conclusões e recomendações para trabalhos futuros (novos sistemas fotovoltaicos).

A Figura 1 apresenta a sequência de desenvolvimento da presente pesquisa e a ligação das atividades em cada fase.
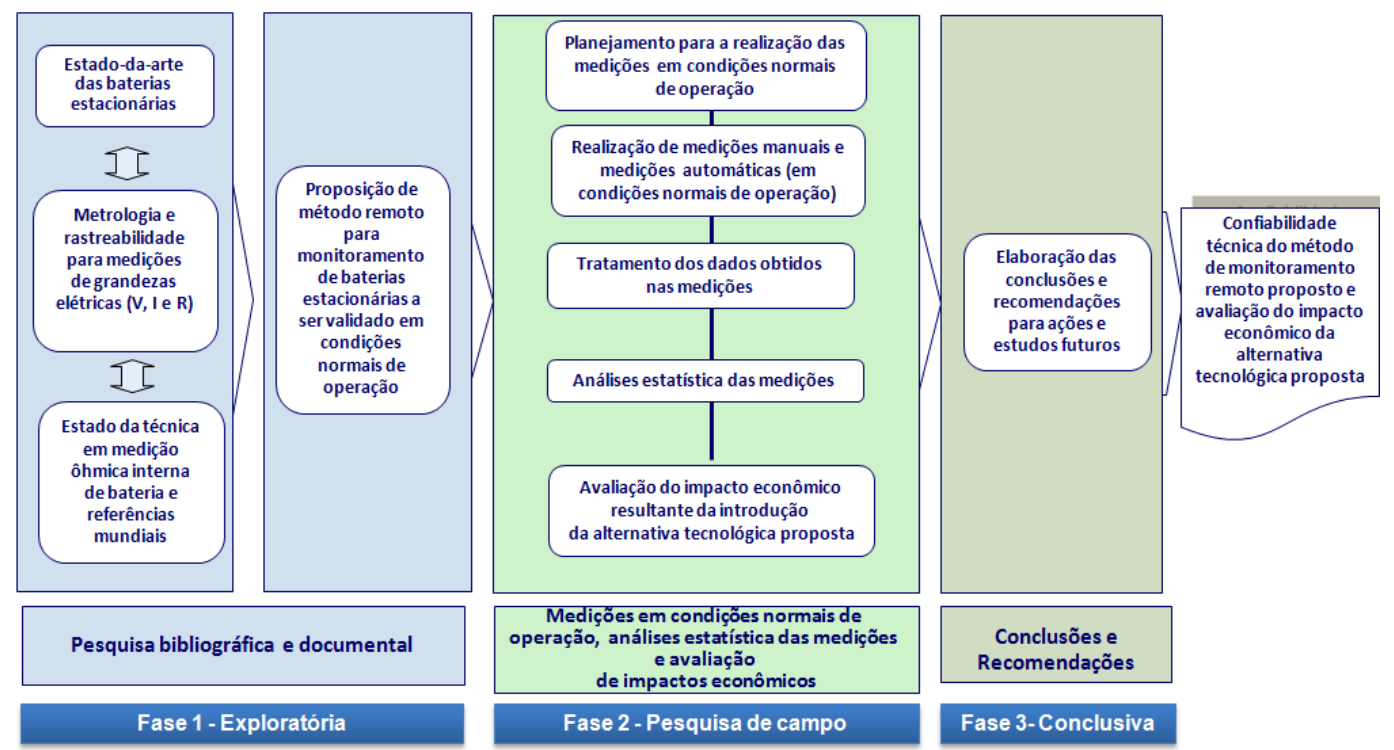

Figura 1 - Desenho da pesquisa

\section{7. \\ Estrutura da dissertação}

A presente pesquisa está estruturada em cinco capítulos, descritos a seguir:

O capítulo 1 (Introdução) caracteriza o problema objeto da dissertação, os objetivos, a metodologia utilizada, identifica a legislação aplicável e define os principais conceitos empregados. O capítulo 2 (estado-da-arte) fundamenta a base conceitual para o desenvolvimento da dissertação e apresenta o estado-da-arte sobre baterias estacionárias como fonte de energia auxiliar na subestação e os métodos de monitoramento de bateria comumente utilizados.

O capítulo 3 descreve as funcionalidades do equipamento de medição remota, a sua instalação e teste de campo.

O capítulo 4, (validação da medição remota em ambiente real de operação) refere-se ao cerne da dissertação. Aborda: (i) as medições laboratoriais de impedância e tensão elétrica com relação às medições em campo (ii) as análises estatísticas dos dados para determinar o nível de confiança com base no qual as condições de ensaio podem ser consideradas estatisticamente similares; (iii) o 
processo de intercomparação com equipamentos de medição portátil de bateria. Este capítulo conceitua e valida o método remoto proposto para monitoramento de baterias estacionárias.

O capítulo 5 encaminha as conclusões, associando-as às questões originalmente formuladas e que refletem os objetivos do trabalho. Finalizando, propõe recomendações para desdobramentos futuros do trabalho. 


\section{2 \\ Baterias estacionárias}

As baterias estacionárias garantem a continuidade do fornecimento de energia numa eventual falha da rede elétrica para aplicações portáteis, sistemas de backup e sistemas de emergência.

Existem baterias do tipo pilhas, que podem fornecer energia de forma irreversível até a sua exaustão completa. E, também, baterias secundárias que asseguram o processo cíclico reversível de carga-descarga. Com base nesses preceitos, as baterias secundárias são as mais utilizadas em atividades industriais. Existem diferentes tipos de baterias, de acordo com sua natureza interna e da sua aplicação-alvo. Assim, quando se escolhe uma bateria, deve-se salientar que cada tipo de bateria oferece características e vantagens que justificam a sua escolha em relação a outras, mas nenhuma das baterias possui todos os requisitos de aplicação.

Os fabricantes de baterias estão cientes das necessidades de cada aplicação e, portanto, oferecem diferentes modelos de modo a assegurar a sua adequação a cada uso.

A primeira bateria foi constituída por Alessandro Volta, formada por apenas dois pedaços de metais distintos (zinco e prata) separados por um pedaço de papelão embebido em uma solução salina. Esta montagem foi denominada célula galvânica. A combinação de várias células iguais constitui uma bateria cuja potência é função do número de células conectadas em série. Em 20 de março de 1800, Volta comunicou sua invenção à Royal Society of London.

A invenção recém-criada de Alessandro Volta, a pilha, contribuiu para os avanços dos estudos sobre a decomposição elétrica e eletrólise da água, decomposição de sais, a exemplo do isolamento do sódio e do potássio, de seus hidróxidos. Em 1813, Michael Faraday pesquisou e elaborou diversas teorias que vieram a constituir os fundamentos da eletroquímica e do eletromagnetismo. 
Em 1859, o físico francês Gaston Planté estudou a polarização entre dois eletrodos idênticos imersos em solução aquosa diluída de ácido sulfúrico. Planté investigou eletrodos de diferentes materiais (prata, chumbo, estanho, cobre, ouro, platina e alumínio). Resumiu os resultados de todas essas experiências em seu artigo intitulado: "Recherches sur la polarização voltaique", que foi publicado em Rendus na Academia Francesa de Ciências, em 1859. Em 26 de março de 1860, Gaston Planté demonstrou, na Academia Francesa de Ciências, as primeiras baterias chumbo-ácidas recarregáveis com nove células ligadas em paralelo e apresentou uma palestra intitulada "Nouvelle pile secondaire d'une grande puissance". Esta foi praticamente a certidão de nascimento da bateria chumboácida.

Atualmente a bateria chumbo-ácida é fabricada e comercializada em todos os continentes, sendo a tecnologia mais utilizada para aplicações industriais.

\section{1. Bateria chumbo-ácida: estado-da-arte}

Comercialmente existem dois tipos de bateria chumbo-ácida estacionária, denominadas ventiladas e reguladas por válvula. As particularidades de cada tecnologia são descritas a seguir [13].

\subsection{1.}

\section{Bateria chumbo-ácida ventilada}

A bateria chumbo-ácida é um sistema eletroquímico no qual os materiais ativos primordiais são: chumbo (e seus compostos) e eletrólito (uma solução aquosa de ácido sulfúrico). Qualquer que seja sua estrutura consiste, basicamente, de dois eletrodos, geralmente em forma de placas e isolados eletricamente; imersos em um eletrólito composto de uma solução aquosa de ácido sulfúrico e alojados em recipiente adequado.

A bateria chumbo-ácida ventilada é composta por placas positivas de peróxido de chumbo $\left(\mathrm{PbO}_{2}\right)$, placas negativas de chumbo metálico $(\mathrm{Pb})$ esponjoso, que utiliza uma solução aquosa de ácido sulfúrico $\left(\mathrm{H}_{2} \mathrm{SO}_{4}\right)$ como eletrólito. Quando a bateria é descarregada, os materiais das placas positivas e 
negativas se transformam em sulfato de chumbo $\left(\mathrm{PbSO}_{4}\right)$ e água $\left(\mathrm{H}_{2} \mathrm{O}\right)$. A Equação 1 descreve a reação que resulta desse processo químico.

$$
\mathrm{PbO}_{2}+\mathrm{Pb} \quad 2 \mathrm{H}_{2} \mathrm{SO}_{4} \underset{\text { Descarga }}{\stackrel{\text { Carga }}{\rightleftarrows}} 2 \mathrm{PbSO}_{4}+2 \mathrm{H}_{2} \mathrm{O} \quad \text { (Equação 1) }
$$

Quando a bateria chumbo-ácida é submetida a um processo de carga, além desta reação ocorre, paralelamente, no final da carga, outra reação que é conhecida como eletrólise da água. A eletrólise da água é a decomposição eletroquímica da água, gerando oxigênio gasoso $\left(\mathrm{O}_{2}\right)$ na superfície da placa positiva, e na placa negativa hidrogênio $\left(\mathrm{H}_{2}\right)$, também na forma gasosa (Equações 2 e 3).

Placa positiva:

$$
2 \mathrm{H}_{2} \mathrm{O} \rightarrow \mathrm{O}_{2}+4 \mathrm{H}^{+}+4 \mathrm{e}^{-} \quad \text { (Equação 2) }
$$

Placa negativa:

$$
2 \mathrm{H}_{2} \mathrm{O}+2 \mathrm{e}^{-} \rightarrow \mathrm{H}_{2}+2 \mathrm{OH}^{-} \quad \text { (Equação 3) }
$$

Cabe ressaltar que nas aplicações estacionárias, nas quais a bateria opera em paralelo com o sistema de energia e com uma tensão elétrica de flutuação para manter suas placas carregadas, este processo de eletrólise da água também ocorre.

Os gases gerados durante o processo de carga, ou na operação da bateria em flutuação, arrastam vapores ácidos e consomem água do eletrólito. Assim, as baterias chumbo-ácidas ventiladas, utilizadas em aplicações estacionárias, devem ser instaladas em ambiente separado dos demais equipamentos eletrônicos. Por segurança a sala deve ser ventilada, pois quando um ambiente atinge um volume de $4 \%$ de hidrogênio na forma gasosa, mediante uma faísca ocorre explosão.

Durante sua operação há necessidade de adição de água destilada ou deionizada, devido à ocorrência da eletrólise da água. As baterias chumbo-ácidas ventiladas utilizam o eletrólito (ácido sulfúrico) na forma líquida, portanto seus elementos ou monoblocos têm que ser instalados em pé. 


\subsection{2.}

\section{Bateria chumbo-ácida regulada por válvula}

A bateria chumbo-ácida regulada por válvula (VRLA-Valve Regulated Lead Acid) possui a mesma composição da bateria ventilada, no entanto o ácido sulfúrico (eletrólito) não se encontra na forma líquida, mantido imobilizado por uma matriz gelificante ou por meio de separador a base de microfibra de vidro.

As baterias reguladas por válvula (acumuladores do tipo chumbo-ácido) apresentam o mesmo princípio de funcionamento das baterias ventiladas. Princípio esse baseado na teoria do sulfato duplo indicando, em essência, que durante o processo de descarga ocorre a formação de sulfato de chumbo em ambas as placas. Este processo é descrito pela equação 1.

Similarmente ao que ocorre com a bateria ventilada, algumas reações indesejáveis (simultâneas à reação principal) também ocorrem na bateria VRLA, a exemplo do processo de eletrólise da água, que provoca a evolução de oxigênio e hidrogênio nas superfícies das placas positiva e negativa. No entanto, a imobilização do eletrólito na bateria VRLA faz com que haja um processo de recombinação interna, no qual o oxigênio gerado na superfície da placa positiva migra até a superfície da placa negativa, reagindo com o chumbo e gerando água como produto final de reação. Este fenômeno é descrito pela equação (4), a seguir:

$$
\mathrm{O}_{2}+4 \mathrm{H}^{+}+4 \mathrm{e}^{-} \rightarrow 2 \mathrm{H}_{2} \mathrm{O} \quad \text { (Equação 4) }
$$

O ciclo do oxigênio, além de consumir o oxigênio gerado internamente, diminui sensivelmente a evolução do hidrogênio, como descrito na equação 4.

Os acumuladores regulados por válvula em condições normais de operação e com tensão elétrica de flutuação produzem aproximadamente hidrogênio na taxa de 1 a $2 \mathrm{ml} \mathrm{de} \mathrm{H}_{2}$ por hora para cada $100 \mathrm{Ah}$ de capacidade da bateria. Todavia, os acumuladores ventilados produzem em torno de $5 \mathrm{a} 14 \mathrm{ml}$ de $\mathrm{H}_{2}$ por hora para cada 100 Ah de capacidade da bateria.

Como não é possível obter um ciclo de hidrogênio, similar ao do oxigênio, a perda deste gás significa perda de água da bateria. Esta perda é intensificada sob condições desfavoráveis de operação. Desta forma não é recomendado o uso deste tipo de baterias em ambientes herméticos, sob risco de ocorrência de explosões. 
A bateria regulada por válvula não necessita de reposição de água, e pode coexistir no mesmo ambiente de outros equipamentos eletrônicos, uma vez que a liberação de gás gerado (99\% é hidrogênio) é cerca de 10 vezes menor que numa bateria ventilada. Além disso, não há o arraste de vapores ácidos, uma vez que este está imobilizado e também pode ser instalada em pé ou deitada.

A temperatura do elemento ou monobloco da bateria VRLA é o valor de temperatura obtida na superfície externa do elemento ou monobloco (na lateral do vaso ou na superfície do polo negativo), pela impossibilidade de acesso ao seu interior.

Nas baterias VRLA, esta temperatura é ligeiramente maior que nas baterias ventiladas. Isto ocorre porque nas baterias ventiladas a corrente de flutuação é utilizada na compensação da auto-descarga e na eletrólise da água. Entretanto, nas baterias VRLA a corrente de flutuação é quase que completamente utilizada pelo ciclo do oxigênio, o qual converte energia elétrica em calor, provocando desta forma o aumento na temperatura dos elementos ou monoblocos.

A expectativa de vida das baterias VRLA está diretamente associada à temperatura dos seus elementos ou monoblocos. Um artifício utilizado para diminuir o efeito da temperatura na expectativa da vida útil das baterias VRLA é efetuar a compensação da tensão elétrica de flutuação. Com isto, nas baterias que têm que operar em temperaturas acima de $25^{\circ} \mathrm{C}$, utiliza-se uma correção na tensão elétrica de flutuação, em função da temperatura de operação, conforme recomendado pelo fabricante da bateria.

Todavia, mesmo com essa compensação da tensão elétrica de flutuação, não se pode esperar a manutenção da mesma expectativa de vida nas condições de referência $\left(25^{\circ} \mathrm{C}\right)$. A Tabela 1 apresenta uma relação típica da vida útil projetada em função da temperatura. 


\section{Tabela 1 - Expectativa de vida útil das baterias chumbo-ácida VRLA}

\begin{tabular}{|c|c|c|}
\hline \multirow{2}{*}{ Temperatura $\left({ }^{\circ} \mathrm{C}\right)$} & \multicolumn{2}{|c|}{ Expectativa de Vida Útil (anos) } \\
\cline { 2 - 3 } & Sem Compensação & Com Compensação \\
\hline 25 & 10 & 10 \\
\hline 30 & 7,0 & 9,5 \\
\hline 35 & 5,0 & 8,0 \\
\hline 40 & 3,5 & 6,0 \\
\hline 45 & 2,5 & 4,0 \\
\hline
\end{tabular}

Fonte: Handbook of Battery Techonology, 3rd edition, 2003.

É importante enfatizar que a compensação da tensão elétrica de flutuação em função da temperatura é fundamental para impedir um processo de aumento gradual da temperatura denominado Avalanche Térmica ("Thermal Runaway"). Este é um processo definido pelo aumento contínuo da temperatura e da corrente de carga da bateria, sem que seja alcançada uma condição de estabilidade, até sua destruição.

As baterias chumbo-ácidas reguladas por válvula são particularmente sujeitas ao processo de avalanche térmica, sobretudo quando operando com equipamentos que não dispõem de mecanismos para correção automática da tensão elétrica de flutuação, em função da temperatura.

O ciclo de recombinação de oxigênio, que propicia as características desejáveis para o funcionamento destes acumuladores, é também a fonte potencial de sua morte prematura e algumas vezes desastrosa.

Para evitar os efeitos da avalanche térmica, os elementos ou baterias devem ser acomodados de forma a proporcionar ventilação suficiente para dissipar o calor gerado quando em operação. O fabricante deve apresentar tabelas ou curvas que indiquem as condições de temperatura, tensão elétrica e corrente de flutuação limites para evitar a avalanche térmica. No caso da temperatura subir além do limite de segurança recomendado pelo fabricante, deve haver um dispositivo de proteção da bateria, incluído nas fontes de corrente contínua, que mantém a bateria carregada em flutuação. 


\section{2.}

\section{Bateria: fonte auxiliar de energia na subestação}

As baterias são elementos vitais na confiabilidade de uma subestação, pois é por meio destas que toda a supervisão e pontos de controles mantêm seu funcionamento numa falha de energia. A bateria opera em paralelo com o sistema retificador e é mantida na tensão elétrica de flutuação (para evitar a autodescarga de suas placas). Somente será acionada na ocorrência de uma falta da energia comercial. Esta aplicação é denominada estacionária, pois suas instalações são fixas, ou seja, não são trocados regularmente de local.

De acordo com a Resolução Anatel 570 e 597, as baterias chumbo-ácidas estacionárias, em função do regime de descarga, são classificados como:

- Alta Intensidade de Descarga: corresponde a tempos de descarga iguais ou menores que 1 hora, aplicados aos sistemas de energia em corrente alternada ininterrupta (Uninterruptible Power Supply - UPS) e aos sistemas de partida de grupos geradores, sendo definida para regime de descarga de $0,25 \mathrm{~h}$ (15 min.) até a tensão elétrica final de $1,60 \mathrm{~V}$, à temperatura de referência de $25^{\circ} \mathrm{C}$;

- Média Intensidade de Descarga: corresponde a tempos de descarga maiores que 1 hora até 20 horas, aplicados aos sistemas de energia em corrente contínua, e devem atender as capacidades de $50 \mathrm{Ah}$ a $3.000 \mathrm{Ah}$ para regime de descarga de $10 \mathrm{~h}$ até a tensão elétrica final de $1,75 \mathrm{~V}$, à temperatura de referência de $25^{\circ} \mathrm{C}$;

- Baixa Intensidade de Descarga: corresponde a tempos de descarga maiores que 20 horas, para regime de descarga de $120 \mathrm{~h}$ até a tensão elétrica final de $1,85 \mathrm{~V}$, à temperatura de referência de $25^{\circ} \mathrm{C}$.

Nestes sistemas, as tensões nominais geralmente são de 125V. No Brasil, a grande maioria das subestações utilizam baterias chumbo-ácidas ventiladas ou reguladas por válvula de média intensidade de descarga. Geralmente a bateria é dimensionada para garantir ao sistema uma autonomia de 10 horas.

Independente da tecnologia da bateria, quando esta permanece em circuito aberto (parada sem conexão a fonte externa) sofre reações internas que provocam a autodescarga de suas placas, com conseqüente diminuição de sua autonomia. Para evitar esta perda, nas aplicações estacionárias as baterias devem ser mantidas em uma tensão elétrica um pouco superior a sua tensão elétrica de circuito aberto. 
Esta tensão elétrica é conhecida como tensão elétrica de flutuação, cujo valor é indicado pelo fabricante.

Nas subestações de energia elétrica, seja nos serviços auxiliares ou no sistema de telecomunicações, as baterias trabalham em regime de flutuação, sendo conectadas em paralelo com o sistema de alimentação principal, conforme apresentado na Figura 2.

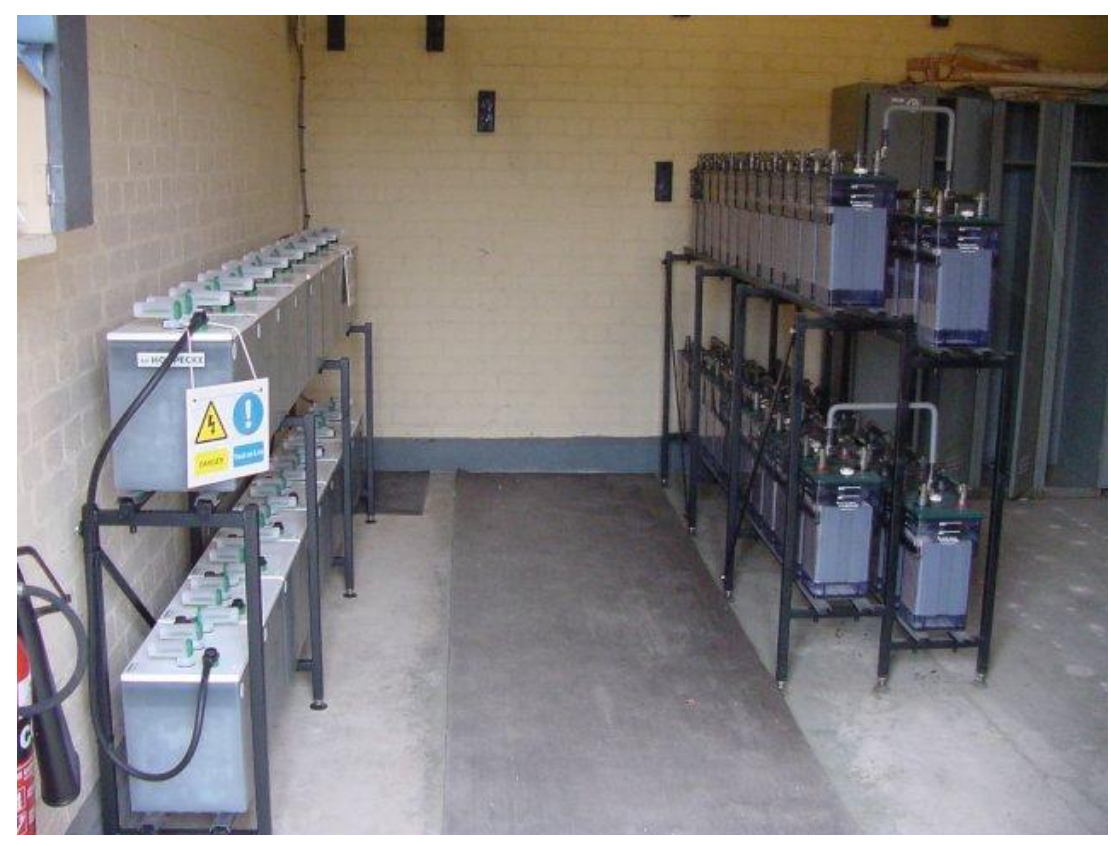

Figura 2 - Sistema de baterias estacionárias

Fonte: http://www.ingeo-electronica.com.ar/baterias.htm

\section{3.}

\section{Bateria: métodos de avaliação de desempenho}

O método proposto de avaliação de desempenho de baterias estacionárias encontra-se em conformidade às normas ABNT e Resoluções Anatel discutidas no item 1.1.3. Ou seja, as baterias chumbo-ácidas ventiladas ou reguladas por válvula (utilizadas em subestações de energia elétrica) devem apresentar uma vida útil projetada superior a dez anos, em regime de flutuação a uma temperatura de operação de $25^{\circ} \mathrm{C}$.

Para que a bateria consiga atingir, no mínimo, o valor estimado de sua vida útil é primordial que sejam realizadas manutenções periódicas, preventivas e corretivas. 
Os parâmetros comumente avaliados são:

- Inspeção visual: a inspeção visual tem como objetivo avaliar se os aspectos construtivos das baterias estão de acordo com o especificado no manual do fabricante e não apresentam anomalias. Para isso, são verificados: corrosões dos pólos, parafusos, abaulamento, etc. As baterias chumbo-ácidas ventiladas possuem o vaso transparente, o que facilita a visualização interna dos componentes da bateria.

- Medida de densidade: este ensaio só é aplicável para a bateria ventilada, pois a bateria VRLA possui o eletrólito imobilizado, não sendo possível a medição deste parâmetro. No caso das baterias chumbo-ácidas, o eletrólito além de ser o agente condutor, ele também é um material ativo e participa das reações de carga e descarga da bateria. A densidade do eletrólito é um indicativo do estado de carga da bateria. Segundo Norma ABNT NBR 14197 e Resolução Anatel 597, o valor da densidade da bateria de média intensidade de descarga deve ser de 1,210 $\mathrm{g} / \mathrm{cm}^{3} \pm 10 \mathrm{~g} / \mathrm{cm}^{3}$.

- Nível do eletrólito: este parâmetro só é aplicável à bateria ventilada. Durante a operação da bateria na tensão elétrica de flutuação, o nível do eletrólito vai diminuindo devido à ocorrência da reação paralela de decomposição da água (gera como subprodutos o hidrogênio e oxigênio gasoso, que é expelido ao ambiente). Periodicamente para que o nível esteja adequado, deve-se realizar reposição de água destilada ou deionizada.

- Tensão elétrica de flutuação: segundo normas ABNT NBR 14197 e ABNT NBR 14204 a tensão elétrica de flutuação tanto da bateria ventilada como VRLA pode apresentar uma variação máxima de $-0,05 \mathrm{~V}$ e $+0,10 \mathrm{~V}$ por elemento. Tensão elétrica inferior a esta faixa pode provocar a sulfatação das placas positivas e negativas. Por outro lado, tensão elétrica superior provocará a corrosão da placa positiva. Ambos os eventos provocam a aceleração da degradação da bateria e diminuição de sua vida útil. Desta forma é indicado o acompanhamento periódico deste parâmetro.

- Temperatura: outro parâmetro muito importante a ser avaliado na bateria é a sua temperatura, pois pode ser um indicativo de problemas de degradação interna, tais como corrosão, avalanche térmica, etc. $\mathrm{Na}$ bateria ventilada é possível medir a temperatura do eletrólito, já na bateria VRLA a temperatura é medida no vaso ou tampa do elemento. Todos os parâmetros descritos anteriormente são realizados com a bateria em operação, isto é na condição de flutuação, que não requer a necessidade de a bateria ser retirada de operação.

- Ensaio de capacidade: o ensaio de capacidade é utilizado para determinar a capacidade real da bateria e sua quantidade de energia disponível. Este ensaio ao contrário dos demais itens listados anteriormente é invasivo e tem que ser realizado com a bateria fora de operação. Sua realização numa situação real de operação é difícil e complicada, pois necessita de acompanhamento constante de um profissional qualificado e também, pode colocar o sistema em risco, pois durante a sua execução, caso haja uma falta de energia comercial, o sistema de backup não atuará. Atualmente não é muito utilizado. Neste 
ensaio a bateria é submetida a uma descarga com corrente constante durante um determinado tempo. Após a bateria ser desconectada do sistema de energia da Subestação, seus pólos terminais positivos e negativos são conectados a uma carga resistiva onde drenará a corrente para descarregar a bateria. Durante a descarga, a tensão elétrica individual de cada elemento é acompanhada, e o teste é finalizado quando um dos elementos atingir o valor de $1,75 \mathrm{~V}$, que é conhecido como instante final de descarga. A capacidade real da bateria é calculada segundo equação 5:

$$
\mathrm{Cr}=\mathrm{i} \times \mathrm{t} \quad \text { (Equação 5) }
$$

$\mathrm{Cr}=$ capacidade da bateria

$\mathrm{i}=$ corrente utilizada na descarga $(\mathrm{A})$

$\mathrm{t}=$ tempo decorrido desde o início do ensaio até o instante final de descarga $(\mathrm{h})$

A Figura 3 mostra um perfil típico de descarga. Geralmente a bateria é descarregada num regime de descarga de 3 ou 5 horas. Após o término da descarga, a bateria deverá ser recarregada (em torno de 14 a 20 horas), para posteriormente ser inserida novamente no sistema de backup da Subestação.

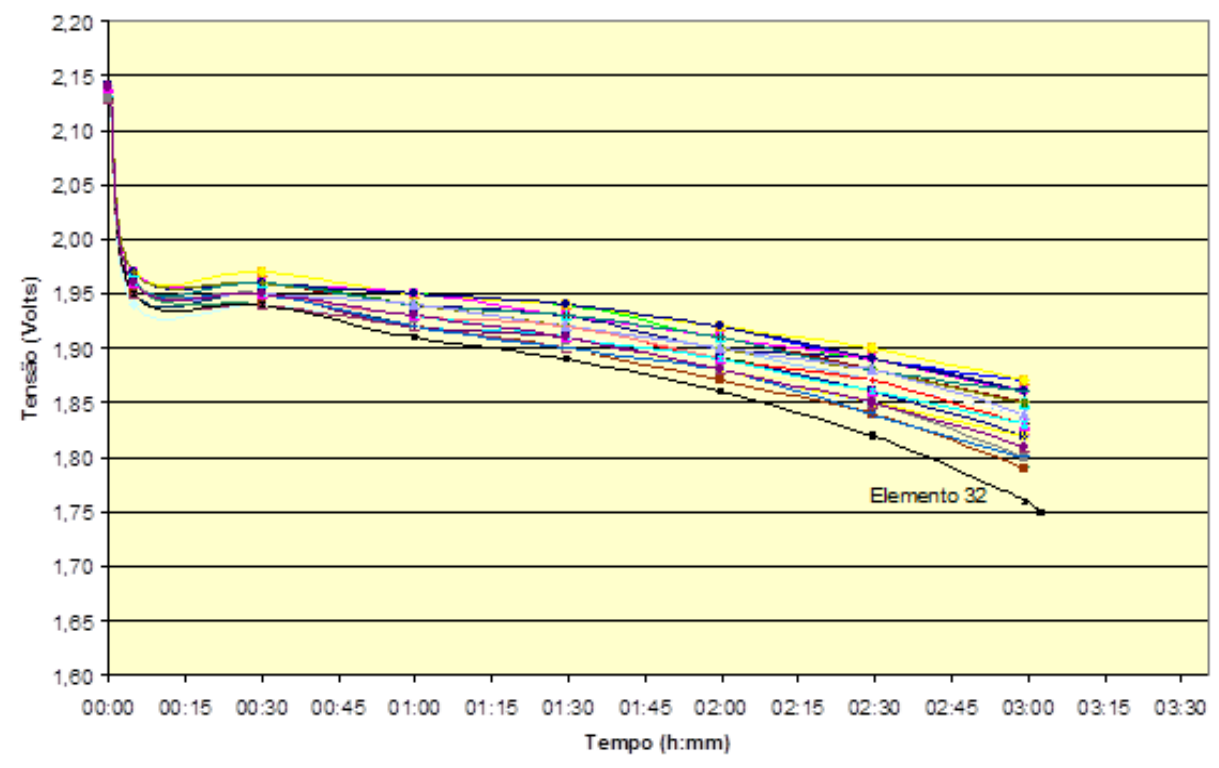

Figura 3 - Curva de descarga de uma bateria chumbo-ácida ventilada

Fonte: Relatório técnico Ligth [3]

Medição de resistência interna (impedância, condutância, resistência): Um sistema elétrico ou eletroquímico, quando atravessado por um fluxo de corrente elétrica, apresenta resistência ou impedância a esse fluxo. Assim o valor absoluto da impedância, condutância ou resistência interna da bateria é uma função da integridade de seus componentes internos, tais como: polos, grades, conexões internas, placas, separadores e eletrólito. A bateria nova apresenta uma determinada resistência interna. No decorrer do seu uso, seus componentes internos sofrerão processos de degradação, que será 
refletido numa variação de sua resistência interna. Esta variação poderá ser detectada pelas medições de condutância ou impedância ou resistência interna. As medidas de impedância ou condutância ou resistência interna, quando realizadas periodicamente, podem ser usadas para acompanhar o processo de degradação da bateria. Obtendo-se dados suficientes, pode ser feita uma projeção da vida útil remanescente da bateria [16-17]. No mercado existem vários equipamentos portáteis para realizar estas medições. A resistência interna pode ser medida através de condutância, impedância e resistência em corrente continua. Cada equipamento portátil realiza a medição de uma maneira específica. Vários estudos realizados mundialmente e no Brasil comprovaram que estas medições são eficazes como ferramenta para acompanhamento do estado de degradação da bateria. As medidas de impedância, condutância ou resistência interna devem ser realizadas com a bateria em flutuação. Cada elemento é medido individualmente. $\mathrm{O}$ equipamento mede também a tensão elétrica de flutuação. Na primeira avaliação, com a bateria nova, calcula-se o valor médio de impedância, condutância ou resistência interna para cada bateria. A partir desta, nas demais avaliações este valor será considerado como sendo o valor de referência. Para a avaliação da impedância e resistência interna são consideradas as seguintes regras:

- Os elementos que apresentarem valores de impedância ou resistência interna inferior a $20 \%$ do valor de referência são considerados em estado normal para operação;

- Os elementos que apresentarem valores de impedância ou resistência interna superior a $20 \%$ do valor de referência, são considerados em estado de alerta;

- Os elementos que apresentarem valores de impedância superior a $50 \%$ do valor de referência indicam que estão em processo de degradação avançada e devem ser substituídos.

Para a avaliação da condutância são consideradas as seguintes regras:

- Os elementos que apresentarem valores superiores a $80 \%$ do valor de referência são considerados em estado normal para operação;

- Os elementos que apresentarem valores de condutância no intervalo de 60 a $80 \%$ inferiores ao Valor de Referência representam um sinal de alerta, indicando que a bateria está com algum problema;

- Os elementos que apresentarem valores de condutância $40 \%$ inferior ao Valor Referência devem ser substituídos imediatamente.

Os Valores de Referência devem ser obtidos 90 dias após a instalação do banco, pois antes desse período a bateria não está totalmente ativada e os materiais ativos de suas placas positivas e negativas não estão totalmente formados. 


\section{3 \\ Monitoramento remoto de baterias}

O monitoramento remoto de baterias otimiza os recursos financeiros com os processos de manutenção e operação das subestações, bem como agrega valor a confiabilidade do sistema. No mercado nacional, as opções de equipamentos para o monitoramento remoto de bateria são restritas e pouco difundidas. Tais fatos colaboraram para o desenvolvimento de um protótipo para o monitoramento remoto de baterias, tal qual ocorre no âmbito de um projeto de pesquisa e desenvolvimento [11].

\section{1. \\ Funcionalidades do protótipo}

A Figura 4 mostra a arquitetura do protótipo do sistema de monitoramento remoto. O hardware é composto por Unidades de Medição (UM) e uma Unidade de Controle (UC). Uma UM mede a tensão elétrica, nível de eletrólito (somente baterias ventiladas) e impedância individual de até quatro elementos, como também a temperatura ambiente de um elemento, resistência de interconexão e corrente de ripple.

Essas medições são transmitidas via comunicação sem fio (wireless) para a UC, que armazena e processa os dados e envia via rede GSM para um Servidor. Os dados são processados e analisados pelo Software de Gestão de Baterias. O sistema também monitora a bateria quando esta entra em descarga (falta da energia comercial). O protótipo mede o valor ôhmico por meio da técnica de impedância, a qual utiliza corrente alternada e tensão elétrica em uma frequência conhecida. As Figuras 5 e 6, respectivamente, mostram a Unidade de Medição e a Unidade de Controle desenvolvidas. Além disso, a Figura 7 apresenta o sistema de baterias estacionárias instalado na subestação Baependi. 


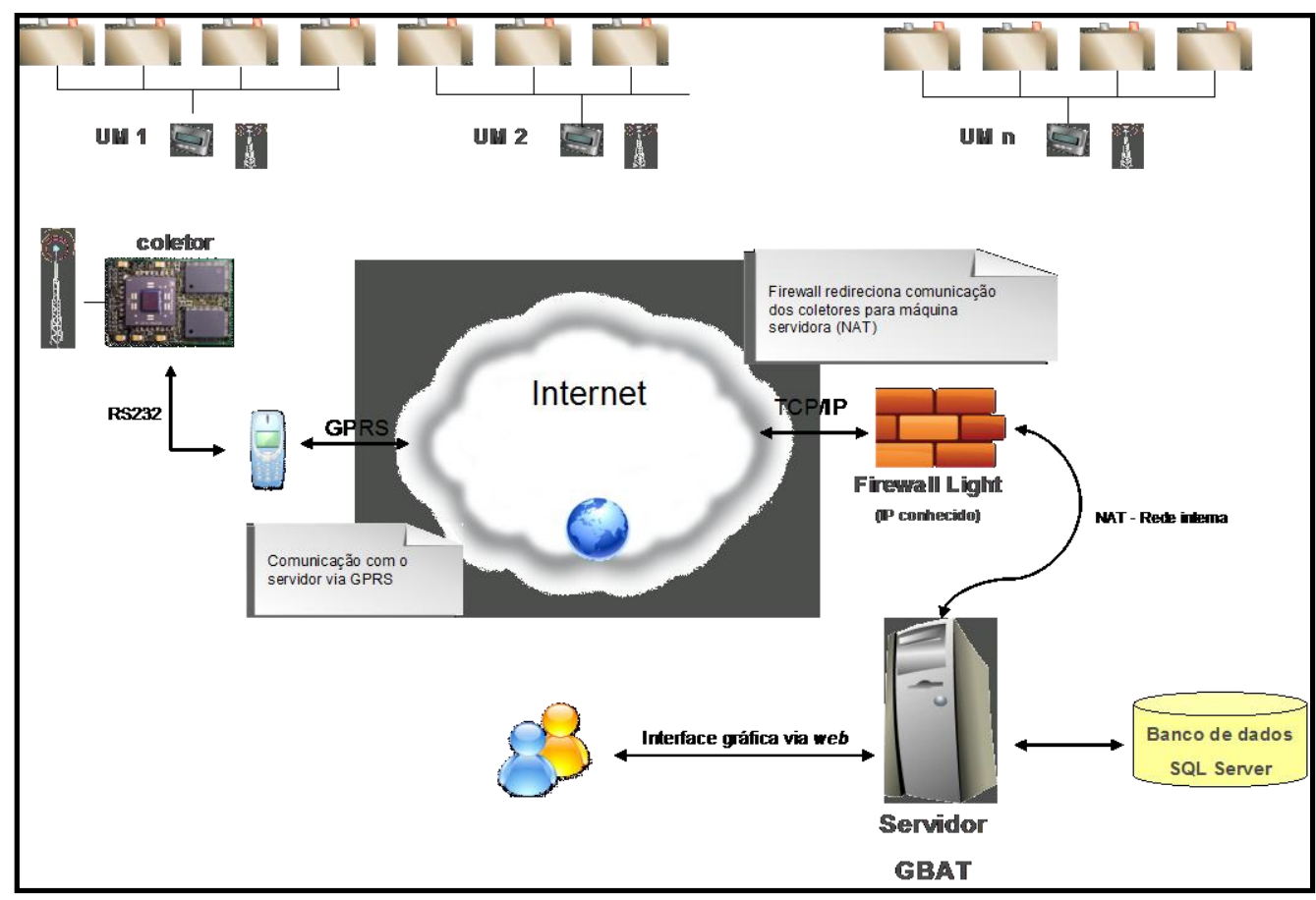

Figura 4 - Arquitetura do sistema de monitoramento remoto

\section{2. \\ Definição dos parâmetros monitoráveis}

Tensão elétrica e impedância são os parâmetros monitoráveis que foram discutidos e avaliados para verificar a confiabilidade do equipamento remoto.

\section{3. \\ Instalação e teste de campo}

Os protótipos foram instalados na Subestação da Light Baependi, em operação na cidade do Rio de Janeiro. Esta Subestação possui dois bancos de baterias chumbo-ácidas ventiladas compostas por 60 elementos cada, tendo sido instalado em um dos bancos. O protótipo é composto por 15 Unidades de Medição (UM) e uma Unidade de Controle (UC). A Figura 6 apresenta a UC do protótipo.

O equipamento proporciona a funcionalidade de programação das medições de acordo com a necessidade do usuário. Entretanto, para este estudo as medições foram realizadas com periodicidade semanal. 

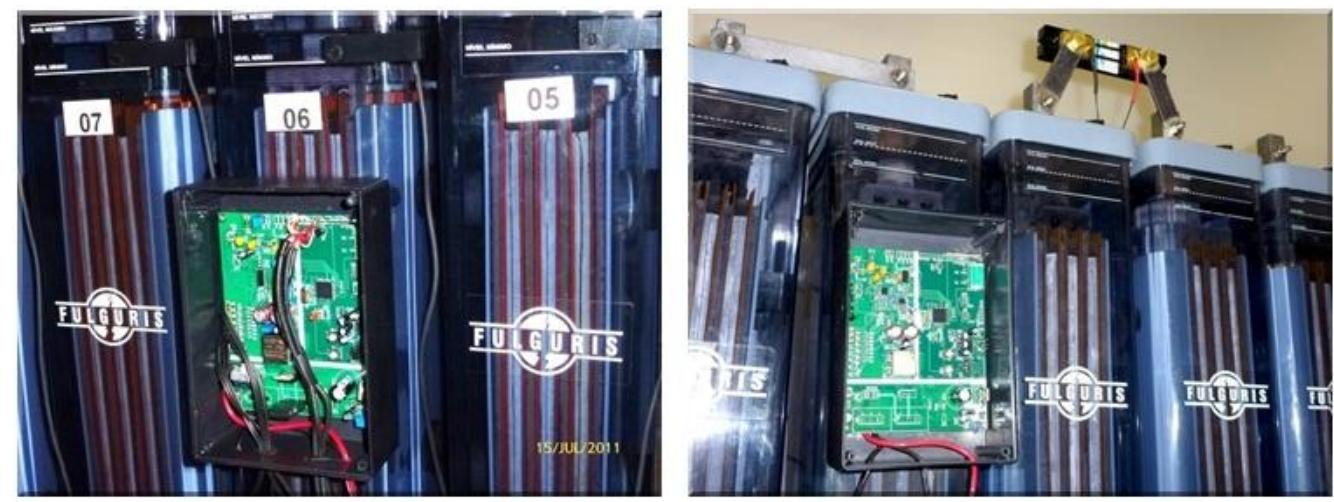

Figura 5 - Unidade de Medida do protótipo do sistema

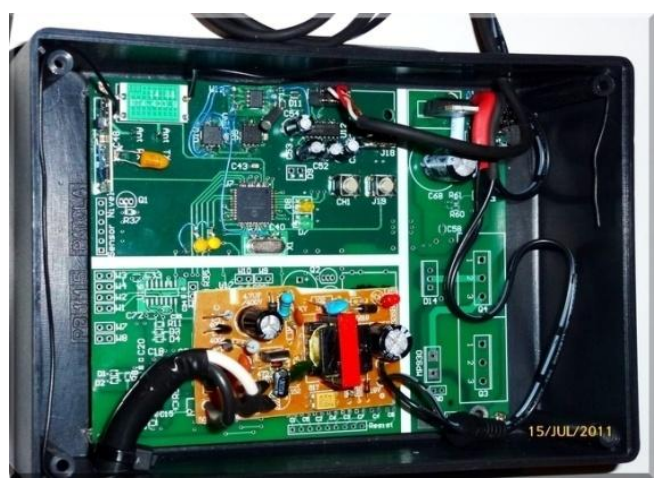

Figura 6 - Unidade de Controle do protótipo do sistema

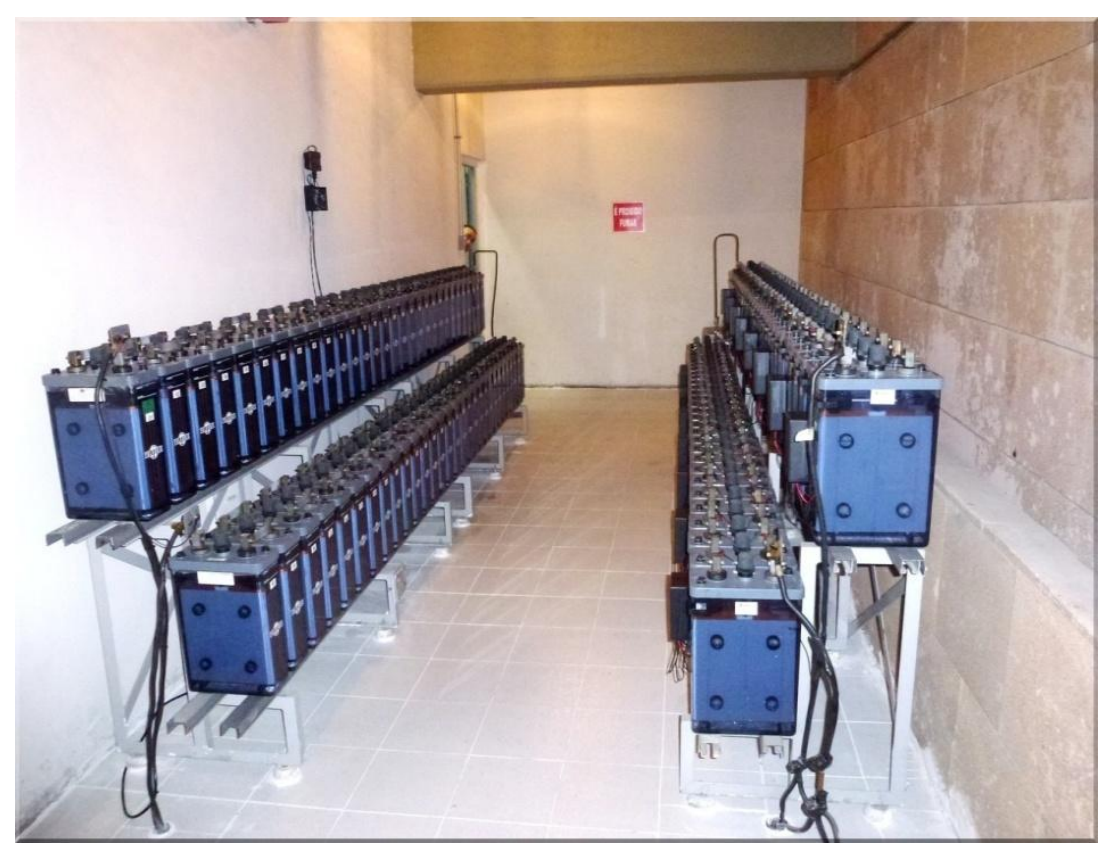

Figura 7 - Sistema de baterias estacionárias localizado na subestação Baependi 
Validação da medição remota em ambiente real de operação: Procedimentos experimentais e resultados

Serão abordados neste capítulo os procedimentos adotados para a validação das medições de impedância e tensão elétrica geradas pelo protótipo em ambiente real de operação.

\section{1. Procedimentos de ensaio para validação das medições}

Para realizar a validação das medições de tensão elétrica e impedância do protótipo de monitoramento remoto foi utilizado um equipamento portátil com capacidade e resolução metrológica compatível com as medições alvo.

O equipamento portátil utilizado foi o modelo EC 2000, fabricado pela World Energy Labs, o qual utiliza metodologia de medição a 4 fios para realizar as medições ôhmicas internas da bateria.

As medições foram realizadas em intervalos regulares (semanais) durante dois meses. Foi medida a tensão elétrica e a impedância de cada elemento que compõe o grupo de baterias no qual o protótipo está instalado, totalizando 60 medições por ensaio. Conforme instrução de operação do instrumento, estas medições foram realizadas com a bateria na condição de flutuação. Visando realizar a análise comparativa dos dados de impedância e de tensão elétrica do equipamento portátil em relação às medições efetuadas pelo protótipo, para cada medição realizada com o equipamento portátil foi solicitado ao sistema de monitoramento remoto a realização de medições destas duas grandezas.

\section{2.}

\section{Calibração do equipamento portátil}

Para assegurar a confiabilidade das medições do equipamento portátil, inicialmente foi realizada uma verificação preliminar de sua calibração. Os 
equipamentos portáteis possuem dispositivo interno de ajuste automático, não sendo possível realizar qualquer tipo de intervenção em suas rotinas de medição.

Desta forma, a verificação da calibração do equipamento portátil foi conduzida conforme descrito a seguir:

Um elemento de bateria VRLA de 150 Ah foi interligado com um strap $^{1}$, por meio de seu polo negativo, ligado em série com um shunt ${ }^{2}$ de $60 \mathrm{~A} / 60 \mathrm{mV}$ devidamente calibrado e referenciado a um certificado de calibração (número PD.SM.11.22A.3986A/CC-01-AA, no Anexo 1), emitido pelo laboratório Fundação CPqD (Centro de Pesquisa e Desenvolvimento em Telecomunicações). Uma das ponteiras de medição do equipamento portátil foi conectada ao polo positivo da bateria e a outra ponteira na extremidade livre do shunt, realizando uma medição com o equipamento portátil do conjunto elemento + strap + shunt . Em seguida outras medições foram realizadas somente com elemento + strap, isto é, sem o shunt, e finalmente apenas com o elemento. A Figura 8a e $8 \mathrm{~b}$ ilustram a realização do ensaio e a Figura 8c apresenta os resultados das medições.

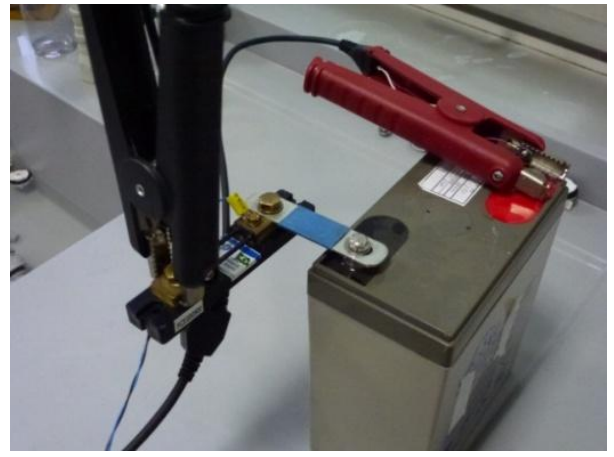

$\mathrm{A}-$ Conjunto elemento + strap + shunt

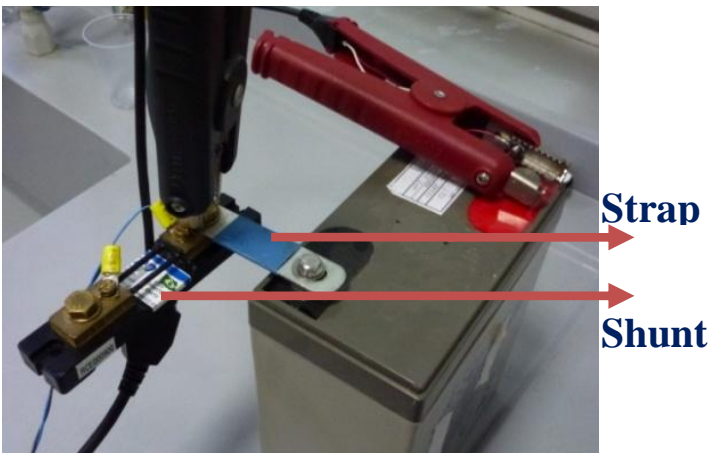

$\mathrm{B}-$ Conjunto elemento + strap

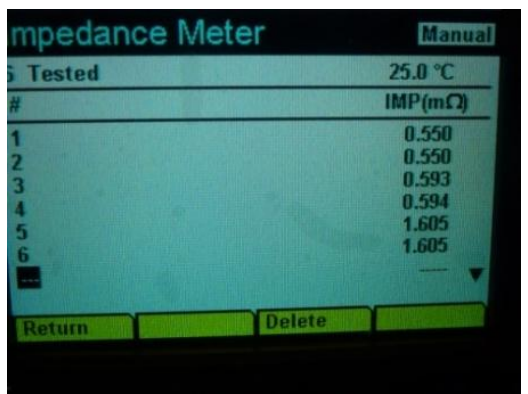

C - Resultado das medições

Figura 8 - Ensaio para validação das medições

${ }^{1}$ Strap: Barra de conexão entre os elementos

${ }^{2}$ Shunt: Dispositivo utilizado para medir corrente continua que circula em um determinado circuito. É fundamental para determinar com maior precisão a corrente que circula em um arranjo. 
A Tabela 2 apresenta os valores obtidos nas medições de resistência elétrica e os resultados das diferenças ôhmicas entre o conjunto elemento + strap + shunt $\mathrm{e}$ o conjunto elemento + strap, assim definindo um procedimento de cálculo que resulta no valor medido do shunt. As medições foram realizadas em duplicidade.

Comparando este valor medido do shunt com o seu valor de calibração $(1,000 \mathrm{mOhm})$ foram obtidos os desvios mostrados na tabela, demonstrando que as medições obtidas com o equipamento portátil são confiáveis.

Tabela 2 - Valores obtidos nas medições de resistência elétrica

\begin{tabular}{ccccccc}
\hline $\begin{array}{c}\text { Número } \\
\text { de } \\
\text { medições }\end{array}$ & $\begin{array}{c}\text { Elemento + strap } \\
+ \text { shunt }(\mathrm{mOhm})\end{array}$ & $\begin{array}{c}\text { Elemento }+ \\
\text { strap } \\
(\mathrm{mOhm})\end{array}$ & $\begin{array}{c}\text { Elemento } \\
(\mathrm{mOhm})\end{array}$ & $\begin{array}{c}\text { Valor calibrado } \\
\text { do } \operatorname{shunt}\left(\mathrm{S}_{\text {cal }}\right) \\
(\mathrm{mOhm})\end{array}$ & $\begin{array}{c}\text { Valor medido do shunt } \\
\left(\mathrm{S}_{\text {med }}\right)=(\mathrm{E}+\mathrm{s}+\mathrm{S})-(\mathrm{E}+\mathrm{s}) \\
(\mathrm{mOhm})\end{array}$ & $\begin{array}{c}\text { Desvio } \\
\left(\mathrm{S}_{\text {med }}-\mathrm{S}_{\text {cal }}\right) /\left(\mathrm{S}_{\text {cal }}\right) \\
(\%)\end{array}$ \\
\hline \hline 1 & 1,605 & 0,593 & 0,550 & 1,000 & 1,012 & 1,20 \\
2 & 1,605 & 0,594 & 0,550 & 1,000 & 1,011 & 1,10 \\
\hline
\end{tabular}

\section{3.}

\section{Análises estatísticas dos dados}

A validação da medição remota em ambiente real de operação foi avaliada mediante testes estatísticos, paramétricos e não paramétricos, referenciados aos níveis de confiança $90 \%, 95 \%$ e $99 \%$. As medições das duas amostras foram realizadas em temperatura ambiente de $25^{\circ} \mathrm{C} \pm 5^{\circ} \mathrm{C}$ e umidade relativa de $60 \% \pm 20 \%$.

A confiabilidade das medições foi avaliada por meio do Teste de Significância para a igualdade de duas médias, utilizando o procedimento descrito por Jairo Simon da Fonseca e Gilberto de Andrade Martins [18]. O teste de significância para a igualdade de duas médias considera as populações normais e independentes. Além disso, um caso particular deste teste assume as variâncias populacionais desconhecidas e admitidas iguais.

Inicialmente, para a realização da análise estatística da medição de impedância e tensão elétrica, os dados das Medidas 1 (Medições SIMBAGEBAT) e das Medidas 2 (equipamento portátil de medição) foram testados com base no teste de hipóteses Kolmogorov-Smirnov (K-S) para verificar sua conformidade à distribuição normal de probabilidade. O teste K-S é um teste não paramétrico que verifica a concordância entre distribuições acumuladas dos valores observados da amostra contra a correspondente distribuição acumulada 
especificada (teórica). Para o caso específico desta dissertação, a distribuição teórica está associada a uma distribuição normal de probabilidade.

Visando à garantia da confiabilidade do resultado do teste de significância para a igualdade de duas médias, após a aplicação do teste K-S foi utilizado o teste de significância para a igualdade de duas variâncias [18]. Para as medições da impedância e tensão elétrica, foi verificado se as variâncias populacionais das amostras podem ser consideradas estatisticamente iguais aos níveis de confiança de $90 \%, 95 \%$ e $99 \%$. A independência entre as duas amostras testadas foi qualitativamente definida, sendo apresentada na seção 4.3.1.3. Por último, aplicase o teste de significância para a igualdade de duas médias, validando as medições de impedância e as medições da tensão elétrica feitas pelo sistema SIMBAGEBAT, aos níveis de confiança de 90\%, 95\% e $99 \%$.

4.3.1. Análise estatística da medição de impedância

A Tabela 3 apresenta os dados das Medidas 1 das medições de impedância de sessenta elementos de baterias do sistema SIMBA-GEBAT. A Tabela 4 apresenta os dados das Medidas 2, do equipamento portátil de medição.

Tabela 3 - Medições de Impedância SIMBA-GEBAT (Medidas 1)

\begin{tabular}{|c|c|c|c|c|c|c|c|c|c|c|c|c|c|}
\hline \multicolumn{14}{|c|}{ Medições SIMBA-GEBAT (mOhms) } \\
\hline Elemento & $31 / 08 / 12$ & $14 / 09 / 12$ & $21 / 09 / 12$ & $22 / 09 / 12$ & $02 / 10 / 12$ & $10 / 10 / 12$ & Elemento & $31 / 08 / 12$ & $14 / 09 / 12$ & $21 / 09 / 12$ & $22 / 09 / 12$ & $02 / 10 / 12$ & $10 / 10 / 12$ \\
\hline 1 & 0,827 & 0,816 & 0,819 & 0,803 & 0,809 & 0,814 & 31 & 0,759 & 0,768 & 0,741 & 0,744 & 0,742 & 0,750 \\
\hline 2 & 0,788 & 0,781 & 0,774 & 0,772 & 0,768 & 0,788 & 32 & 0,750 & 0,751 & 0,737 & 0,734 & 0,735 & 0,746 \\
\hline 3 & 0,773 & 0,785 & 0,777 & 0,769 & 0,766 & 0,780 & 33 & 0,740 & 0,723 & 0,708 & 0,714 & 0,711 & 0,714 \\
\hline 4 & 0,760 & 0,744 & 0,738 & 0,731 & 0,736 & 0,758 & 34 & 0,721 & 0,710 & 0,696 & 0,703 & 0,704 & 0,709 \\
\hline 5 & 0,804 & 0,772 & 0,777 & 0,790 & 0,790 & 0,782 & 35 & 0,681 & 0,776 & 0,783 & 0,799 & 0,770 & 0,770 \\
\hline 6 & 0,785 & 0,749 & 0,777 & 0,761 & 0,761 & 0,757 & 36 & 0,721 & 0,702 & 0,690 & 0,693 & 0,691 & 0,710 \\
\hline 7 & 0,758 & 0,741 & 0,743 & 0,726 & 0,726 & 0,725 & 37 & 0,718 & 0,735 & 0,769 & 0,766 & 0,773 & 0,764 \\
\hline 8 & 0,727 & 0,810 & 0,790 & 0,795 & 0,796 & 0,796 & 38 & 0,783 & 0,745 & 0,756 & 0,729 & 0,732 & 0,765 \\
\hline 9 & 0,783 & 0,779 & 0,783 & 0,777 & 0,776 & 0,799 & 39 & 0,672 & 0,782 & 0,786 & 0,784 & 0,795 & 0,795 \\
\hline 10 & 0,804 & 0,862 & 0,845 & 0,879 & 0,834 & 0,834 & 40 & 0,691 & 0,774 & 0,751 & 0,751 & 0,750 & 0,750 \\
\hline 11 & 0,753 & 0,709 & 0,735 & 0,732 & 0,726 & 0,758 & 41 & 0,761 & 0,759 & 0,767 & 0,751 & 0,754 & 0,776 \\
\hline 12 & 0,711 & 0,717 & 0,701 & 0,700 & 0,704 & 0,714 & 42 & 0,703 & 0,810 & 0,796 & 0,801 & 0,797 & 0,797 \\
\hline 13 & 0,740 & 0,797 & 0,779 & 0,793 & 0,796 & 0,796 & 43 & 0,688 & 0,687 & 0,684 & 0,685 & 0,686 & 0,696 \\
\hline 14 & 0,713 & 0,775 & 0,770 & 0,773 & 0,784 & 0,784 & 44 & 0,710 & 0,834 & 0,805 & 0,829 & 0,819 & 0,819 \\
\hline 15 & 0,704 & 0,786 & 0,753 & 0,762 & 0,754 & 0,754 & 45 & 0,668 & 0,655 & 0,649 & 0,652 & 0,657 & 0,656 \\
\hline 16 & 0,764 & 0,829 & 0,814 & 0,825 & 0,803 & 0,803 & 46 & 0,676 & 0,761 & 0,747 & 0,752 & 0,749 & 0,749 \\
\hline 17 & 0,787 & 0,779 & 0,775 & 0,769 & 0,772 & 0,775 & 47 & 0,717 & 0,715 & 0,704 & 0,710 & 0,711 & 0,720 \\
\hline 18 & 0,726 & 0,718 & 0,738 & 0,720 & 0,728 & 0,724 & 48 & 0,713 & 0,778 & 0,758 & 0,766 & 0,767 & 0,767 \\
\hline 19 & 0,778 & 0,840 & 0,817 & 0,841 & 0,816 & 0,816 & 49 & 0,659 & 0,729 & 0,719 & 0,717 & 0,722 & 0,722 \\
\hline 20 & 0,757 & 0,742 & 0,741 & 0,738 & 0,734 & 0,751 & 50 & 0,696 & 0,815 & 0,827 & 0,810 & 0,790 & 0,790 \\
\hline 21 & 0,768 & 0,743 & 0,710 & 0,709 & 0,710 & 0,711 & 51 & 0,678 & 0,666 & 0,673 & 0,666 & 0,667 & 0,677 \\
\hline 22 & 0,764 & 0,780 & 0,719 & 0,721 & 0,720 & 0,725 & 52 & 0,663 & 0,729 & 0,731 & 0,737 & 0,702 & 0,702 \\
\hline 23 & 0,740 & 0,731 & 0,697 & 0,692 & 0,698 & 0,706 & 53 & 0,657 & 0,647 & 0,657 & 0,666 & 0,663 & 0,671 \\
\hline 24 & 0,699 & 0,770 & 0,768 & 0,783 & 0,756 & 0,756 & 54 & 0,621 & 0,742 & 0,732 & 0,740 & 0,728 & 0,728 \\
\hline 25 & 0,731 & 0,711 & 0,725 & 0,717 & 0,724 & 0,735 & 55 & 0,631 & 0,623 & 0,627 & 0,625 & 0,625 & 0,631 \\
\hline 26 & 0,753 & 0,753 & 0,745 & 0,719 & 0,716 & 0,754 & 56 & 0,618 & 0,604 & 0,611 & 0,593 & 0,596 & 0,622 \\
\hline 27 & 0,697 & 0,701 & 0,695 & 0,669 & 0,671 & 0,671 & 57 & 0,677 & 0,769 & 0,719 & 0,748 & 0,736 & 0,736 \\
\hline 28 & 0,687 & 0,776 & 0,740 & 0,758 & 0,761 & 0,761 & 58 & 0,648 & 0,645 & 0,640 & 0,642 & 0,647 & 0,667 \\
\hline 29 & 0,756 & 0,742 & 0,751 & 0,758 & 0,758 & 0,767 & 59 & 0,656 & 0,653 & 0,651 & 0,649 & 0,652 & 0,677 \\
\hline 30 & 0,805 & 0,853 & 0,832 & 0,871 & 0,855 & 0,855 & 60 & 0,665 & 0,708 & 0,736 & 0,709 & 0,709 & 0,725 \\
\hline
\end{tabular}


Tabela 4 - Medições de Impedância do Equipamento Portátil (Medidas 2)

\begin{tabular}{|c|c|c|c|c|c|c|c|c|c|c|c|c|c|}
\hline \multicolumn{14}{|c|}{ Medições Equipamento Portátil (mOhms) } \\
\hline Elemento & $31 / 08 / 12$ & $14 / 09 / 12$ & $21 / 09 / 12$ & $22 / 09 / 12$ & $02 / 10 / 12$ & $10 / 10 / 12$ & Elemento & $31 / 08 / 12$ & $14 / 09 / 12$ & $21 / 09 / 12$ & $22 / 09 / 12$ & $02 / 10 / 12$ & $10 / 10 / 12$ \\
\hline 1 & 0,832 & 0,827 & 0,825 & 0,820 & 0,820 & 0,839 & 31 & 0,800 & 0,761 & 0,797 & 0,781 & 0,781 & 0,806 \\
\hline 2 & 0,799 & 0,778 & 0,804 & 0,772 & 0,772 & 0,816 & 32 & 0,780 & 0,751 & 0,756 & 0,760 & 0,760 & 0,771 \\
\hline 3 & 0,771 & 0,780 & 0,763 & 0,767 & 0,767 & 0,774 & 33 & 0,791 & 0,782 & 0,774 & 0,750 & 0,750 & 0,788 \\
\hline 4 & 0,787 & 0,757 & 0,771 & 0,763 & 0,763 & 0,782 & 34 & 0,790 & 0,750 & 0,770 & 0,764 & 0,764 & 0,765 \\
\hline 5 & 0,796 & 0,763 & 0,772 & 0,783 & 0,783 & 0,791 & 35 & 0,726 & 0,733 & 0,749 & 0,720 & 0,720 & 0,747 \\
\hline 6 & 0,772 & 0,739 & 0,766 & 0,748 & 0,748 & 0,763 & 36 & 0,789 & 0,758 & 0,764 & 0,771 & 0,771 & 0,772 \\
\hline 7 & 0,779 & 0,770 & 0,771 & 0,757 & 0,757 & 0,761 & 37 & 0,780 & 0,758 & 0,787 & 0,782 & 0,782 & 0,782 \\
\hline 8 & 0,760 & 0,740 & 0,745 & 0,746 & 0,746 & 0,777 & 38 & 0,775 & 0,760 & 0,787 & 0,764 & 0,764 & 0,798 \\
\hline 9 & 0,779 & 0,778 & 0,787 & 0,769 & 0,769 & 0,799 & 39 & 0,732 & 0,736 & 0,734 & 0,745 & 0,745 & 0,746 \\
\hline 10 & 0,812 & 0,795 & 0,829 & 0,784 & 0,784 & 0,833 & 40 & 0,724 & 0,701 & 0,701 & 0,700 & 0,700 & 0,726 \\
\hline 11 & 0,772 & 0,730 & 0,760 & 0,751 & 0,751 & 0,783 & 41 & 0,759 & 0,758 & 0,758 & 0,747 & 0,747 & 0,778 \\
\hline 12 & 0,771 & 0,735 & 0,750 & 0,739 & 0,739 & 0,754 & 42 & 0,780 & 0,766 & 0,771 & 0,767 & 0,767 & 0,771 \\
\hline 13 & 0,747 & 0,729 & 0,743 & 0,746 & 0,746 & 0,757 & 43 & 0,763 & 0,747 & 0,763 & 0,761 & 0,761 & 0,760 \\
\hline 14 & 0,725 & 0,720 & 0,723 & 0,734 & 0,734 & 0,740 & 44 & 0,784 & 0,755 & 0,779 & 0,769 & 0,769 & 0,789 \\
\hline 15 & 0,756 & 0,723 & 0,732 & 0,724 & 0,724 & 0,750 & 45 & 0,717 & 0,693 & 0,716 & 0,702 & 0,702 & 0,714 \\
\hline 16 & 0,779 & 0,764 & 0,775 & 0,753 & 0,753 & 0,782 & 46 & 0,711 & 0,697 & 0,702 & 0,699 & 0,699 & 0,707 \\
\hline 17 & 0,777 & 0,764 & 0,785 & 0,769 & 0,769 & 0,795 & 47 & 0,756 & 0,752 & 0,727 & 0,732 & 0,732 & 0,751 \\
\hline 18 & 0,747 & 0,748 & 0,773 & 0,757 & 0,757 & 0,754 & 48 & 0,708 & 0,688 & 0,696 & 0,697 & 0,697 & 0,725 \\
\hline 19 & 0,810 & 0,787 & 0,811 & 0,786 & 0,786 & 0,818 & 49 & 0,679 & 0,669 & 0,667 & 0,672 & 0,672 & 0,694 \\
\hline 20 & 0,802 & 0,790 & 0,791 & 0,785 & 0,785 & 0,796 & 50 & 0,715 & 0,727 & 0,710 & 0,690 & 0,690 & 0,720 \\
\hline 21 & 0,777 & 0,745 & 0,752 & 0,739 & 0,739 & 0,754 & 51 & 0,697 & 0,675 & 0,676 & 0,681 & 0,681 & 0,681 \\
\hline 22 & 0,781 & 0,776 & 0,765 & 0,758 & 0,758 & 0,765 & 52 & 0,679 & 0,681 & 0,687 & 0,702 & 0,702 & 0,685 \\
\hline 23 & 0,760 & 0,745 & 0,733 & 0,743 & 0,743 & 0,747 & 53 & 0,672 & 0,657 & 0,672 & 0,669 & 0,669 & 0,684 \\
\hline 24 & 0,740 & 0,738 & 0,753 & 0,726 & 0,726 & 0,745 & 54 & 0,692 & 0,682 & 0,690 & 0,678 & 0,678 & 0,707 \\
\hline 25 & 0,728 & 0,705 & 0,733 & 0,716 & 0,716 & 0,742 & 55 & 0,702 & 0,693 & 0,697 & 0,696 & 0,696 & 0,707 \\
\hline 26 & 0,761 & 0,743 & 0,765 & 0,736 & 0,736 & 0,784 & 56 & 0,694 & 0,664 & 0,690 & 0,678 & 0,678 & 0,697 \\
\hline 27 & 0,706 & 0,696 & 0,702 & 0,699 & 0,699 & 0,710 & 57 & 0,719 & 0,669 & 0,698 & 0,686 & 0,686 & 0,707 \\
\hline 28 & 0,726 & 0,690 & 0,708 & 0,711 & 0,711 & 0,731 & 58 & 0,692 & 0,673 & 0,689 & 0,680 & 0,680 & 0,704 \\
\hline 29 & 0,787 & 0,756 & 0,772 & 0,774 & 0,774 & 0,782 & 59 & 0,661 & 0,664 & 0,674 & 0,667 & 0,667 & 0,672 \\
\hline 30 & 0,803 & 0,782 & 0,821 & 0,805 & 0,805 & 0,822 & 60 & 0,698 & 0,698 & 0,726 & 0,699 & 0,699 & 0,725 \\
\hline
\end{tabular}

\subsubsection{1.}

\section{Teste Kolmogorov-Smirnov (K-S)}

O teste K-S foi utilizado para testar se os dados apresentados nas Tabelas 3 e 4 seguem uma distribuição normal de probabilidade. Inicialmente foram feitas inferências estatísticas que forneceram uma ideia preliminar acerca da distribuição de probabilidades que segue as amostras estudadas.

Em primeiro lugar foram tratados os dados das Medidas 1-Medições de Impedância SIMBA-GEBAT.

A Tabela 5, apresenta a estatística descritiva, a qual forneceu valores próximos da média, mediana e moda, o que permite inferir que a amostra segue uma distribuição normal de probabilidade com média $\mu$ e variância $\sigma^{\mathbf{2}}$. Além disso, a Tabela 6 apresenta a frequência absoluta em cada intervalo de classe. Pode-se observar na figura 9, o histograma da amostra, o qual apresenta um sino com perfil similar ao de uma distribuição normal. 
Tabela 5 - Estatística descritiva

\begin{tabular}{lr}
\hline \multicolumn{1}{c}{ Estatística Descritiva } & \multicolumn{1}{c}{ Valor } \\
\hline Média & $\mathbf{0 , 7 4 0 ~ \mathbf { m O h m }}$ \\
Erro padrão & $0,003 \mathrm{mOhm}$ \\
Mediana & $\mathbf{0 , 7 4 3 \mathbf { m O h m }}$ \\
Moda & $\mathbf{0 , 7 1 0 ~ \mathbf { m o h m }}$ \\
Desvio padrão & $0,053 \mathrm{mOhm}$ \\
Variância da amostra & $0,002 \mathrm{mOhm}$ \\
Curtose & $-0,067$ \\
Assimetria & $-0,245$ \\
Intervalo & $0,286 \mathrm{mOhm}$ \\
Valor mínimo & $0,593 \mathrm{mOhm}$ \\
Valor máximo & $0,879 \mathrm{mOhm}$ \\
Soma & $266,338 \mathrm{mOhm}$ \\
Contagem & 360 \\
\hline
\end{tabular}

Tabela 6 - Intervalo do histograma

\begin{tabular}{cc}
\hline Bloco $(\mathrm{mohm})$ & Frequência \\
\hline 0,593 & 1 \\
0,622 & 5 \\
0,650 & 15 \\
0,679 & 31 \\
0,707 & 33 \\
0,736 & 77 \\
0,765 & 75 \\
0,793 & 70 \\
0,822 & 35 \\
0,851 & 12 \\
0,880 & 6 \\
\hline
\end{tabular}

\section{Histograma}

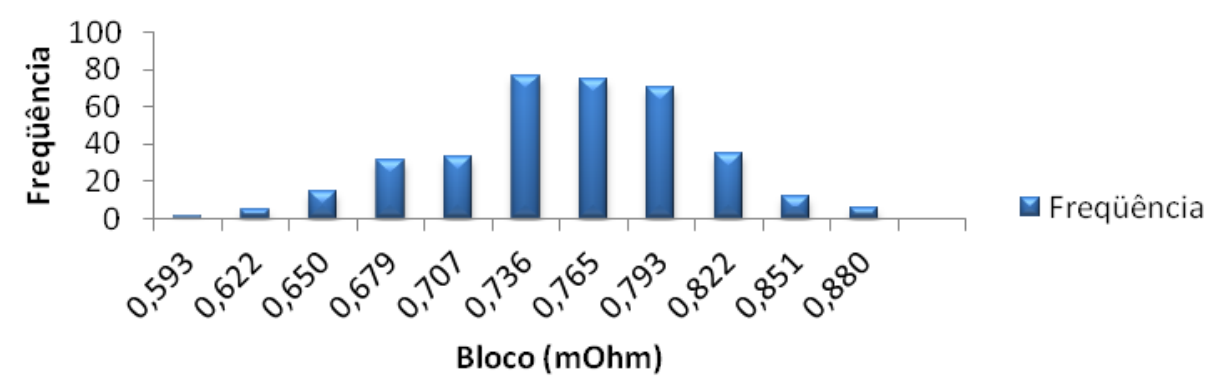


Figura 9 - Histograma de frequência: medições de impedância SIMBAGEBAT

Foram calculados os seguintes estimadores dos parâmetros desta amostra:

\section{Medidas $1 \sim \mathrm{N}\left(\mu, \sigma^{2}\right)$}

$$
\begin{aligned}
& \overline{x_{1}}=0,740 \\
& s_{1}^{2}=0,002
\end{aligned}
$$

A seguir foi aplicado o teste K-S para determinar se a medidas 1 segue uma distribuição normal de probabilidade com os estimadores dos parâmetros calculados aos níveis de confiança de $90 \%, 95 \%$ e $99 \%$ :

\section{- Hipótese:}

$\mathrm{H}_{\mathrm{o}}=$ As medições das medidas 1 seguem uma distribuição normal de probabilidade

$\mathrm{H}_{1}=$ As medições das medidas 1 não seguem uma distribuição normal de probabilidade

Tabela 7 - Tabela de frequência absoluta

\begin{tabular}{|c|c|c|c|c|}
\hline No & \multicolumn{2}{|c|}{ Intervalo (mOhm) } & Frequência absoluta & Frequência acumulada \\
\hline 1 & 0,593 & 0,622 & 6 & 6 \\
\hline 2 & 0,622 & 0,650 & 15 & 21 \\
\hline 3 & 0,650 & 0,679 & 31 & 52 \\
\hline 4 & 0,679 & 0,707 & 33 & 85 \\
\hline 5 & 0,707 & 0,736 & 77 & 162 \\
\hline 6 & 0,736 & 0,765 & 75 & 237 \\
\hline 7 & 0,765 & 0,793 & 70 & 307 \\
\hline 8 & 0,793 & 0,822 & 35 & 342 \\
\hline 9 & 0,822 & 0,851 & 12 & 354 \\
\hline 10 & 0,851 & 0,880 & 6 & 360 \\
\hline
\end{tabular}

A seguir, os dados das medidas 1 foram padronizados em uma distribuição normal de probabilidades com $\mu=0$ e $\sigma^{2}=\mathbf{1}$, permitindo calcular as frequências esperadas ou teóricas. Assim os valores de $\mathbf{Z} \sim \mathbf{N}(\mathbf{0 , 1})$ [Anexo 6] são obtidos pela seguinte equação (6): 


$$
\mathrm{Z}=\frac{\mathrm{X}-\mu}{\sigma}
$$

(Equação 6)

Nessa equação,

$\mathrm{X}=$ valor do intervalo da Tabela 7

$$
\begin{aligned}
\mu & =0,740 \\
\sigma & =0,053
\end{aligned}
$$

Distribuição normal de probabilidade com média zero e variância um

Tabela 8 - Cálculo da frequência esperada

\begin{tabular}{|c|c|c|c|c|c|c|c|c|c|}
\hline No & \multicolumn{2}{|c|}{$\begin{array}{c}\text { Intervalo } \\
\text { (mOhm) }\end{array}$} & \multicolumn{2}{|c|}{ Intervalo Z } & \multicolumn{2}{c|}{ Área do Intervalo Z } & Área em Z & $\mathbf{e}_{\mathbf{i}}$ & $\mathbf{f}_{\mathbf{i}}$ \\
\hline 1 & 0,593 & 0,622 & $-2,7750$ & $-2,2340$ & 0,0028 & 0,0127 & 0,0100 & 3,6 & 6 \\
\hline 2 & 0,622 & 0,650 & $-2,2340$ & $-1,6930$ & 0,0127 & 0,0452 & 0,0325 & 11,7 & 15 \\
\hline 3 & 0,650 & 0,679 & $-1,6930$ & $-1,1520$ & 0,0452 & 0,1247 & 0,0794 & 28,6 & 31 \\
\hline 4 & 0,679 & 0,707 & $-1,1520$ & $-0,6110$ & 0,1247 & 0,2706 & 0,1459 & 52,5 & 33 \\
\hline 5 & 0,707 & 0,736 & $-0,6110$ & $-0,0699$ & 0,2706 & 0,4721 & 0,2015 & 72,5 & 77 \\
\hline 6 & 0,736 & 0,765 & $-0,0699$ & 0,4711 & 0,4721 & 0,6812 & 0,2091 & 75,3 & 75 \\
\hline 7 & 0,765 & 0,793 & 0,4711 & 1,0121 & 0,6812 & 0,8443 & 0,1630 & 58,7 & 70 \\
\hline 8 & 0,793 & 0,822 & 1,0121 & 1,5531 & 0,8443 & 0,9398 & 0,0955 & 34,4 & 35 \\
\hline 9 & 0,822 & 0,851 & 1,5531 & 2,0941 & 0,9398 & 0,9819 & 0,0421 & 15,1 & 12 \\
\hline 10 & 0,851 & 0,880 & 2,0941 & 2,6503 & 0,9819 & 0,9960 & 0,0141 & 5,1 & 6 \\
\hline
\end{tabular}

Nesta tabela,

$\mathrm{e}_{\mathrm{i}}=$ Frequência esperada $=($ Área em Z $) *($ Tamanho da amostra $=360)$

$\mathrm{f}_{\mathrm{i}}=$ Frequência absoluta da amostra

Tabela 9 - Cálculo da estatística D

\begin{tabular}{|c|c|c|c|c|c|c|}
\hline No & $\mathbf{e}_{\mathbf{i}}$ & $\mathbf{f}_{\mathbf{i}}$ & $\mathbf{e}_{\mathbf{a}}$ & $\mathbf{f}_{\mathbf{a}}$ & $\mathbf{d}_{\mathbf{i}}$ & $\mathbf{D}=\mathbf{d}_{\mathbf{i}} / \mathbf{n}$ \\
\hline 1 & 3,6 & 6 & 3,6 & 6 & 2,4068 & 0,007 \\
\hline 2 & 11,7 & 15 & 15,3 & 21 & 5,7117 & 0,016 \\
\hline 3 & 28,6 & 31 & 43,9 & 52 & 8,1146 & 0,023 \\
\hline 4 & 52,5 & 33 & 96,4 & 85 & 11,4267 & 0,032 \\
\hline 5 & 72,5 & 77 & 169,0 & 162 & 6,9695 & 0,019 \\
\hline 6 & 75,3 & 75 & 244,2 & 237 & 7,2411 & 0,020 \\
\hline 7 & 58,7 & 70 & 302,9 & 307 & 4,0619 & 0,011 \\
\hline 8 & 34,4 & 35 & 337,3 & 342 & 4,6645 & 0,013 \\
\hline 9 & 15,1 & 12 & 352,5 & 354 & 1,5180 & 0,004 \\
\hline 10 & 5,1 & 6 & 357,6 & 360 & 2,4411 & 0,007 \\
\hline
\end{tabular}


Nesta tabela,

$\mathrm{e}_{\mathrm{i}}=$ Frequência esperada

$\mathrm{f}_{\mathrm{i}}=$ Frequência absoluta da amostra

$\mathrm{e}_{\mathrm{a}}=$ Frequência esperada acumulada

$\mathrm{f}_{\mathrm{a}}=$ Frequência absoluta da amostra acumulada

$\mathrm{d}_{\mathrm{i}}=$ Diferença: $\left|\mathbf{f}_{\mathbf{a}}-\mathbf{e}_{\mathbf{a}}\right|$

$\mathrm{n}=$ Tamanho da amostra $=360$

$\mathrm{D}=$ Valor da estatística do teste K-S para cada intervalo

$\mathrm{Na}$ Tabela 9, pode-se observar que a maior diferença " $\mathrm{D}$ " é 0,032. Então o valor da estatística $D_{\max }$ do teste K-S é:

$$
\mathrm{D}_{\max }=0,032
$$

A figura 10 apresenta as diferenças do teste K-S.

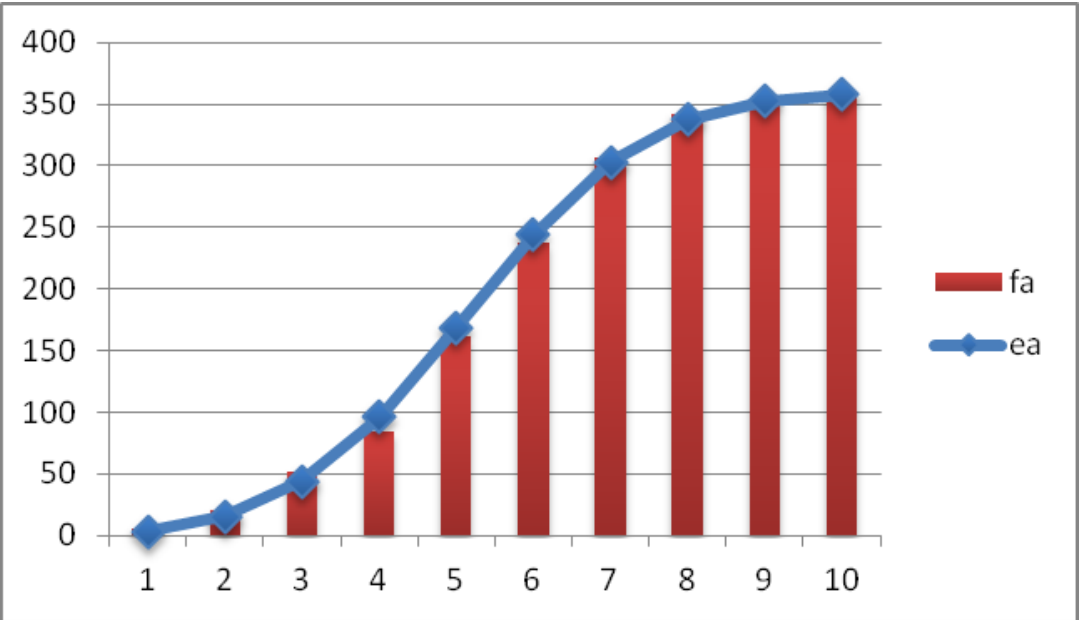

Figura 10 - Frequência absoluta da amostra acumulada vs Frequência esperada acumulada

- Regra de decisão:

$\left(\mathrm{D} / \mathrm{H}_{\mathrm{o}}\right.$ Verdadeira $) \sim$ Distribuição $\mathrm{D}_{(\alpha ; \mathrm{N})}$

$\alpha=$ Nível de significância

$\mathrm{N}=$ Número do intervalo adotado $=10$

Observação: Anexo 2: Tabela Distribuição D.

Adotando $\alpha=1 \%$

$\mathrm{D}_{\max }=0,032<\mathrm{D}_{(0,01 ; 10)}=0,490$ 


\section{Conclusão:}

Com um nível de confiança de 99\%, os dados das medidas 1 seguem uma distribuição normal com $\boldsymbol{\mu}=\mathbf{0 , 7 4 0}$ e $\boldsymbol{\sigma}^{2}=\mathbf{0 , 0 0 2}$.

Adotando $\alpha=5 \%$

$\mathrm{D}_{\max }=0,032<\mathrm{D}_{(0,05 ; 10)}=0,410$

\section{Conclusão:}

Com um nível de confiança de 95\%, os dados das medidas 1 seguem uma distribuição normal $\operatorname{com} \boldsymbol{\mu}=\mathbf{0 , 7 4 0}$ e $\boldsymbol{\sigma}^{2}=\mathbf{0 , 0 0 2}$.

$$
\begin{aligned}
& \text { Adotando } \alpha=\mathbf{1 0 \%} \\
& \mathrm{D}_{\max }=0,032<\mathrm{D}_{(0,1 ; 10)}=0,368
\end{aligned}
$$

\section{Conclusão:}

Com um nível de confiança de $90 \%$, os dados das medidas 1 seguem uma distribuição normal com $\boldsymbol{\mu}=\mathbf{0 , 7 4 0}$ e $\boldsymbol{\sigma}^{2}=\mathbf{0 , 0 0 2}$.

Em seguida trataram-se os dados das medidas 2 - Medições de Impedância do Equipamento Portátil (Medidas 2)

Tabela 10 - Estatística descritiva

\begin{tabular}{lr}
\hline \multicolumn{1}{c}{ Estatística Descritiva } & \multicolumn{1}{c}{ Valor } \\
\hline Média & $\mathbf{0 , 7 4 4 0} \mathbf{~ m O h m}$ \\
Erro padrão & 0,0021 mOhm \\
Mediana & $\mathbf{0 , 7 5 0 0 ~} \mathbf{m O h m}$ \\
Moda & $\mathbf{0 , 7 0 2 4} \mathbf{m O h m}$ \\
Desvio padrão & 0,0401 mOhm \\
Variância da amostra & 0,0016 mOhm $^{\mathbf{2}}$ \\
Curtose & $-0,7278$ \\
Assimetria & $-0,1910$ \\
Intervalo & 0,1812 mOhm \\
Valor mínimo & 0,6574 mOhm \\
Valor máximo & 0,8386 mOhm \\
& 267,8286 \\
Soma & mOhm \\
Contagem & 360 \\
\hline
\end{tabular}


Tabela 11 - Intervalo do histograma

\begin{tabular}{cc}
\hline Bloco $(\mathrm{mOhm})$ & Frequência \\
\hline 0,6574 & 1 \\
0,6755 & 18 \\
0,6936 & 30 \\
0,7118 & 46 \\
0,7299 & 30 \\
0,7480 & 47 \\
0,7661 & 71 \\
0,7842 & 67 \\
0,8024 & 30 \\
0,8205 & 12 \\
0,8386 & 8 \\
\hline
\end{tabular}

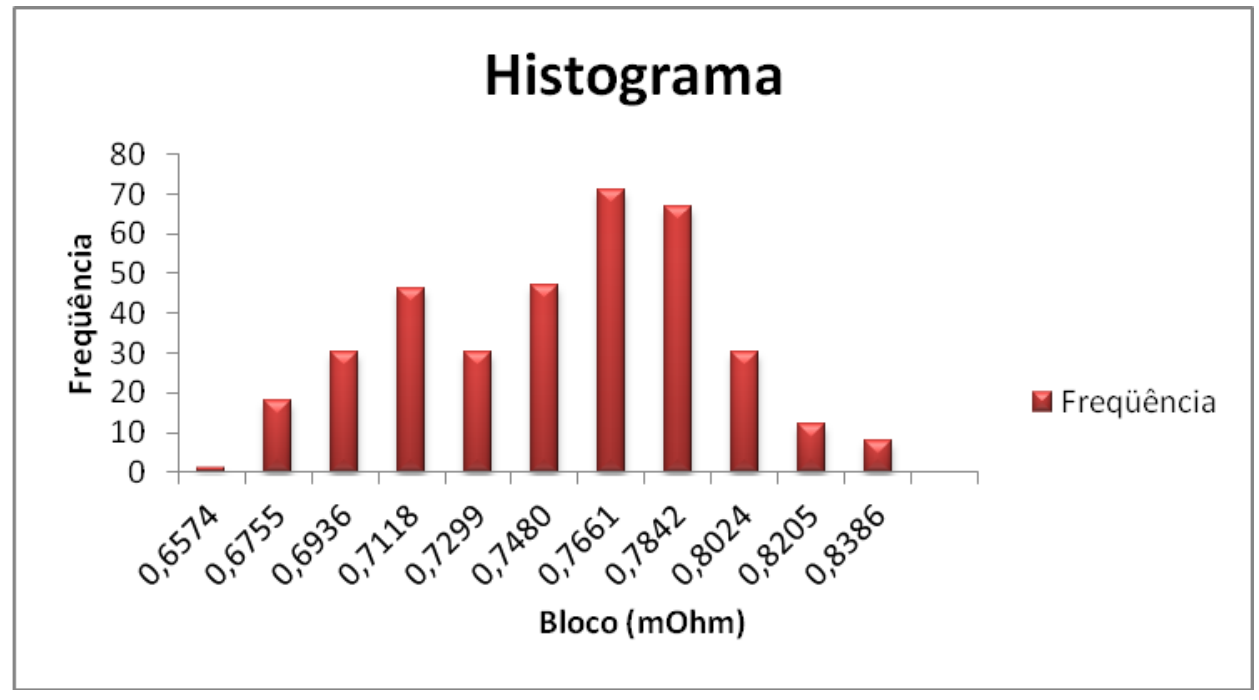

Figura 11 - Histograma de frequência: Medidas de impedância obtidas utilizando o equipamento portátil

A estatística descritiva forneceu valores próximos da média, mediana e moda, portanto pode-se inferir que a amostra segue uma Distribuição Normal de Probabilidade com média $\mu$ e variância $\sigma^{\mathbf{2}}$. Além disso, o histograma da amostra apresenta um sino com perfil similar ao de uma distribuição normal.

Foram calculados os seguintes estimadores dos parâmetros desta amostra:

Medidas $2 \sim \mathrm{N}\left(\mu, \sigma^{2}\right)$ 


$$
\begin{aligned}
& \overline{x_{2}}=0,7440 \\
& s_{2}^{2}=0,0016
\end{aligned}
$$

A seguir aplica-se o teste K-S para determinar se a medidas 2 segue uma distribuição normal de probabilidade com os estimadores dos parâmetros calculados aos níveis de confiança de $90 \%, 95 \%$ e $99 \%$ :

\section{- Hipótese:}

$\mathrm{H}_{\mathrm{o}}=$ As medições das medidas 2 seguem uma distribuição normal de probabilidade

$\mathrm{H}_{1}=$ As medições das medidas 2 não seguem uma distribuição normal de probabilidade

Tabela 12 - Tabela de frequência absoluta

\begin{tabular}{|c|c|c|c|c|}
\hline No & \multicolumn{2}{|c|}{ Intervalo (mOhm) } & Frequência absoluta & Frequência acumulada \\
\hline 1 & 0,6574 & 0,6755 & 19 & 19 \\
\hline 2 & 0,6755 & 0,6936 & 30 & 49 \\
\hline 3 & 0,6936 & 0,7118 & 46 & 95 \\
\hline 4 & 0,7118 & 0,7299 & 30 & 125 \\
\hline 5 & 0,7299 & 0,7480 & 47 & 172 \\
\hline 6 & 0,7480 & 0,7661 & 71 & 243 \\
\hline 7 & 0,7661 & 0,7842 & 67 & 310 \\
\hline 8 & 0,7842 & 0,8024 & 30 & 340 \\
\hline 9 & 0,8024 & 0,8205 & 12 & 352 \\
\hline 10 & 0,8205 & 0,8386 & 8 & 360 \\
\hline
\end{tabular}

A seguir os dados das medidas 2 foram padronizados em uma distribuição normal de probabilidades com $\mu=0$ e $\sigma^{2}=1$ permitindo calcular as frequências esperadas ou teóricas. Assim os valores de $\mathbf{Z} \sim \mathbf{N}(\mathbf{0 , 1})$ são obtidos pela equação (6).

Para este caso, os valores são:

$\mathrm{X}=$ valor do intervalo da Tabela 12

$$
\begin{aligned}
\mu & =0,7440 \\
\sigma & =0,0401
\end{aligned}
$$


Tabela 13 - Cálculo da frequência esperada

\begin{tabular}{|c|c|c|c|c|c|c|c|c|c|}
\hline No & \multicolumn{2}{|c|}{$\begin{array}{c}\text { Intervalo } \\
\text { (mOhm) }\end{array}$} & \multicolumn{2}{|c|}{ Intervalo Z } & \multicolumn{2}{c|}{ Área Z } & Área em Z & $\mathbf{e}_{\mathbf{i}}$ & $\mathbf{f}_{\mathbf{i}}$ \\
\hline 1 & 0,6574 & 0,6755 & $-2,1596$ & $-1,7077$ & 0,0154 & 0,0438 & 0,0284 & 10,2 & 19 \\
\hline 2 & 0,6755 & 0,6936 & $-1,7077$ & $-1,2559$ & 0,0438 & 0,1046 & 0,0607 & 21,9 & 30 \\
\hline 3 & 0,6936 & 0,7118 & $-1,2559$ & $-0,8040$ & 0,1046 & 0,2107 & 0,1061 & 38,2 & 46 \\
\hline 4 & 0,7118 & 0,7299 & $-0,8040$ & $-0,3521$ & 0,2107 & 0,3624 & 0,1517 & 54,6 & 30 \\
\hline 5 & 0,7299 & 0,7480 & $-0,3521$ & 0,0998 & 0,3624 & 0,5397 & 0,1774 & 63,8 & 47 \\
\hline 6 & 0,7480 & 0,7661 & 0,0998 & 0,5516 & 0,5397 & 0,7094 & 0,1697 & 61,1 & 71 \\
\hline 7 & 0,7661 & 0,7842 & 0,5516 & 1,0035 & 0,7094 & 0,8422 & 0,1328 & 47,8 & 67 \\
\hline 8 & 0,7842 & 0,8024 & 1,0035 & 1,4554 & 0,8422 & 0,9272 & 0,0850 & 30,6 & 30 \\
\hline 9 & 0,8024 & 0,8205 & 1,4554 & 1,9072 & 0,9272 & 0,9718 & 0,0445 & 16,0 & 12 \\
\hline 10 & 0,8205 & 0,8386 & 1,9072 & 2,3591 & 0,9718 & 0,9908 & 0,0191 & 6,9 & 8 \\
\hline
\end{tabular}

Onde,

$\mathrm{e}_{\mathrm{i}}=$ Frequência esperada $=($ Área em Z $) *($ Tamanho da amostra $=360)$

$\mathrm{f}_{\mathrm{i}}=$ Frequência absoluta da amostra

Tabela 14 - Cálculo da frequência esperada

\begin{tabular}{|c|c|c|c|c|c|c|}
\hline No & $\mathbf{e}_{\mathbf{i}}$ & $\mathbf{f}_{\mathbf{i}}$ & $\mathbf{e}_{\mathbf{a}}$ & $\mathbf{f}_{\mathbf{a}}$ & $\mathbf{d}_{\mathbf{i}}$ & $\mathbf{D}=\mathbf{d}_{\mathbf{i}} / \mathbf{n}$ \\
\hline 1 & 10,2 & 19 & 10,2 & 19 & 8,7611 & 0,024 \\
\hline 2 & 21,9 & 30 & 32,1 & 49 & 16,8947 & 0,047 \\
\hline 3 & 38,2 & 46 & 70,3 & 95 & 24,6922 & 0,069 \\
\hline 4 & 54,6 & 30 & 124,9 & 125 & 0,0899 & 0,000 \\
\hline 5 & 63,8 & 47 & 188,8 & 172 & $-16,7577$ & $-0,047$ \\
\hline 6 & 61,1 & 71 & 249,8 & 243 & $-6,8379$ & $-0,019$ \\
\hline 7 & 47,8 & 67 & 297,6 & 310 & 12,3569 & 0,034 \\
\hline 8 & 30,6 & 30 & 328,3 & 340 & 11,7471 & 0,033 \\
\hline 9 & 16,0 & 12 & 344,3 & 352 & 7,7129 & 0,021 \\
\hline 10 & 6,9 & 8 & 351,2 & 360 & 8,8421 & 0,025 \\
\hline
\end{tabular}

Onde,

$\mathrm{e}_{\mathrm{i}}=$ Frequência esperada

$\mathrm{f}_{\mathrm{i}}=$ Frequência absoluta da amostra

$\mathrm{e}_{\mathrm{a}}=$ Frequência esperada acumulada

$\mathrm{f}_{\mathrm{a}}=$ Frequência absoluta da amostra acumulada

$\mathrm{d}_{\mathrm{i}}=$ Diferença: $\left|\mathbf{f}_{\mathbf{a}}-\mathbf{e}_{\mathbf{a}}\right|$

$\mathrm{n}=$ Tamanho da amostra $=360$

$\mathrm{D}=$ Valor da estatística do teste $\mathrm{K}-\mathrm{S}$ para cada intervalo 
Na Tabela 14, pode-se observar que o valor máximo de "D" é 0,069. Então o valor da estatística $D_{\max }$ do teste K-S é:

$$
\mathrm{D}_{\max }=0,069
$$

A figura 12 apresenta as diferenças do teste K-S.

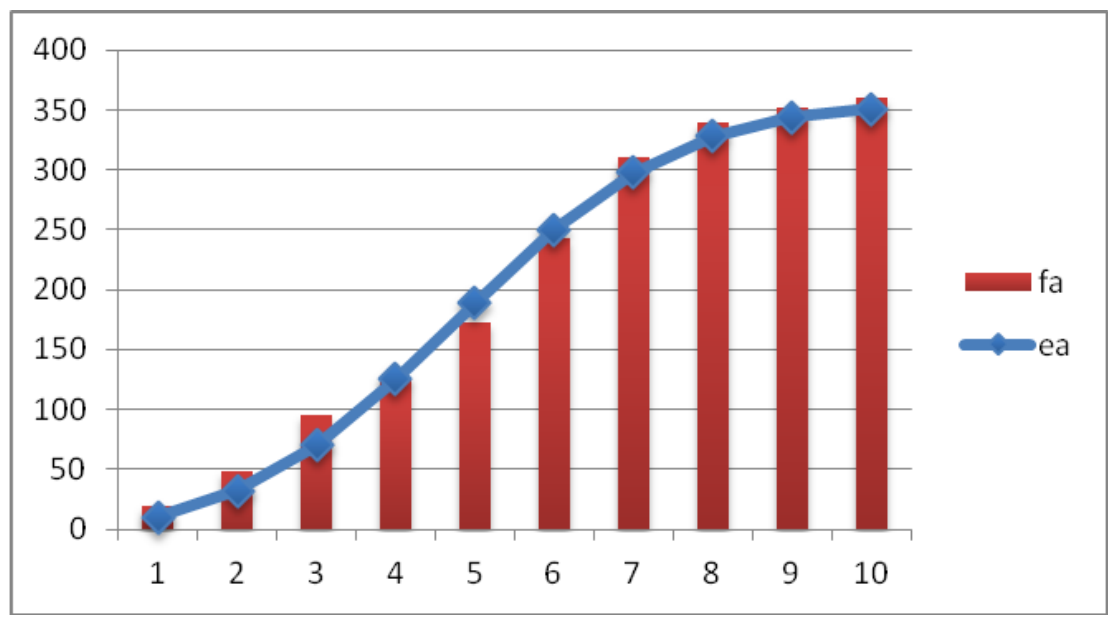

Figura 12 - Frequência absoluta da amostra acumulada vs Frequência esperada acumulada

- Regra de decisão:

$\left(\mathrm{D} / \mathrm{H}_{\mathrm{o}}\right.$ Verdadeira $) \sim$ Distribuição $\mathrm{D}_{(\alpha ; \mathrm{N})}$

$\alpha=$ Nível de significância

$\mathrm{N}=$ Número do intervalo adotado $=10$

Observação: Anexo 2: Tabela Distribuição D.

Adotando $\alpha=1 \%$

$\mathrm{D}_{\max }=0,069<\mathrm{D}_{(0,01 ; 10)}=0,514$

\section{Conclusão:}

Com um nível de confiança de $99 \%$ os dados das medidas 2 seguem uma distribuição normal com $\boldsymbol{\mu}=\mathbf{0 , 7 4 4 0}$ e $\boldsymbol{\sigma}^{2}=\mathbf{0 , 0 0 1 6}$.

Adotando $\alpha=\mathbf{5 \%}$

$\mathrm{D}_{\max }=0,069<\mathrm{D}_{(0,05 ; 10)}=0,432$ 


\section{Conclusão:}

Com um nível de confiança de $95 \%$ os dados das medidas 1 seguem uma distribuição normal com $\boldsymbol{\mu}=\mathbf{0 , 7 4 4 0}$ e $\boldsymbol{\sigma}^{2}=\mathbf{0 , 0 0 1 6}$.

$$
\begin{aligned}
& \text { Adotando } \alpha=\mathbf{1 0} \% \\
& \mathrm{D}_{\max }=0,069<\mathrm{D}_{(0,1 ; 10)}=0,388
\end{aligned}
$$

\section{Conclusão:}

Com um nível de confiança de $90 \%$ os dados das medidas 1 seguem uma distribuição normal com $\boldsymbol{\mu}=\mathbf{0 , 7 4 4 0}$ e $\boldsymbol{\sigma}^{2}=\mathbf{0 , 0 0 1 6}$.

\subsubsection{2.}

\section{Teste de significância para duas variâncias}

Para garantir a confiabilidade do resultado do teste de significância entre duas médias é necessário determinar se as variâncias das duas populações podem ser consideradas estatisticamente iguais a um nível de confiança determinado. Para o efeito da presente dissertação foram testadas as variâncias das duas populações de medições aos níveis de confiança de 90\%, 95\% e 99\%, segundo o procedimento descrito por Jairo Simon da Fonseca e Gilberto de Andrade Martins [15][18].

- Hipótese:

$$
\begin{aligned}
& \mathrm{H}_{\mathrm{o}}: \sigma_{1}^{2}=\sigma_{2}^{2} \\
& \mathrm{H}_{1}: \sigma_{1}^{2} \neq \sigma_{2}^{2}
\end{aligned}
$$

- Para $\alpha=1 \% ; \alpha=5 \% ; \alpha=10 \% ;$ A variável é $F$ com:

$$
\begin{aligned}
& \varphi_{1}=n_{1}-1=360-1=359 \\
& \varphi_{\mathbf{2}}=n_{\mathbf{2}}-1=360-1=359
\end{aligned}
$$

- Com auxilio da tabela da distribuição "F" (Anexos 3, 4 e 5), determinam-se a Região de Aceitação (RA) e a Região Critica (RC), para $\alpha=1 \% ; \alpha=5 \% ; \alpha=10 \%$. 

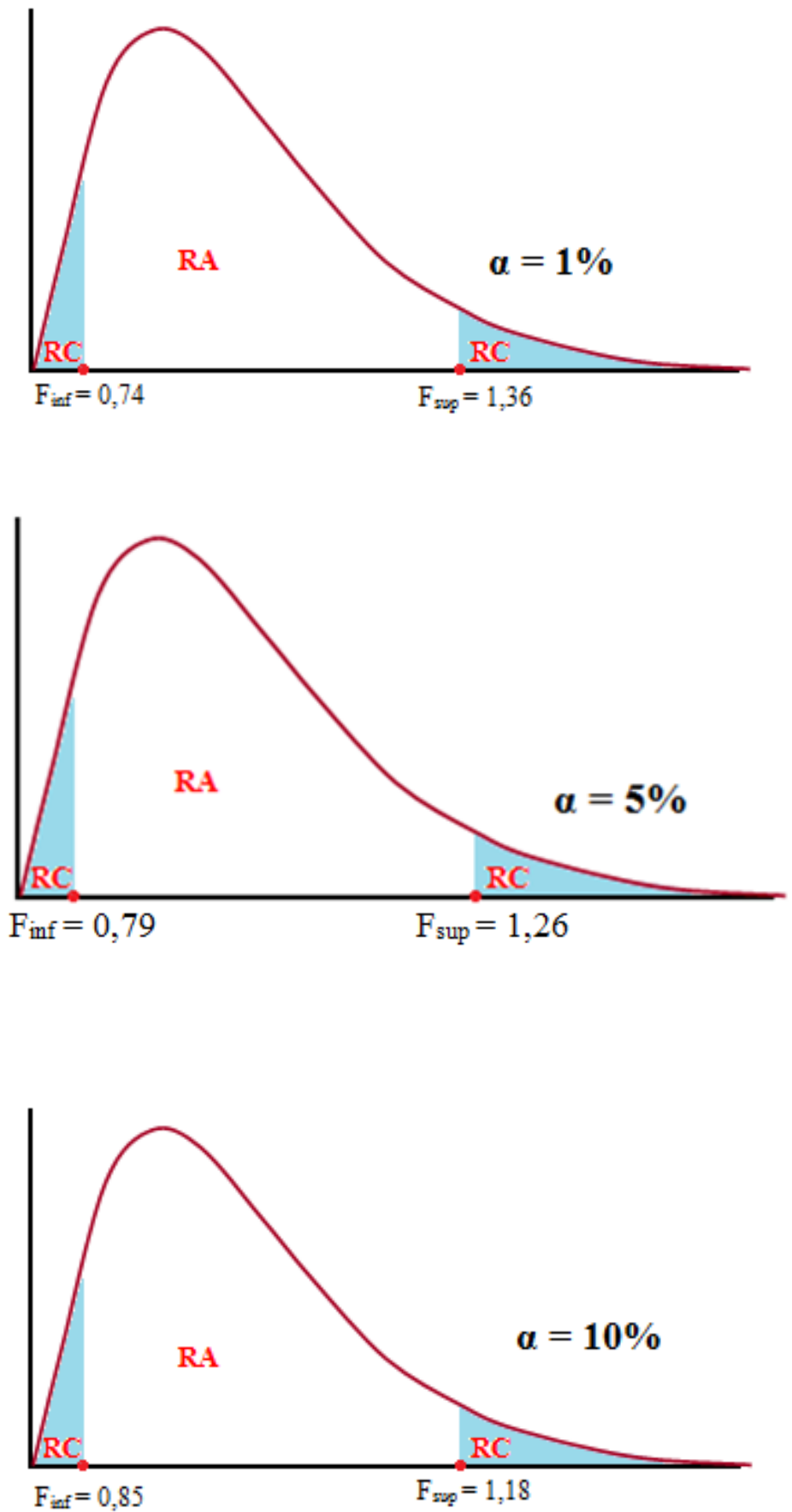

- Cálculo do valor da variável:

$$
\begin{gathered}
F_{\text {cal }}=\frac{s_{1}^{2}}{s_{2}^{2}} \quad \text { (Equação 7) } \\
F_{\text {cal }}=\frac{0,002}{0,0016} \\
F_{\text {cal }}=1,25
\end{gathered}
$$




\section{- Conclusão:}

As variâncias das duas populações podem ser consideradas estatisticamente iguais aos níveis de confiança de $95 \%$ e $99 \%$ e diferentes para um nível de confiança de $90 \%$. Assim, para efeito do cálculo da incerteza do sistema de medição, recomenda-se utilizar um nível de confiança de 95\% com um fator de abrangência $\mathrm{k}=2$.

\subsubsection{3.}

Independência nas medições das amostras

As medições feitas com o sistema remoto e as medições feitas com o equipamento portátil são consideradas independentes, pelo fato de o valor da medição com o sistema remoto não ter incidência no valor da medição com o instrumento e vice-versa. Além disso, as baterias são consideradas independentes e os valores da impedância e da tensão elétrica de um elemento não afetam o valor da mesma grandeza em outro elemento de bateria.

\subsubsection{4.}

\section{Teste de significância para a igualdade de duas médias}

Visando determinar o nível de confiança no qual podem ser consideradas estatisticamente iguais as medições da impedância feitas pelo sistema SIMBAGEBAT e aquelas realizadas pelo equipamento portátil, os dados das amostras foram submetidos ao teste paramétrico de significância para a igualdade de duas médias.

Para validar a sua aplicação faz-se necessário assegurar que os dados sejam normais, independentes, e as variâncias populacionais desconhecidas, mas consideradas iguais. Nas seções anteriores, foi demonstrado que as duas amostras cumprem com os critérios mencionados.

A seguir, foi aplicado o teste:

\section{- Hipóteses:}

$$
\begin{aligned}
& \mathrm{H}_{\mathrm{o}}: \mu_{1}=\mu_{\mathbf{2}} \\
& \mathrm{H}_{1}: \mu_{1} \neq \mu_{\mathbf{2}}
\end{aligned}
$$

- Para $\alpha=1 \% ; \alpha=5 \% ; \alpha=10 \%$; A variável "t" com: 


$$
\varphi_{1}=n_{1}+n_{2}-2=360+360-2=718
$$

- Com auxilio da tabela da distribuição normal $Z \sim N(0,1)$, (Anexo 6), determinam-se a Região de Aceitação (RA) e a Região Critica (RC), para $\alpha=1 \% ; \alpha=5 \% ; \alpha=10 \%$.
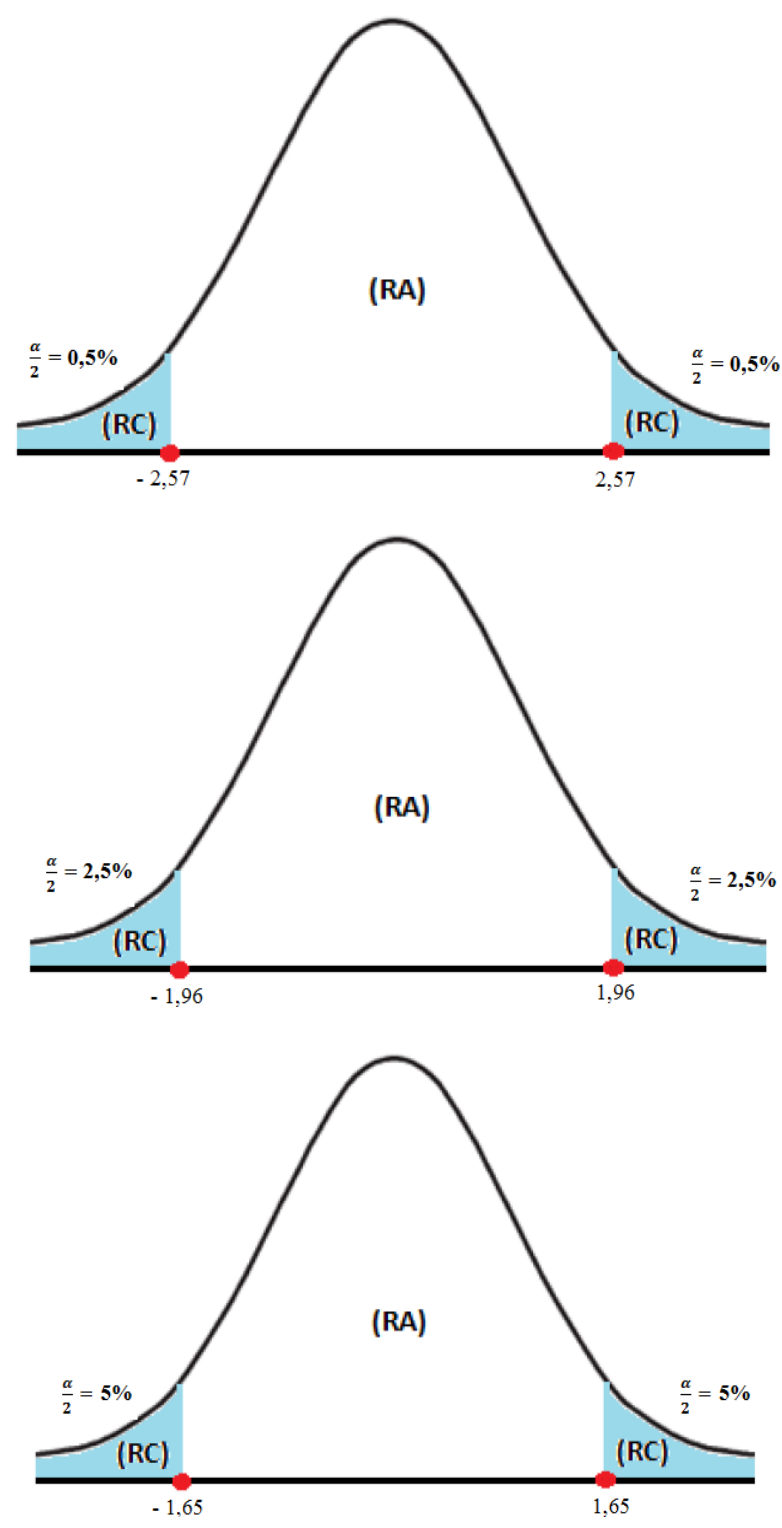

- Cálculo do valor da variável:

$$
t_{c a l}=\frac{\left(\bar{x}_{1}-\bar{x}_{2}\right)}{S_{c} \cdot \sqrt{\frac{n_{1}+n_{2}}{n_{1} \cdot n_{2}}}}
$$

Onde,

$$
S_{c}=\sqrt{\frac{\left(n_{1}-1\right) S_{1}^{2}+\left(n_{2}-1\right) S_{2}^{2}}{n_{1}+n_{2}-2}}
$$


Usando a equação (9), a seguir, foi calculado o valor $S_{c}$ :

$$
\begin{aligned}
& S_{c}=\sqrt{\frac{(359)(0,002)+(359)(0,0016)}{360+360-2}} \\
& S_{c}=0,04243
\end{aligned}
$$

Usando a equação (8), a seguir, foi calculado $t_{c a l}$.

$$
\begin{aligned}
& t_{\text {cal }}=\frac{(0,740-0,7440)}{(0,04243) \cdot \sqrt{\frac{360+360}{(360) \cdot(360)}}} \\
& \boldsymbol{t}_{\text {cal }}=-\mathbf{1 , 2 6}
\end{aligned}
$$

\section{- Conclusão:}

Como $\mathrm{t}_{\mathrm{cal}}=-1,26$, não se pode rejeitar $\mathrm{H}_{\mathrm{o}}: \mu_{\mathbf{1}}=\mu_{\mathbf{2}}$, aos níveis de significância de $1 \%, 5 \%$ e $10 \%$.

O teste de significância de igualdade entre duas médias demonstrou que as medições de impedância feitas pelo sistema SIMBA-GEBAT e pelo equipamento portátil podem ser considerados estatisticamente iguais, aos níveis de confiança de $90 \%, 95 \%$ e $99 \%$.

\subsection{2.}

\section{Análise estatística da medição da tensão elétrica}

A Tabela 15 apresenta resultados das medições da tensão elétrica de sessenta elementos de baterias do sistema SIMBA-GEBAT. A Tabela 16 apresenta os dados das Medidas 2 das medições do equipamento portátil de medição. 
Tabela 15 - Medidas da tensão elétrica SIMBA-GEBAT (Medidas 1)

\begin{tabular}{|c|c|c|c|c|c|c|c|c|c|c|c|c|c|}
\hline \multicolumn{14}{|c|}{ Mediç̃os SIMBA-GEBAT (V) } \\
\hline Elemento & $31 / 08 / 12$ & $14 / 09 / 12$ & $21 / 09 / 12$ & $22 / 09 / 12$ & $02 / 10 / 12$ & $10 / 10 / 12$ & Elemento & $31 / 08 / 12$ & $14 / 09 / 12$ & $21 / 09 / 12$ & $22 / 09 / 12$ & $02 / 10 / 12$ & $10 / 10 / 12$ \\
\hline 1 & 2,175 & 2,175 & 2,176 & 2,176 & 2,172 & 2,185 & 31 & 2,170 & 2,175 & 2,178 & 2,176 & 2,175 & 2,177 \\
\hline 2 & 2,177 & 2,176 & 2,176 & 2,177 & 2,173 & 2,177 & 32 & 2,168 & 2,174 & 2,179 & 2,176 & 2,175 & 2,175 \\
\hline 3 & 2,178 & 2,179 & 2,178 & 2,178 & 2,179 & 2,177 & 33 & 2,180 & 2,181 & 2,188 & 2,182 & 2,183 & 2,182 \\
\hline 4 & 2,178 & 2,177 & 2,178 & 2,179 & 2,175 & 2,172 & 34 & 2,188 & 2,188 & 2,187 & 2,189 & 2,190 & 2,190 \\
\hline 5 & 2,189 & 2,189 & 2,188 & 2,188 & 2,188 & 2,179 & 35 & 2,181 & 2,182 & 2,190 & 2,182 & 2,183 & 2,181 \\
\hline 6 & 2,188 & 2,189 & 2,188 & 2,188 & 2,189 & 2,180 & 36 & 2,180 & 2,180 & 2,191 & 2,189 & 2,190 & 2,192 \\
\hline 7 & 2,188 & 2,188 & 2,189 & 2,187 & 2,188 & 2,195 & 37 & 2,198 & 2,198 & 2,196 & 2,197 & 2,194 & 2,199 \\
\hline 8 & 2,189 & 2,186 & 2,188 & 2,186 & 2,187 & 2,185 & 38 & 2,209 & 2,209 & 2,206 & 2,208 & 2,205 & 2,205 \\
\hline 9 & 2,180 & 2,188 & 2,180 & 2,179 & 2,180 & 2,178 & 39 & 2,205 & 2,204 & 2,202 & 2,204 & 2,200 & 2,200 \\
\hline 10 & 2,181 & 2,179 & 2,180 & 2,179 & 2,181 & 2,178 & 40 & 2,206 & 2,207 & 2,206 & 2,207 & 2,207 & 2,206 \\
\hline 11 & 2,186 & 2,185 & 2,186 & 2,187 & 2,189 & 2,197 & 41 & 2,201 & 2,195 & 2,198 & 2,195 & 2,197 & 2,200 \\
\hline 12 & 2,190 & 2,190 & 2,183 & 2,183 & 2,182 & 2,191 & 42 & 2,199 & 2,199 & 2,196 & 2,198 & 2,195 & 2,197 \\
\hline 13 & 2,204 & 2,204 & 2,203 & 2,204 & 2,200 & 2,200 & 43 & 2,201 & 2,203 & 2,203 & 2,200 & 2,206 & 2,207 \\
\hline 14 & 2,200 & 2,199 & 2,199 & 2,200 & 2,196 & 2,196 & 44 & 2,204 & 2,204 & 2,200 & 2,203 & 2,203 & 2,204 \\
\hline 15 & 2,206 & 2,205 & 2,205 & 2,205 & 2,201 & 2,201 & 45 & 2,185 & 2,185 & 2,182 & 2,184 & 2,181 & 2,183 \\
\hline 16 & 2,203 & 2,202 & 2,202 & 2,203 & 2,199 & 2,197 & 46 & 2,185 & 2,184 & 2,185 & 2,183 & 2,181 & 2,180 \\
\hline 17 & 2,207 & 2,207 & 2,206 & 2,207 & 2,203 & 2,203 & 47 & 2,184 & 2,184 & 2,182 & 2,183 & 2,181 & 2,181 \\
\hline 18 & 2,202 & 2,202 & 2,201 & 2,202 & 2,197 & 2,197 & 48 & 2,184 & 2,180 & 2,183 & 2,183 & 2,182 & 2,180 \\
\hline 19 & 2,200 & 2,199 & 2,199 & 2,199 & 2,195 & 2,193 & 49 & 2,210 & 2,222 & 2,195 & 2,200 & 2,199 & 2,200 \\
\hline 20 & 2,197 & 2,196 & 2,195 & 2,197 & 2,192 & 2,189 & 50 & 2,195 & 2,220 & 2,198 & 2,196 & 2,199 & 2,200 \\
\hline 21 & 2,198 & 2,196 & 2,195 & 2,196 & 2,192 & 2,190 & 51 & 2,205 & 2,220 & 2,210 & 2,195 & 2,212 & 2,205 \\
\hline 22 & 2,200 & 2,200 & 2,205 & 2,207 & 2,202 & 2,201 & 52 & 2,203 & 2,219 & 2,210 & 2,203 & 2,199 & 2,199 \\
\hline 23 & 2,201 & 2,200 & 2,199 & 2,200 & 2,196 & 2,194 & 53 & 2,185 & 2,168 & 2,183 & 2,181 & 2,186 & 2,181 \\
\hline 24 & 2,205 & 2,205 & 2,204 & 2,204 & 2,200 & 2,200 & 54 & 2,183 & 2,169 & 2,185 & 2,182 & 2,187 & 2,180 \\
\hline 25 & 2,196 & 2,197 & 2,197 & 2,199 & 2,199 & 2,195 & 55 & 2,184 & 2,170 & 2,184 & 2,182 & 2,186 & 2,181 \\
\hline 26 & 2,198 & 2,197 & 2,198 & 2,199 & 2,198 & 2,198 & 56 & 2,183 & 2,168 & 2,184 & 2,181 & 2,186 & 2,180 \\
\hline 27 & 2,196 & 2,198 & 2,196 & 2,199 & 2,197 & 2,196 & 57 & 2,185 & 2,167 & 2,181 & 2,182 & 2,185 & 2,180 \\
\hline 28 & 2,198 & 2,197 & 2,198 & 2,199 & 2,199 & 2,200 & 58 & 2,183 & 2,175 & 2,183 & 2,182 & 2,187 & 2,182 \\
\hline 29 & 2,172 & 2,180 & 2,185 & 2,180 & 2,178 & 2,175 & 59 & 2,186 & 2,177 & 2,186 & 2,183 & 2,185 & 2,180 \\
\hline 30 & 2,169 & 2,174 & 2,178 & 2,175 & 2,174 & 2,173 & 60 & 2,181 & 2,175 & 2,183 & 2,182 & 2,185 & 2,180 \\
\hline
\end{tabular}

Tabela 16 - Medida da tensão elétrica do Equipamento Portátil (Medidas 2)

\begin{tabular}{|c|c|c|c|c|c|c|c|c|c|c|c|c|c|}
\hline \multicolumn{14}{|c|}{ Medições Equipamento Portátil (V) } \\
\hline Elemento & $31 / 08 / 12$ & $14 / 09 / 12$ & $21 / 09 / 12$ & $22 / 09 / 12$ & $02 / 10 / 12$ & $10 / 10 / 12$ & Elemento & $31 / 08 / 12$ & $14 / 09 / 12$ & $21 / 09 / 12$ & $22 / 09 / 12$ & $02 / 10 / 12$ & $10 / 10 / 12$ \\
\hline 1 & 2,19 & 2,19 & 2,19 & 2,19 & 2,19 & 2,20 & 31 & 2,16 & 2,17 & 2,16 & 2,17 & 2,17 & 2,16 \\
\hline 2 & 2,19 & 2,19 & 2,19 & 2,19 & 2,19 & 2,19 & 32 & 2,16 & 2,17 & 2,16 & 2,17 & 2,17 & 2,16 \\
\hline 3 & 2,19 & 2,19 & 2,19 & 2,19 & 2,19 & 2,19 & 33 & 2,18 & 2,18 & 2,19 & 2,18 & 2,18 & 2,18 \\
\hline 4 & 2,19 & 2,19 & 2,19 & 2,19 & 2,19 & 2,18 & 34 & 2,19 & 2,19 & 2,19 & 2,19 & 2,19 & 2,19 \\
\hline 5 & 2,19 & 2,19 & 2,19 & 2,19 & 2,19 & 2,18 & 35 & 2,18 & 2,18 & 2,19 & 2,18 & 2,18 & 2,18 \\
\hline 6 & 2,19 & 2,19 & 2,19 & 2,19 & 2,19 & 2,18 & 36 & 2,18 & 2,18 & 2,19 & 2,19 & 2,19 & 2,19 \\
\hline 7 & 2,19 & 2,19 & 2,19 & 2,19 & 2,19 & 2,20 & 37 & 2,18 & 2,18 & 2,18 & 2,18 & 2,18 & 2,18 \\
\hline 8 & 2,19 & 2,19 & 2,19 & 2,19 & 2,19 & 2,19 & 38 & 2,19 & 2,19 & 2,19 & 2,19 & 2,19 & 2,19 \\
\hline 9 & 2,18 & 2,18 & 2,18 & 2,18 & 2,18 & 2,19 & 39 & 2,19 & 2,19 & 2,19 & 2,19 & 2,19 & 2,19 \\
\hline 10 & 2,18 & 2,18 & 2,18 & 2,18 & 2,18 & 2,19 & 40 & 2,19 & 2,19 & 2,19 & 2,19 & 2,19 & 2,19 \\
\hline 11 & 2,19 & 2,19 & 2,19 & 2,19 & 2,19 & 2,20 & 41 & 2,19 & 2,18 & 2,19 & 2,18 & 2,18 & 2,19 \\
\hline 12 & 2,19 & 2,19 & 2,18 & 2,18 & 2,18 & 2,19 & 42 & 2,18 & 2,18 & 2,18 & 2,18 & 2,18 & 2,18 \\
\hline 13 & 2,19 & 2,19 & 2,19 & 2,19 & 2,19 & 2,19 & 43 & 2,19 & 2,19 & 2,19 & 2,19 & 2,19 & 2,19 \\
\hline 14 & 2,19 & 2,19 & 2,19 & 2,19 & 2,19 & 2,19 & 44 & 2,19 & 2,19 & 2,19 & 2,19 & 2,19 & 2,19 \\
\hline 15 & 2,19 & 2,19 & 2,19 & 2,19 & 2,19 & 2,19 & 45 & 2,19 & 2,19 & 2,19 & 2,19 & 2,19 & 2,19 \\
\hline 16 & 2,19 & 2,19 & 2,19 & 2,19 & 2,19 & 2,19 & 46 & 2,19 & 2,19 & 2,19 & 2,19 & 2,19 & 2,19 \\
\hline 17 & 2,19 & 2,19 & 2,19 & 2,19 & 2,19 & 2,19 & 47 & 2,19 & 2,19 & 2,19 & 2,19 & 2,19 & 2,19 \\
\hline 18 & 2,19 & 2,19 & 2,19 & 2,19 & 2,19 & 2,19 & 48 & 2,19 & 2,18 & 2,19 & 2,19 & 2,19 & 2,19 \\
\hline 19 & 2,19 & 2,19 & 2,19 & 2,19 & 2,19 & 2,19 & 49 & 2,20 & 2,22 & 2,20 & 2,19 & 2,19 & 2,20 \\
\hline 20 & 2,18 & 2,18 & 2,19 & 2,19 & 2,19 & 2,19 & 50 & 2,19 & 2,22 & 2,19 & 2,19 & 2,19 & 2,20 \\
\hline 21 & 2,18 & 2,18 & 2,19 & 2,18 & 2,18 & 2,19 & 51 & 2,20 & 2,22 & 2,20 & 2,20 & 2,20 & 2,20 \\
\hline 22 & 2,19 & 2,19 & 2,20 & 2,19 & 2,19 & 2,20 & 52 & 2,20 & 2,21 & 2,20 & 2,19 & 2,19 & 2,20 \\
\hline 23 & 2,19 & 2,19 & 2,19 & 2,19 & 2,19 & 2,19 & 53 & 2,19 & 2,17 & 2,19 & 2,19 & 2,19 & 2,19 \\
\hline 24 & 2,19 & 2,19 & 2,19 & 2,19 & 2,19 & 2,19 & 54 & 2,19 & 2,18 & 2,19 & 2,19 & 2,19 & 2,19 \\
\hline 25 & 2,18 & 2,18 & 2,18 & 2,19 & 2,19 & 2,18 & 55 & 2,19 & 2,18 & 2,19 & 2,19 & 2,19 & 2,19 \\
\hline 26 & 2,19 & 2,19 & 2,19 & 2,19 & 2,19 & 2,19 & 56 & 2,19 & 2,18 & 2,19 & 2,19 & 2,19 & 2,19 \\
\hline 27 & 2,18 & 2,19 & 2,18 & 2,19 & 2,19 & 2,18 & 57 & 2,19 & 2,18 & 2,19 & 2,19 & 2,19 & 2,19 \\
\hline 28 & 2,19 & 2,19 & 2,19 & 2,19 & 2,19 & 2,19 & 58 & 2,19 & 2,19 & 2,19 & 2,19 & 2,19 & 2,19 \\
\hline 29 & 2,16 & 2,17 & 2,17 & 2,17 & 2,17 & 2,16 & 59 & 2,19 & 2,18 & 2,19 & 2,19 & 2,19 & 2,19 \\
\hline 30 & 2,16 & 2,16 & 2,16 & 2,17 & 2,17 & 2,16 & 60 & 2,19 & 2,19 & 2,19 & 2,19 & 2,19 & 2,19 \\
\hline
\end{tabular}




\subsubsection{1.}

\section{Teste Kolmogorov-Smirnov (K-S)}

O teste K-S foi utilizado para testar se os dados apresentados nas Tabelas 15 e 16 seguem distribuição normal de probabilidade. Inicialmente foram feitas inferências estatísticas que forneceram uma idéia preliminar acerca da distribuição de probabilidades que segue as amostras estudadas.

Primeiramente, foram tratados os dados das medidas 1 - Medições de tensão elétrica da SIMBA-GEBAT.

A Tabela 17 apresenta a estatística descritiva, a qual forneceu valores próximos da média, mediana e moda, portanto pode-se inferir que a amostra segue uma distribuição normal de probabilidade com média $\mu$ e variância $\sigma^{\mathbf{2}}$. A Tabela 18 apresenta a frequência absoluta em cada intervalo. Além disso, o histograma da figura 13, embora apresente uma frequência atípica na faixa de 2,195 V, oferece um perfil similar ao de uma distribuição normal.

Tabela 17 - Estatística descritiva

\begin{tabular}{|c|c|}
\hline Estatística Descritiva & Valor \\
\hline Média & $2,191 \mathrm{~V}$ \\
\hline Erro padrão & $0,001 \mathrm{~V}$ \\
\hline Mediana & $2,189 \mathrm{~V}$ \\
\hline Moda & $2,200 \mathrm{~V}$ \\
\hline Desvio padrão & $0,011 \mathrm{~V}$ \\
\hline Variância da amostra & $0,00012 v^{2}$ \\
\hline Curtose & $-0,806$ \\
\hline Assimetria & 0,093 \\
\hline Intervalo & $0,055 \mathrm{~V}$ \\
\hline Valor mínimo & $2,167 \mathrm{~V}$ \\
\hline Valor máximo & $2,222 \mathrm{~V}$ \\
\hline Soma & $788,646 \mathrm{~V}$ \\
\hline Contagem & 360 \\
\hline
\end{tabular}


Tabela 18 - Intervalo do histograma

\begin{tabular}{cc}
\hline Bloco $(\mathrm{V})$ & Frequência \\
\hline 2,167 & 1 \\
2,173 & 10 \\
2,178 & 39 \\
2,184 & 71 \\
2,189 & 61 \\
2,195 & 15 \\
2,200 & 91 \\
2,206 & 46 \\
2,211 & 21 \\
2,217 & 1 \\
2,222 & 4 \\
\hline
\end{tabular}

\section{Histograma}

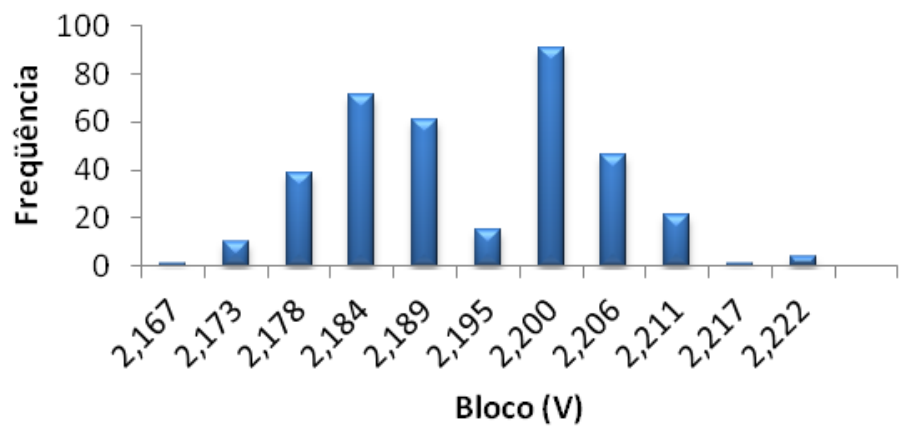

๑reqüência

Figura 13 - Histograma de frequência: Medições da tensão elétrica do SIMBAT-GEBAT

Foram calculados os seguintes estimadores dos parâmetros desta amostra:

\footnotetext{
Medidas $1 \sim \mathrm{N}\left(\mu, \sigma^{2}\right)$

$\overline{x_{1}}=2,191$

$s_{1}^{2}=0,00012$
}

A seguir foi aplicado o teste K-S para determinar se a medidas 1 segue uma distribuição normal de probabilidade com os estimadores dos parâmetros calculados aos níveis de confiança de $90 \%, 95 \%$ e $99 \%$ : 


\section{- Hipótese:}

$\mathrm{H}_{\mathrm{o}}=$ As medições das medidas 1 seguem uma distribuição normal de probabilidade.

$\mathrm{H}_{1}=$ As medições das medidas 1 não seguem uma distribuição normal de probabilidade.

Tabela 19 - Tabela de frequência absoluta

\begin{tabular}{|c|c|c|c|c|}
\hline No & \multicolumn{2}{|c|}{ Intervalo (V) } & Frequência absoluta & Frequência acumulada \\
\hline 1 & 2,167 & 2,173 & 11 & 11 \\
\hline 2 & 2,173 & 2,178 & 39 & 50 \\
\hline 3 & 2,178 & 2,184 & 71 & 121 \\
\hline 4 & 2,184 & 2,189 & 61 & 182 \\
\hline 5 & 2,189 & 2,195 & 15 & 197 \\
\hline 6 & 2,195 & 2,200 & 91 & 288 \\
\hline 7 & 2,200 & 2,206 & 46 & 334 \\
\hline 8 & 2,206 & 2,211 & 21 & 355 \\
\hline 9 & 2,211 & 2,217 & 1 & 356 \\
\hline 10 & 2,217 & 2,222 & 4 & 360 \\
\hline
\end{tabular}

A seguir, os dados das medidas 1 foram padronizados em uma distribuição normal de probabilidades com $\mu=0$ e $\sigma^{2}=\mathbf{1}$, para calcular as frequências esperadas ou teóricas. Assim os valores de $\mathbf{Z} \sim \mathbf{N}(\mathbf{0 , 1})$ são obtidos pela equação 6 (Pagina 45):

Onde,

$\mathrm{X}=$ valor do intervalo da Tabela 19

$$
\begin{aligned}
\mu & =2,191 \\
\sigma & =0,011
\end{aligned}
$$

Tabela 20 - Cálculo da frequência esperada

\begin{tabular}{|c|c|c|c|c|c|c|c|c|c|}
\hline No & \multicolumn{2}{|c|}{ Intervalo (V) } & \multicolumn{2}{|c|}{ Intervalo Z } & \multicolumn{2}{c|}{ Área do Intervalo Z } & Área em Z & $\mathbf{e}_{\mathbf{i}}$ & $\mathbf{f}_{\mathbf{i}}$ \\
\hline 1 & 2,167 & 2,173 & $-2,1581$ & $-1,6569$ & 0,0155 & 0,0488 & 0,0333 & 12,0 & 11 \\
\hline 2 & 2,173 & 2,178 & $-1,6569$ & $-1,1557$ & 0,0488 & 0,1239 & 0,0751 & 27,0 & 39 \\
\hline 3 & 2,178 & 2,184 & $-1,1557$ & $-0,6546$ & 0,1239 & 0,2564 & 0,1325 & 47,7 & 71 \\
\hline 4 & 2,184 & 2,189 & $-0,6546$ & $-0,1534$ & 0,2564 & 0,4390 & 0,1827 & 65,8 & 61 \\
\hline 5 & 2,189 & 2,195 & $-0,1534$ & 0,3478 & 0,4390 & 0,6360 & 0,1970 & 70,9 & 15 \\
\hline 6 & 2,195 & 2,200 & 0,3478 & 0,8490 & 0,6360 & 0,8020 & 0,1660 & 59,8 & 91 \\
\hline 7 & 2,200 & 2,206 & 0,8490 & 1,3501 & 0,8020 & 0,9115 & 0,1095 & 39,4 & 46 \\
\hline 8 & 2,206 & 2,211 & 1,3501 & 1,8513 & 0,9115 & 0,9679 & 0,0564 & 20,3 & 21 \\
\hline 9 & 2,211 & 2,217 & 1,8513 & 2,3525 & 0,9679 & 0,9907 & 0,0227 & 8,2 & 1 \\
\hline 10 & 2,217 & 2,222 & 2,3525 & 2,8536 & 0,9907 & 0,9978 & 0,0072 & 2,6 & 4 \\
\hline
\end{tabular}


Onde,

$\mathrm{e}_{\mathrm{i}}=$ Frequência esperada $=($ Área em Z $) *($ Tamanho da amostra $=360)$

$\mathrm{f}_{\mathrm{i}}=$ Frequência absoluta da amostra

Tabela 21 - Cálculo da estatística D

\begin{tabular}{|c|c|c|c|c|c|c|}
\hline No & $\mathbf{e}_{\mathbf{i}}$ & $\mathbf{f}_{\mathbf{i}}$ & $\mathbf{e}_{\mathbf{a}}$ & $\mathbf{f}_{\mathbf{a}}$ & $\mathbf{d}_{\mathbf{i}}$ & $\mathbf{D}=\mathbf{d}_{\mathbf{i}} / \mathbf{n}$ \\
\hline 1 & 12,0 & 11 & 12,0 & 11 & 0,9910 & 0,003 \\
\hline 2 & 27,0 & 39 & 39,0 & 50 & 10,9638 & 0,030 \\
\hline 3 & 47,7 & 71 & 86,7 & 121 & 34,2709 & 0,095 \\
\hline 4 & 65,8 & 61 & 152,5 & 182 & 29,5094 & 0,082 \\
\hline 5 & 70,9 & 15 & 223,4 & 197 & 26,3937 & 0,073 \\
\hline 6 & 59,8 & 91 & 283,2 & 288 & 4,8288 & 0,013 \\
\hline 7 & 39,4 & 46 & 322,6 & 334 & 11,4213 & 0,032 \\
\hline 8 & 20,3 & 21 & 342,9 & 355 & 12,1086 & 0,034 \\
\hline 9 & 8,2 & 1 & 351,1 & 356 & 4,9227 & 0,014 \\
\hline 10 & 2,6 & 4 & 353,7 & 360 & 6,3438 & 0,018 \\
\hline
\end{tabular}

Nesta tabela,

$\mathrm{e}_{\mathrm{i}}=$ Frequência esperada

$\mathrm{f}_{\mathrm{i}}=$ Frequência absoluta da amostra

$\mathrm{e}_{\mathrm{a}}=$ Frequência esperada acumulada

$\mathrm{f}_{\mathrm{a}}=$ Frequência absoluta da amostra acumulada

$\mathrm{d}_{\mathrm{i}}=$ Diferença: $\left|\mathbf{f}_{\mathbf{a}}-\mathbf{e}_{\mathbf{a}}\right|$

$\mathrm{n}=$ Tamanho da amostra $=360$

$\mathrm{D}=$ Valor da estatística do teste K-S para cada intervalo

$\mathrm{Na}$ Tabela 21, pode-se observar que o valor máximo de " $\mathrm{D}$ ” é 0,095. Então o valor da estatística $D_{\max }$ do teste K-S é:

$$
\mathrm{D}_{\max }=0,095
$$

A figura 14 apresenta as diferenças do teste K-S. 


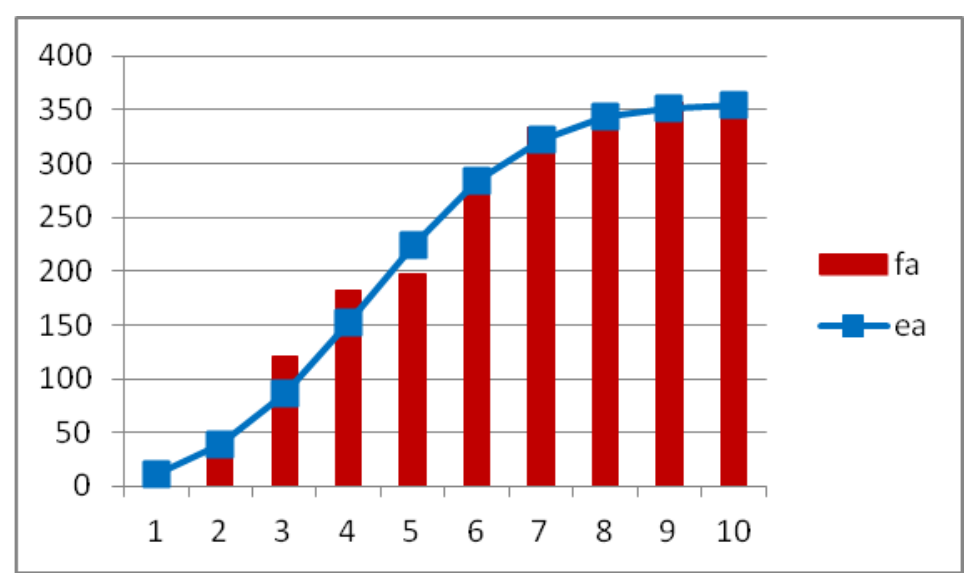

Figura 14 - Frequência absoluta da amostra acumulada vs Frequência esperada acumulada

- Regra de decisão:

$\left(\mathrm{D} / \mathrm{H}_{\mathrm{o}}\right.$ Verdadeira $) \sim$ Distribuição $\mathrm{D}_{(\alpha ; \mathrm{N})}$

$\alpha=$ Nível de significância

$\mathrm{N}=$ Número do intervalos adotado $=10$

Observação: Anexo 2: Tabela Distribuição D.

$$
\begin{aligned}
& \text { Adotando } \alpha=\mathbf{1 \%} \\
& \mathrm{D}_{\max }=0,095<\mathrm{D}_{(0,01 ; 10)}=0,490
\end{aligned}
$$

\section{Conclusão:}

Com um nível de confiança de $99 \%$, os dados das medidas 1 seguem uma distribuição normal com $\boldsymbol{\mu}=\mathbf{2 , 1 9 1}$ e $\boldsymbol{\sigma}^{2}=\mathbf{0 , 0 0 0 1 2}$.

$$
\begin{aligned}
& \text { Adotando } \alpha=\mathbf{5 \%} \\
& \mathrm{D}_{\max }=0,0095<\mathrm{D}_{(0,05 ; 10)}=0,410
\end{aligned}
$$

\section{Conclusão:}

Com um nível de confiança de 95\%, os dados das medidas 1 seguem uma distribuição normal com $\boldsymbol{\mu}=\mathbf{2 , 1 9 1}$ e $\boldsymbol{\sigma}^{2}=\mathbf{0 , 0 0 0 1 2}$.

$$
\begin{aligned}
& \text { Adotando } \alpha=\mathbf{1 0 \%} \\
& \mathrm{D}_{\max }=0,095<\mathrm{D}_{(0,1 ; 10)}=0,368
\end{aligned}
$$




\section{Conclusão:}

Com um nível de confiança de $90 \%$, os dados das medidas 1 seguem uma distribuição normal com $\boldsymbol{\mu}=\mathbf{2 , 1 9 1}$ e $\boldsymbol{\sigma}^{2}=\mathbf{0 , 0 0 0 1 2}$.

Em seguida trataram-se os dados das Medidas 2 - Medições da tensão elétrica do equipamento portátil (Medidas 2)

Tabela 22 - Estatística descritiva

\begin{tabular}{lr}
\hline Estatística Descritiva & \multicolumn{1}{c}{ Valor } \\
\hline Média & $\mathbf{2 , 1 9} \mathbf{V}$ \\
Erro padrão & $0,00043 \mathbf{V}$ \\
Mediana & $\mathbf{2 , 1 9 V}$ \\
Moda & $\mathbf{2 , 1 9 V}$ \\
Desvio padrão & $0,0083 \mathbf{V}$ \\
Variância da amostra & $0,0001 \mathbf{V}^{2}$ \\
Curtose & 4,42 \\
Assimetria & $-0,91$ \\
Intervalo & $0,06 \mathbf{V}$ \\
Mínimo & $2,16 \mathrm{~V}$ \\
Máximo & $2,22 \mathbf{V}$ \\
Soma & $787,44 \mathbf{V}$ \\
Contagem & 360,00 \\
\hline
\end{tabular}

Tabela 23 - Intervalo do histograma

\begin{tabular}{cc}
\hline Bloco $(\mathrm{V})$ & Frequência \\
\hline 2,16 & 12 \\
2,17 & 13 \\
2,18 & 62 \\
2,20 & 252 \\
2,21 & 17 \\
2,22 & 4 \\
\hline
\end{tabular}

\section{Histograma}

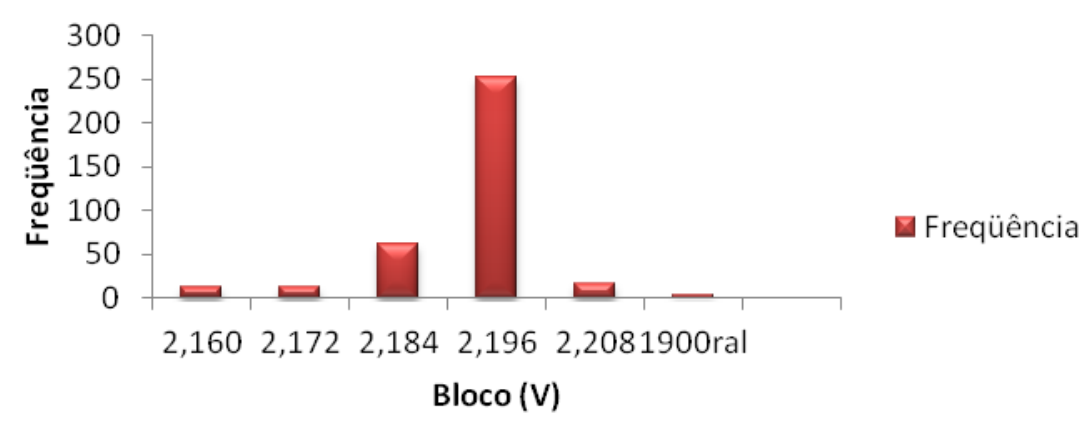


Figura 15 - Histograma de frequência: Medidas da tensão Elétrica do Equipamento Portátil

A estatística descritiva forneceu valores iguais em quanto à média, mediana $\mathrm{e}$ moda, portanto pode-se inferir que a amostra segue uma Distribuição Normal de Probabilidade com média $\mu$ e variância $\sigma^{\mathbf{2}}$. Além disso, o histograma da amostra apresenta um sino com perfil similar ao de uma distribuição normal.

$70 \%$ das medições feitas concentram-se na faixa de 2,20V. Por isso, para evitar ter intervalos com frequências nulas, foi assumido um número de intervalo $n=5$.

Foram calculados os seguintes estimadores dos parâmetros desta amostra:

\section{Medidas $2 \sim \mathrm{N}\left(\mu, \sigma^{2}\right)$}

$\overline{x_{2}}=2,19$

$s_{2}^{2}=0,0001$

A seguir foi aplicado o teste K-S para determinar se a medidas 2 segue uma distribuição normal de probabilidade com os estimadores dos parâmetros calculados aos níveis de confiança de $90 \%, 95 \%$ e $99 \%$ :

- Hipótese:

$\mathrm{H}_{\mathrm{o}}=$ As medições das medidas 2 seguem uma distribuição normal de probabilidade.

$\mathrm{H}_{1}=$ As medições das medidas 2 não seguem uma distribuição normal de probabilidade.

Tabela 24 - Tabela de frequência absoluta

\begin{tabular}{|c|c|c|c|c|}
\hline No & \multicolumn{2}{|c|}{ Intervalo (V) } & Frequência absoluta & Frequência acumulada \\
\hline 1 & 2,16 & 2,17 & 25 & 25 \\
\hline 2 & 2,17 & 2,18 & 62 & 87 \\
\hline 3 & 2,18 & 2,20 & 252 & 339 \\
\hline 4 & 2,20 & 2,21 & 17 & 356 \\
\hline 5 & 2,21 & 2,22 & 4 & 360 \\
\hline
\end{tabular}


A seguir os dados das medidas 2 serão padronizados em uma distribuição normal de probabilidades com $\mu=0$ e $\sigma^{2}=\mathbf{1}$ para calcular as frequências esperadas ou teóricas. Assim os valores de $\mathbf{Z} \sim \mathbf{N}(\mathbf{0 , 1})$ são obtidos pela equação 6 (Pagina 45).

Para este caso, os valores são:

$\mathrm{X}=$ valor do intervalo da tabela de frequência absoluta

$\mu=2,19$

$\sigma=0,0083$

Tabela 25 - Cálculo da frequência esperada

\begin{tabular}{|c|c|c|c|c|c|c|c|c|}
\hline No & \multicolumn{2}{|c|}{ Intervalo (V) } & \multicolumn{2}{c|}{ Intervalo Z } & \multicolumn{2}{c|}{$\begin{array}{c}\text { Área do } \\
\text { Intervalo Z }\end{array}$} & $\begin{array}{c}\text { Área em } \\
\mathbf{Z}\end{array}$ & $\mathbf{e}_{\mathbf{i}}$ \\
\hline 1 & 2,16 & 2,17 & $-3,3128$ & $-1,8584$ & 0,0005 & 0,0316 & 0,0311 & 11,2 \\
\hline 2 & 2,17 & 2,18 & $-1,8584$ & $-0,4040$ & 0,0316 & 0,3431 & 0,3116 & 112,2 \\
\hline 3 & 2,18 & 2,20 & $-0,4040$ & 1,0504 & 0,3431 & 0,8532 & 0,5101 & 183,6 \\
\hline 4 & 2,20 & 2,21 & 1,0504 & 2,5048 & 0,8532 & 0,9939 & 0,1406 & 50,6 \\
\hline 5 & 2,21 & 2,22 & 2,5048 & 3,9591 & 0,9939 & 1,0000 & 0,0061 & 2,2 \\
\hline
\end{tabular}

Nesta tabela,

$\mathrm{e}_{\mathrm{i}}=$ Frequência esperada $=($ Área em Z $) *($ Tamanho da amostra $=360)$

$\mathrm{f}_{\mathrm{i}}=$ Frequência absoluta da amostra

Tabela 26 - Cálculo da estatística D

\begin{tabular}{|c|c|c|c|c|c|c|}
\hline No & $\mathbf{e}_{\mathbf{i}}$ & $\mathbf{f}_{\mathbf{i}}$ & $\mathbf{e}_{\mathbf{a}}$ & $\mathbf{f}_{\mathbf{a}}$ & $\mathbf{d}_{\mathbf{i}}$ & $\mathbf{D}=\mathbf{d}_{\mathbf{i}} / \mathbf{n}$ \\
\hline 1 & 11,2 & 25 & 11,2 & 25 & 13,8054 & 0,038 \\
\hline 2 & 112,2 & 62 & 123,4 & 87 & 36,3527 & 0,101 \\
\hline 3 & 183,6 & 252 & 307,0 & 339 & 32,0037 & 0,089 \\
\hline 4 & 50,6 & 17 & 357,6 & 356 & 1,6281 & 0,005 \\
\hline 5 & 2,2 & 4 & 359,8 & 360 & 0,1798 & 0,001 \\
\hline
\end{tabular}

Nesta tabela,

$\mathrm{e}_{\mathrm{i}}=$ Frequência esperada

$\mathrm{f}_{\mathrm{i}}=$ Frequência absoluta da amostra

$\mathrm{e}_{\mathrm{a}}=$ Frequência esperada acumulada

$\mathrm{f}_{\mathrm{a}}=$ Frequência absoluta da amostra acumulada

$\mathrm{d}_{\mathrm{i}}=$ Diferença: $\left|\mathbf{f}_{\mathbf{a}}-\mathbf{e}_{\mathbf{a}}\right|$

$\mathrm{n}=$ Tamanho da amostra $=360$

$\mathrm{D}=$ Valor da estatística do teste K-S para cada intervalo 
Na Tabela 26, pode-se observar que o valor máximo de "D" é 0,101. Então o valor da estatística $D_{\max }$ do teste K-S é:

$$
\mathrm{D}_{\max }=0,101
$$

A figura 16 apresenta as diferenças do teste K-S.

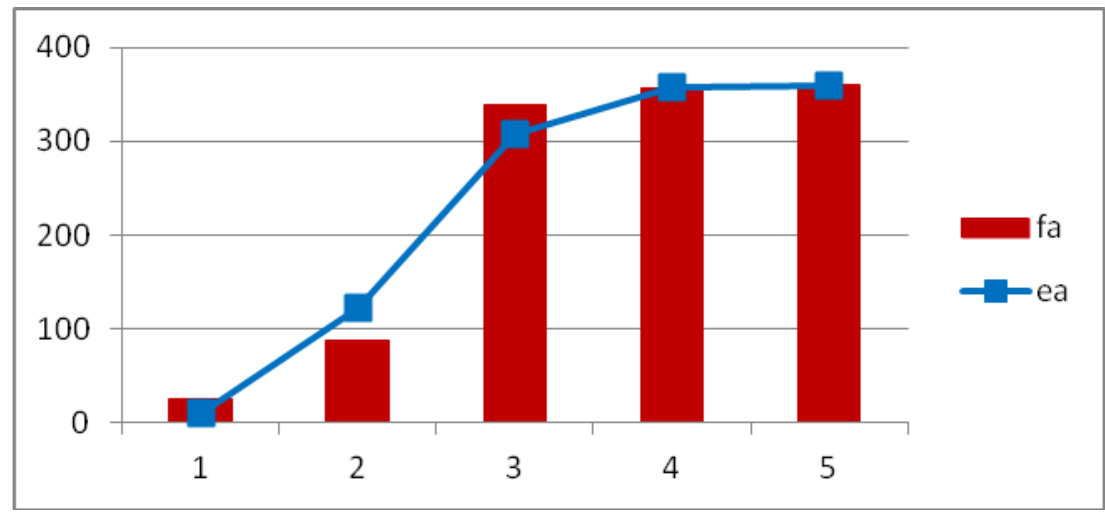

Figura 16 - Frequência absoluta da amostra acumulada vs Frequência esperada acumulada

- Regra de decisão:

$\left(\mathrm{D} / \mathrm{H}_{\mathrm{o}}\right.$ Verdadeira $) \sim$ Distribuição $\mathrm{D}_{(\alpha ; \mathrm{N})}$

$\alpha=$ Nível de significância

$\mathrm{N}=$ Número do intervalo adotado $=5$

Observação: Anexo 2: Tabela Distribuição D.

Adotando $\alpha=1 \%$

$\mathrm{D}_{\max }=0,101<\mathrm{D}_{(0,01 ; 5)}=0,669$

\section{Conclusão:}

Com um nível de confiança de $99 \%$ os dados das medidas 2 seguem uma distribuição normal $\operatorname{com} \boldsymbol{\mu}=\mathbf{2 , 1 9}$ e $\boldsymbol{\sigma}^{2}=\mathbf{0 , 0 0 0 1}$.

Adotando $\alpha=5 \%$

$\mathrm{D}_{\max }=0,101<\mathrm{D}_{(0,05 ; 5)}=0,565$

\section{Conclusão:}

Com um nível de confiança de $95 \%$ os dados das medidas 1 seguem uma distribuição normal com $\boldsymbol{\mu}=\mathbf{2 , 1 9}$ e $\boldsymbol{\sigma}^{2}=\mathbf{0 , 0 0 0 1}$. 
$\mathrm{D}_{\max }=0,101<\mathrm{D}_{(0,1 ; 5)}=0,510$

\section{Conclusão:}

Com um nível de confiança de $90 \%$ os dados das medidas 1 seguem uma distribuição normal com $\boldsymbol{\mu}=\mathbf{2 , 1 9}$ e $\boldsymbol{\sigma}^{2}=\mathbf{0 , 0 0 0 1}$.

\subsubsection{2.}

\section{Teste de significância para duas variâncias}

A seguir, foi aplicado o teste de significância para duas variâncias, segundo o procedimento descrito por Jairo Simon da Fonseca e Gilberto de Andrade Martins [15][18].

- Hipótese:

$\mathrm{H}_{\mathrm{o}}: \sigma_{1}^{2}=\sigma_{2}^{2}$
$\mathrm{H}_{1}: \sigma_{1}^{2} \neq \sigma_{2}^{2}$

- Para $\alpha=1 \% ; \alpha=5 \% ; \alpha=10 \% ;$ A variável é $F$ com:

$$
\begin{aligned}
& \varphi_{1}=n_{1}-1=360-1=359 \\
& \varphi_{2}=n_{2}-1=360-1=359
\end{aligned}
$$

- Com auxilio da tabela da distribuição "F" (Anexos 3, 4 e 5), determinam-se a Região de Aceitação (RA) e a Região Critica (RC), $\operatorname{para} \alpha=1 \% ; \alpha=5 \% ; \alpha=10 \%$.

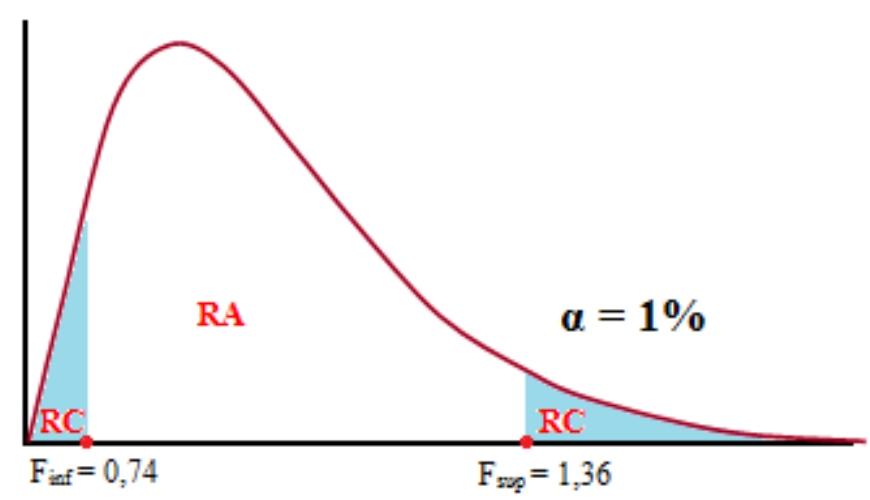



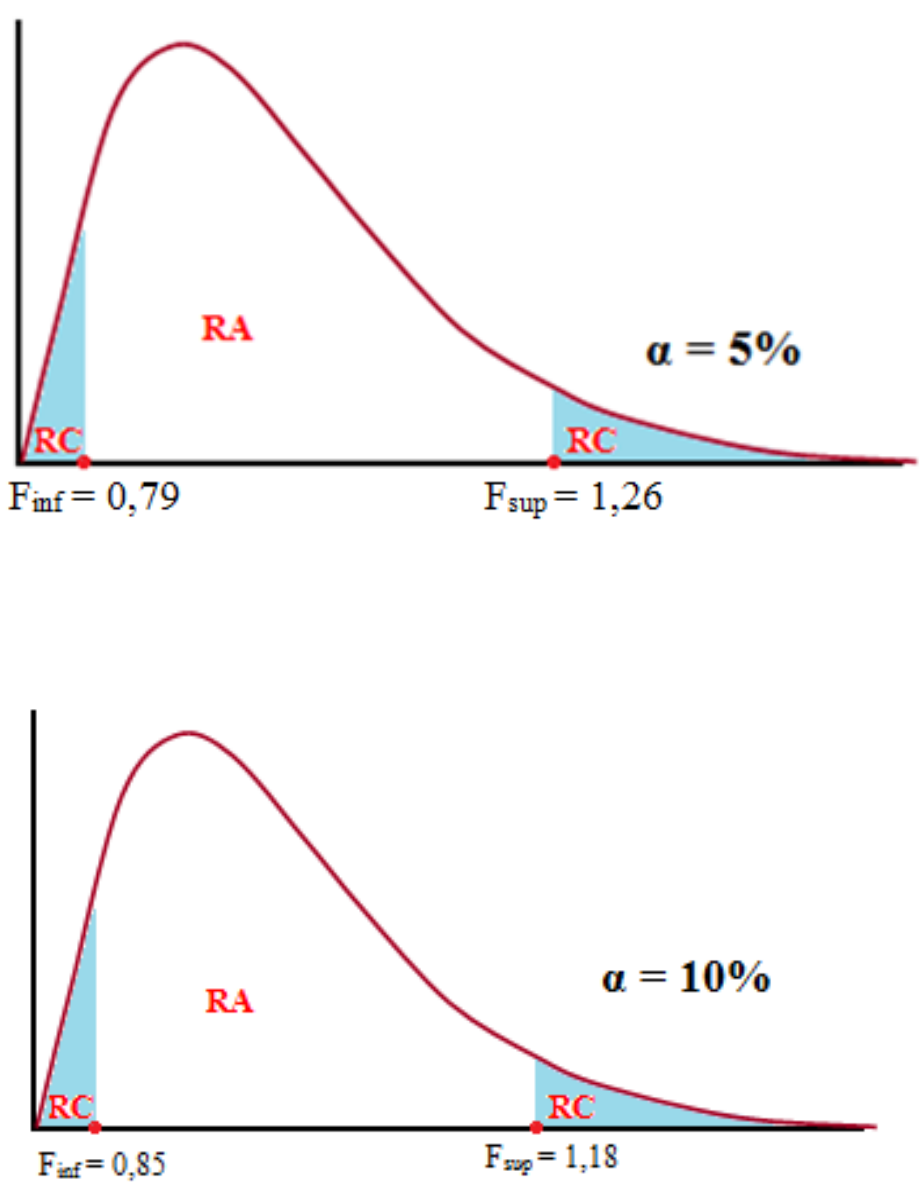

- Cálculo do valor da variável:

Aplicando-se a equação (7):

$$
F_{\text {cal }}=\frac{0,00012}{0,0001}
$$

$$
F_{\text {cal }}=1,20
$$

\section{- Conclusão:}

As variâncias das duas populações podem ser consideradas estatisticamente iguais aos níveis de confiança de $95 \%$ e $99 \%$ e diferentes para um nível de confiança de $90 \%$. Assim, para efeito do cálculo da incerteza do sistema de medição, recomenda-se utilizar um nível de confiança de 95\% com um fator de abrangência $\mathrm{k}=2$. 


\subsubsection{3.}

\section{Teste de significância para a igualdade de duas médias}

Visando determinar o nível de confiança no qual podem ser consideradas estatisticamente iguais as medições da tensão elétrica feitas pelo sistema SIMBAGEBAT e as feitas pelo equipamento portátil, os dados das amostras foram submetidos ao teste paramétrico de significância para a igualdade de duas médias.

Para a aplicação é necessário que os dados sejam normais, independentes, e as variâncias populacionais desconhecidas, mas consideradas iguais. Nas seções anteriores, foi demonstrado que as duas amostras cumprem com os critérios mencionados.

A seguir, aplica-se o teste:

- Hipóteses:

$\mathrm{H}_{\mathrm{o}}: \mu_{1}=\mu_{\mathbf{2}}$
$\mathrm{H}_{1}: \mu_{1} \neq \mu_{\mathbf{2}}$

- Para $\alpha=1 \% ; \alpha=5 \% ; \alpha=10 \%$; A variável "tt" com:

$\varphi_{1}=n_{1}+n_{2}-2=360+360-2=718$

- Com auxilio da tabela da distribuição normal Z N(0,1), (Anexo 6), determinam-se a Região de Aceitação (RA) e a Região Critica (RC), para $\alpha=1 \% ; \alpha=5 \% ; \alpha=10 \%$.

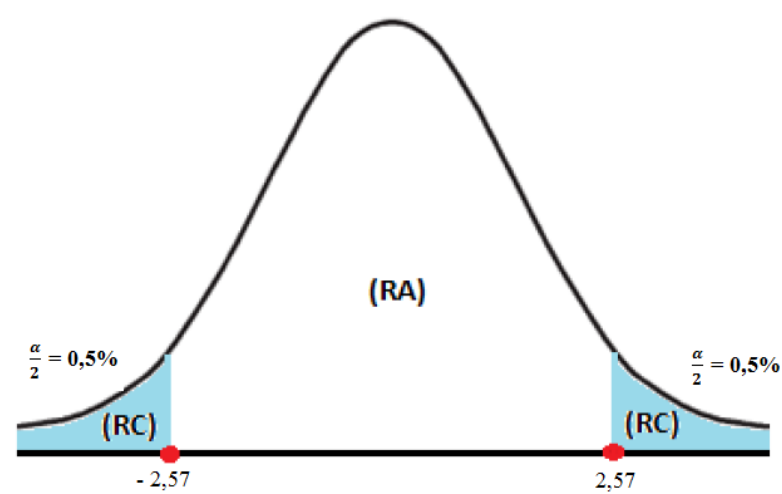



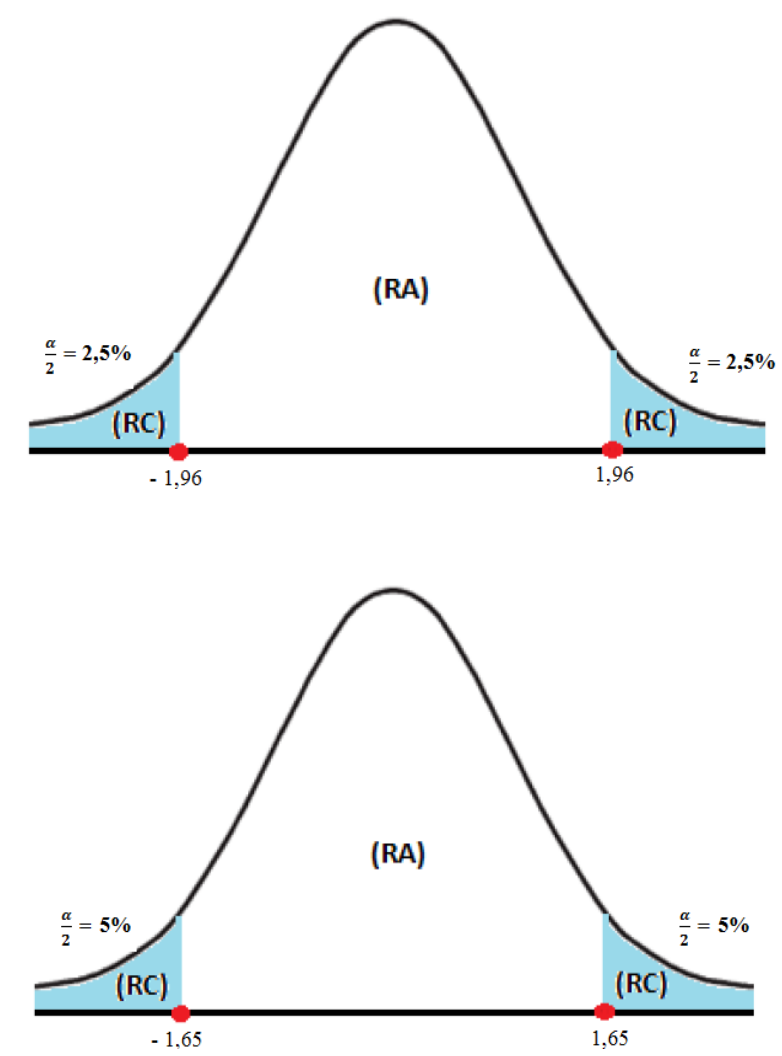

- Cálculo do valor da variável:

Aplicando-se a equação (9):

$$
\begin{gathered}
S_{c}=\sqrt{\frac{(359)(0,0001)+(359)(0,00012)}{360+360-2}} \\
S_{c}=0,01404881
\end{gathered}
$$

Aplicando-se a equação (8):

$$
t_{\text {cal }}=\frac{(2,191-2,19)}{(0,01404881) \cdot \sqrt{\frac{360+360}{(360) \cdot(360)}}}
$$

$$
t_{\text {cal }}=0.95
$$

- Conclusão:

Como $t_{\text {cal }}=0,95$, não se pode rejeitar $\mathrm{H}_{\mathrm{o}}: \mu_{\mathbf{1}}=\mu_{\mathbf{2}}$, aos níveis de significância de $1 \%, 5 \%$ e $10 \%$.

O teste de significância de igualdade entre duas médias demonstrou que as medições de impedância feitas pelo sistema SIMBA-GEBAT e pelo equipamento portátil podem ser considerados estatisticamente iguais, aos níveis de confiança de $90 \%, 95 \%$ e $99 \%$. 


\section{5 \\ Conclusões}

No presente trabalho foi possível validar em condições reais de operação a técnica de monitoramento remoto de baterias estacionárias desenvolvida em ambiente laboratorial. A validação foi efetuada mediante testes estatísticos, paramétricos e não paramétricos, realizados em níveis de confiança de 90\%, 95\% e $99 \%$.

Para a validação estatística foi utilizado o teste de significância para a igualdade de duas médias, que considera as populações normais e independentes.

A conformidade à distribuição normal de probabilidade foi realizada com base nos testes de hipóteses K-S e de significância para a igualdade de duas variâncias. De forma qualitativa foi definida a independência entre as duas amostras testadas.

Foram consideradas independentes devido ao fato do valor da medição realizada com o sistema remoto não ter incidência sobre o valor da medição realizada com o instrumento e vice-versa.

Os resultados do teste K-S permitiram demonstrar para os níveis de confiança de $90 \%$, 95\% e 99\% que os dados das amostras 1 e 2 seguem uma distribuição normal para as medidas de impedância e de tensão elétrica.

Os resultados da significância para a igualdade de duas variâncias das duas populações, de impedância e de tensão elétrica, foram considerados estatisticamente iguais aos níveis de confiança de $95 \%$ e $99 \%$ e diferentes para um nível de confiança de $90 \%$.

O teste de significância de igualdade entre duas médias demonstrou que as medições de impedância e tensão elétrica feitas pelo sistema SIMBA-GEBAT e pelo equipamento portátil podem ser considerados estatisticamente iguais, aos níveis de confiança de $90 \%, 95 \%$ e $99 \%$.

As análises estáticas dos dados do equipamento de monitoramento remoto de baterias (frente ao equipamento portátil) demonstraram que o método de 
monitoramento apresenta confiabilidade em suas medições de tensão elétrica e impedância.

O equipamento validado no presente trabalho possui a vantagem de operar remotamente, resultando em uma poderosa ferramenta que proporciona aos usuários aumento da confiabilidade dos sistemas de backup de energia e auxilio na sua tomada de decisão crítica. E mais, realiza as medições de forma automática sem a necessidade de interferência por profissional especializado, o que proporciona aos usuários uma diminuição dos custos operacionais e erros por falhas humanas.

Como resultado e contribuição do trabalho, a nova metodologia proposta foi validada. Por já estar inserida no mercado e estar disponível para outras concessionárias que dela desejarem fazer uso, constitui inovação tecnológica nacional. 


\section{Referências bibliográficas}

[1] ROSOLEM, M.F.N.C.; BECK, R.F.;BARRETO JUNIOR; J.T. Estudo da viabilidade de avaliação de baterias chumbo-ácidas através dos métodos de condutância e impedância. Campinas:CPqD, 2001. 100p. (Light. Programa de P\&D Aneel - Projeto 3105/2001). Projeto concluído.

[2] ROSOLEM, M.F.N.C.; BECK, R.F.;PESENTI, G.R.. Estudo para detecção e gerenciamento de falhas de baterias. Campinas: $\mathrm{CPqD}$, 2006. 235p. (Light. Programa de P\&D Aneel - Projeto 019/2006). Projeto concluído.

[3] ROSOLEM, M.F.N.C.; BECK, R.F.;SOARES, L.A. Estudo da viabilidade de avaliação de baterias chumbo ácidas através dos métodos de condutância e impedância: Resultado da avaliação de baterias instaladas em subestações da Light - Final, Campinas, 2002, 36p. Relatório Técnico CPqD PD.33.11.25A.0014A/RT-04-AA

[4] ROSOLEM, M.F.N.C.; BECK, R.F.;PESENTI, G.R.. Desenvolvimento de sistema para monitoração remota de baterias. Campinas: $\mathrm{CPqD}$, 2008.350p. (Light. Programa de P\&D Aneel - Projeto 033/2008). Projeto concluído.

[5] ROSOLEM, M.F.N.C.; BECK, R.F.; CARDOSO, P.E.; SOARES, L.A.; YAMAGUTI, F. (2004). Stationary VRLA battery evaluations: Internal measurements and capacity test. An experience at the Claro Cellular Mobile Company. BATTCON 2004 - Florida, USA.

[6] ROSOLEM, M.F.N.C.; BECK, R.F.; CARDOSO, P.E.; SOARES, L.A. (2004). Evaluation of the relationship between conductance and capacity measurements of VRLA batteries in Brazil. INTELEC 2004 - Chicago, USA.

[7] ROSOLEM, M.F.N.C.; BECK, R.F.; JÚNIOR, M.G.R. (2000). Evaluation tools for batteries employed in outdoor cabinets - An experience of a brazilian telecom company. INTELEC 2000 - Phoenix/EUA.

[8] ROSOLEM, M.F.N.C.; BECK, R.F.; SOARES, L.A. (2002). Failure detection of stationary lead-acid batteries in service in various regions of Brazil. INTELEC 2002 - Montreal/Canadá. 
[9] PINHEL, A.S; ROSOLEM, M.F.N.C.; BECK, R.F.; SOARES, L.A.; SANTOS, G.R.; $\quad$ ARIOLI, V.T.; $\quad$ FRARE, P.T. (2008). Impacto da estocagem na vida útil de baterias chumbo-ácidas reguladas por válvula - (VRLA). $23^{\circ}$ Congresso Brasileiro de Manutenção, Santos-SP, Brasil.

[10] PESENTI, G.R.; $\quad$ ROSOLEM, M.F.N.C.; $\quad$ BECK, R.F.; $\quad$ SANTOS, G.R.; LOPES, P.H.O.; NAZARI, R.S.; ARIOLI, V.T. (2012). Sistema de monitoração remota para baterias chumbo-ácidas estacionárias. SENDI - Rio de Janeiro/Brasil.

[11] PESENTI, G.R.; $\quad$ ROSOLEM, M.F.N.C.; BECK, R.F.; SOARES, L.A.; SANTOS, G.R.; ARIOLI, V.T.; FRARE, P.T.; LOPES, P.H.O. (2010). Stationary lead-Acid batteries maintenance management system. INTELEC - Orlando/EUA.

[12] VIM. Vocabulário Internacional de Metrologia: Conceitos fundamentais e gerais e termos associados (VIM). 94 p. Duque de Caxias, RJ, INMETRO, 2012.

[13] BERNDT, D. Maintenance-free batteries - A handbook of battery technology. $3^{\text {rd }}$ edition, 2001.

[14] ROSOLEM, M.F.N.C.; BECK, R.F.; SOARES, L.A.; SANTOS, G.R.; ARIOLI, V.T.; FRARE, P.T.; FONSECA, J.C. (2009). The batterie's regulatory process in Brazilian Telecommunications Industry. Telescon Viena/Austria.

[15] VERGARA, S.C. Métodos de pesquisa em administração. São Paulo: Atlas, 2005

[16] SALAMEH, Z. M.; $\quad$ CASACCA, M.A.; LYNCH, W.A. $\quad$ (1992). A mathematical model for lead-acid batterie. IEEE Transactions on Energy Conversion, volume 7 , no. 1, 93-98

[17] JANTHARAMIN, N.; ZHANG, L. (2008). New dynamic model for leadacid batteries. IEEE.

[18] FONSECA, J.S.; MARTINS, G.A. Curso de estatística. $6^{\text {a }}$ Edição. São Paulo. Editora Atlas S.A., 2012. p. 213-215. 


\section{Anexo 1 - Certificado de calibração shunt de 60 a / 60 mv}

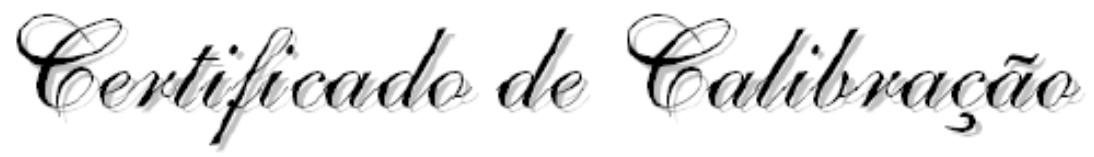

Calibration Certificate

\section{Número: PD.SM.11.22A.3986A/CC-01-AA}

Equipamento: Shunt de Corrente

Fabricante: KRON

Manufocturer

Modelo: $60 \mathrm{~A} / 60 \mathrm{mV}$

Número de Série: 35599

Identificação: RCE000900

Cliente: Fundação CPQD - ASE

custome:

Contato: Vitor Torquato Arioli

Data da calibração: 03/Out/2012

Condições Ambientais - Temperatura: $23 \pm 3^{\circ} \mathrm{C}$, Umidade: $55 \pm 15 \%$ Ambient Condrions

Este certificado atende aos requisitos estabelecidos na norma NBR ISO/IEC 17025/2005, relativos a competência do laboratório incluindo sua rastreabilidade a padröes nacionais de medida (ou ao Sistema Internacional de Unidades - SI). A presente calibração näo está inserida em escopo de acreditaçäo do Laboratório de Calibração do $\mathrm{CPqD}$ pelo Cgcre para calibração de equipamentos nas áreas de: optica, tempo e frequéncia e rádio frequência (124).

\begin{abstract}
This certificate meets the NBR ISOMEC 17025/2005 accreditation requirements to ensure the laboratory accreditation requirements to ensure the laboratory competence including traceability to national standards or according to the International System of Units (SI). This calibration is not within the scope of $C P q D$ Laboratory accreditation by Cgcre of instrument calibration capabilities for optics, time and frequency and radio frequency (124).
\end{abstract}

Este documento foi assinado digitalmente

Luis Antônio Bueno Metrologista Metrologist
Este documento foi assinado digitalmente

Vicente Olímpio Pavan

Responsável pelo Lab. de Cal.

\begin{tabular}{|c|c|}
\hline & 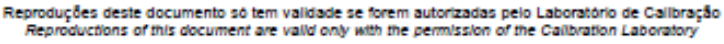 \\
\hline $\begin{array}{l}\text { CPQD - Todos os diretos reservados. } \\
\text { CPQD - AV rights resenved. }\end{array}$ & \\
\hline
\end{tabular}




\section{CPP}

Laboratório de Calibração

PD.SM.11.22A.3986A/CC-01-AA

\section{Identificação do laboratório de calibraçäo}

Fundação CPqD - Centro de Pesquisa e Desenvolvimento em Telecomunicações

Rod. Campinas-Mogi-Mirim, km 118,5 - SP340

Caixa Postal 6070

13086-902 - Campinas - SP

Diretoria de Laboratórios e Infraestrutura de Redes

Gerência de Tecnologia em Terminais e Equipamentos

Laboratório de Calibração labcal@cpad.com.br

Telefone: (19) 3705-7118 Fax: (19) 3705-6558

\section{Identificação do Cliente}

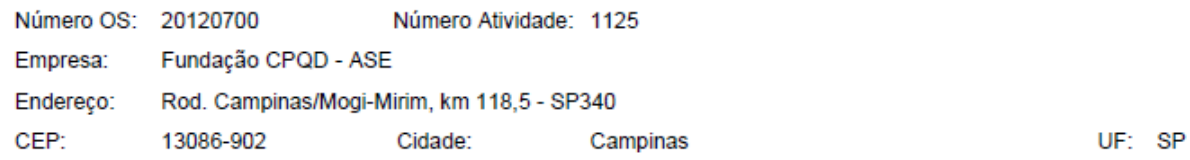

\section{Procedimento de calibração}

A calibração é executada empregando-se métodos de comparação direta ou da substituição contra padrões controlados, mantendo uma cadeia de rastreabilidade a padrões nacionais e/ou internacionais.

Para Medidas de Tensão AC/DC, Corrente AC/DC e Resistência são empregados, como padrões, calibradores e multímetros de precisão, shunt, décadas resistiva e osciloscópio, rastreados a padrões nacionais e/ou internacionais, todos mantidos sobre controle metrológico e interligados à USC por cabos de baixíssima perda e histerese, conforme procedimento PD.70.300.022.000 (Medidores AC/DC Analógicos e Digitais), PD 70.300.048.000 (Fontes AC/DC Analógicos e Digitais / Simuladores de Resistência e Carga Dinâmica), PD.70.300.049.000 (Shunt de Corrente), PD.70.300.023.000 (Ponta de Corrente) e PD.70.300.024.000 (Medidor de Potência HP).

Para minimização de componentes de incerteza do Tipo A, são realizadas, no mínimo, duas leituras por ponto, sendo adotada a média das leituras como resultado da medição. A incerteza de medição é a combinação da incerteza tipo A com as demais incertezas do sistema de medição.

\section{Padrões utilizados}

\begin{tabular}{|l|l|l|l|c|l|}
\hline Fabricante & \multicolumn{1}{|c|}{ Modelo } & \multicolumn{1}{c|}{ Descrição } & $\begin{array}{c}\text { Série ou } \\
\text { Patrimônio }\end{array}$ & Validade & \multicolumn{1}{c|}{ Rastreabilidade } \\
\hline Agilent & $34970 \mathrm{~A}$ & Data Acquisition / Switch Unit & MY44035819 & ago/2013 & PD.SM.11.22A.2669A - CPqD \\
\hline HP & $6671 \mathrm{~A}$ & System DC Power Supply & $3351 \mathrm{~A} 00492$ & - & Não Requer Calibração \\
\hline Kron & $60 \mathrm{~A} 60 \mathrm{mV}$ & Shunt de Corrente & 5914 & jul/2013 & $118061-101$ - IPT - RBC \\
\hline
\end{tabular}

Os resultados desta calibração referem-se, exclusivamente, a esta USC (Unidade Sob Calibração).

\section{Resultados obtidos}

As incertezas expandidas de medição relatadas nas tabelas contidas no item resultados obtidos, são declaradas como as incertezas padrão de medição multiplicadas pelo fator de abrangência k, o qual para uma distribuição $t$ com respectivo Veff (graus de liberdade efetivos), corresponde a uma probabilidade de abrangência de aproximadamente $95 \%$. A incerteza padrão da medição foi determinada de acordo com a publicação EA-4/02.

\begin{tabular}{|c|c|c|}
\hline & $\begin{array}{l}\text { Reproduçóes deste documento só tem validade se forem autorizadas pelo Laboratório de Calibração } \\
\text { Reproductions of this document are valíd only with the permission of the Calibration Laboratory }\end{array}$ & \\
\hline $\begin{array}{l}C P q D-\text { Todos os direitos reservados. } \\
C P q D-A \text { All nights reserved. }\end{array}$ & & Laboratório de Calibraçâo \\
\hline
\end{tabular}




\section{CPP}

5.1 Resultado da Medição

\begin{tabular}{|c|c|c|c|c|c|c|c|}
\hline $\begin{array}{c}\text { Valor } \\
\text { Nominal }\end{array}$ & $\begin{array}{c}\text { VVC } \\
\text { Aplicado }\end{array}$ & $\begin{array}{c}\text { VVc } \\
\text { Medido }\end{array}$ & $\begin{array}{c}\text { Valor } \\
\text { Correspondente } \\
\text { ao Medido }\end{array}$ & Erro & $\begin{array}{c}\text { Graus de } \\
\text { Liberdade } \\
\text { Efetivos }\end{array}$ & $\begin{array}{c}\text { Fator de } \\
\text { Abrangência } \\
\mathbf{k}\end{array}$ & $\begin{array}{c}\text { Incerteza } \\
\text { de Mediçäo }\end{array}$ \\
\hline [ A ] & [A ] & [ $\mathbf{~ m V ~ ] ~}$ & [ A ] & {$[\%]$} & [ - ] & [ - ] & $\pm[\%]$ \\
\hline 5,0000 & 5,0448 & 5,0775 & 5,0775 & 0,65 & $\infty$ & 2,00 & 0,15 \\
\hline 11,0000 & 11,0090 & 11,0803 & 11,0803 & 0,65 & $\infty$ & 2,00 & 0,15 \\
\hline 16,0000 & 15,9981 & 16,1003 & 16,1003 & 0,64 & $\infty$ & 2,00 & 0,15 \\
\hline 20,0000 & 20,0008 & 20,1304 & 20,1304 & 0,65 & $\infty$ & 2,00 & 0,15 \\
\hline 30,0000 & 29,9783 & 30,1688 & 30,1688 & 0,64 & $\infty$ & 2,00 & 0,15 \\
\hline 40,0000 & 40,0019 & 40,2544 & 40,2544 & 0,63 & $\infty$ & 2,00 & 0,16 \\
\hline 50,0000 & 49,9867 & 50,2956 & 50,2956 & 0,62 & $\infty$ & 2,00 & 0,16 \\
\hline 60,0000 & 59,9467 & 60,3283 & 60,3283 & 0,64 & $\infty$ & 2,00 & 0,16 \\
\hline
\end{tabular}

6 Histórico de alteraçōes

\begin{tabular}{|c|c|l|}
\hline $\begin{array}{c}\text { Data de início de } \\
\text { vigência }\end{array}$ & Versão & Descriçöes das alterações realizadas \\
\hline 03/Out/2012 & AA & Primeira versão aprovada. \\
\hline
\end{tabular}

\begin{tabular}{|l|l|}
\hline \multicolumn{2}{|c|}{$\begin{array}{c}\text { Reproduçóes deste documento só tem validade se forem autorizadas pelo Laboratório de Calibração } \\
\text { Reproductions of this document are valid only with the permission of the Calibration Laboratory }\end{array}$} \\
\hline $\begin{array}{l}\text { CP } q D-\text { Todos os direitos reservados. } \\
\text { CPqD - All rights reserved. }\end{array}$ & \\
\hline
\end{tabular}




\section{Anexo 2 - Tabela Distribuição D}

\section{CRITICAL VALUES OF D*}

\begin{tabular}{|c|c|c|c|}
\hline $\begin{array}{c}\text { Sample } \\
\text { size } \\
n\end{array}$ & $D_{.10}$ & $D_{.05}$ & $D_{.01}$ \\
\hline 1 & 0,950 & 0,975 & 0,995 \\
\hline 2 & 0,776 & 0,842 & 0,929 \\
\hline 3 & 0,642 & 0,708 & 0,828 \\
\hline 4 & 0,564 & 0,624 & 0,733 \\
\hline 5 & 0,510 & 0,565 & 0,669 \\
\hline 6 & 0,470 & 0,521 & 0,618 \\
\hline 7 & 0,438 & 0,486 & 0,577 \\
\hline 8 & 0,411 & 0,457 & 0,543 \\
\hline 9 & 0,388 & 0,432 & 0,514 \\
\hline 10 & 0,368 & 0,410 & 0,490 \\
\hline 11 & 0,352 & 0,391 & 0,468 \\
\hline 12 & 0,338 & 0,375 & 0,450 \\
\hline 13 & 0,325 & 0,361 & 0,433 \\
\hline 14 & 0,314 & 0,349 & 0,418 \\
\hline 15 & 0,304 & 0,338 & 0,404 \\
\hline 16 & 0,295 & 0,328 & 0,392 \\
\hline 17 & 0,286 & 0,318 & 0,381 \\
\hline 18 & 0,278 & 0,309 & 0,371 \\
\hline 19 & 0,272 & 0,301 & 0,363 \\
\hline 20 & 0,264 & 0,294 & 0,356 \\
\hline 25 & 0,24 & 0,27 & 0,32 \\
\hline 30 & 0,22 & 0,24 & 0,29 \\
\hline
\end{tabular}

*Adapted from F. J. Massey, Jr., "The Kolgomorov-Smirnov test for goodness of fit" J. Amer. Statist. Ass., Vol. 46 (1951), p. 70, with the kind permission of the author and Publisher. 


\section{Anexo 3- Tabela de Distribuição F para 1- $\alpha=90 \%$}

\section{$1-\alpha=0.9$}

$1-\alpha=P\left(F \leq f_{\alpha, v, v 2}\right)$

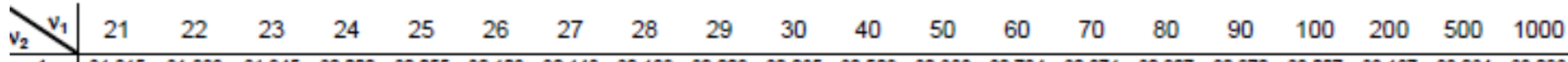

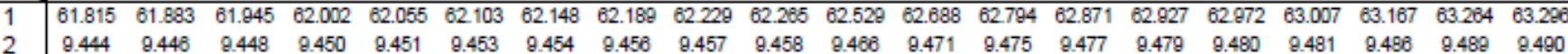
$\begin{array}{llllllllllllllllllll}5.182 & 5.180 & 5.178 & 5.176 & 5.175 & 5.173 & 5.172 & 5.170 & 5.168 & 5.168 & 5.160 & 5.155 & 5.151 & 5.149 & 5.147 & 5.145 & 5.144 & 5.139 & 5.136 & 5.135\end{array}$ $\begin{array}{llllllllllllllllllll}3.841 & 3.837 & 3.834 & 3.831 & 3.828 & 3.826 & 3.823 & 3.821 & 3.818 & 3.817 & 3.804 & 3.795 & 3.790 & 3.786 & 3.782 & 3.780 & 3.778 & 3.769 & 3.764 & 3.762\end{array}$ $\begin{array}{llllllllllllllllllll}3202 & 3.198 & 3.194 & 3.191 & 3.187 & 3.194 & 3.181 & 3.179 & 3.176 & 3.174 & 3.157 & 3.147 & 3.140 & 3.135 & 3.132 & 3.129 & 3.126 & 3.116 & 3.109 & 3.107\end{array}$ $\begin{array}{llllllllllllllllllll}2.831 & 2.827 & 2.822 & 2.818 & 2.815 & 2.811 & 2.808 & 2.805 & 2.803 & 2.800 & 2.781 & 2.770 & 2.762 & 2.756 & 2.752 & 2.748 & 2746 & 2.734 & 2.727 & 2.25\end{array}$ $\begin{array}{llllllllllllllllllll}2.599 & 2.564 & 2580 & 2.575 & 2.571 & 2.568 & 2.564 & 2.561 & 2.558 & 2.555 & 2535 & 2.523 & 2.514 & 2508 & 2.504 & 2.500 & 2497 & 2.444 & 2.476 & 2473 \\ 2.419 & 2.414 & 2409 & 2404 & 2.400 & 2.396 & 2.392 & 2.399 & 2.386 & 2.383 & 2361 & 2.348 & 2.339 & 2.333 & 2.328 & 2.324 & 2.321 & 2.307 & 2.298 & 2.295\end{array}$ $\begin{array}{llllllllllllllllllll}2.292 & 2.287 & 2.282 & 2.277 & 2.272 & 2.268 & 2.285 & 2.261 & 2.258 & 2.255 & 2.232 & 2.218 & 2.208 & 2.202 & 2.196 & 2.192 & 2.189 & 2.174 & 2.165 & 2.162\end{array}$ $10 \quad \begin{array}{llllllllllllllllllll}2.194 & 2.188 & 2.183 & 2.178 & 2.174 & 2.170 & 2.166 & 2.162 & 2.158 & 2.155 & 2.132 & 2.117 & 2.107 & 2.100 & 2.005 & 2.090 & 2.087 & 2.071 & 2.062 & 2.050\end{array}$

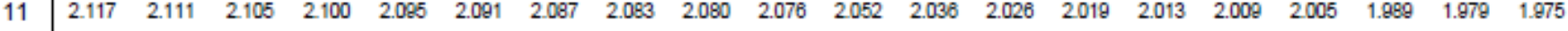
$\begin{array}{lllllllllllllllllllll}12 & 2.053 & 2.047 & 2.041 & 2036 & 2.031 & 2.027 & 2.022 & 2.019 & 2.015 & 2.011 & 1.986 & 1.970 & 1.960 & 1.062 & 1.048 & 1.942 & 1.838 & 1.921 & 1.911 & 1.007\end{array}$

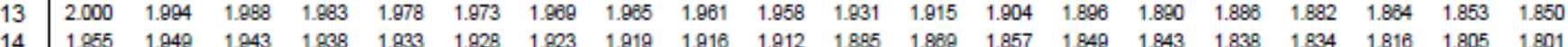

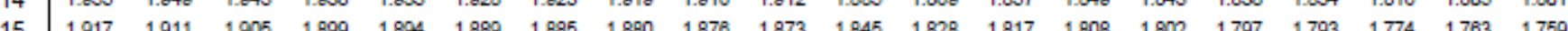

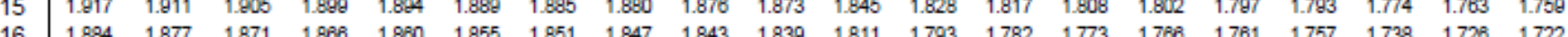

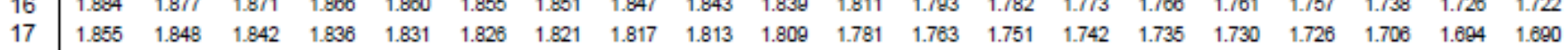

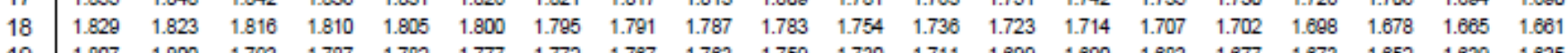
$19 \begin{array}{llllllllllllllllllll}1.807 & 1.800 & 1.793 & 1.787 & 1.782 & 1.777 & 1.772 & 1.767 & 1.763 & 1.759 & 1.730 & 1.711 & 1.809 & 1.690 & 1.683 & 1.677 & 1.673 & 1.652 & 1.639 & 1.635\end{array}$ $20 \begin{array}{llllllllllllllllllll}1.786 & 1.779 & 1.773 & 1.787 & 1.761 & 1.756 & 1.751 & 1.746 & 1.742 & 1.738 & 1.708 & 1.600 & 1.877 & 1.687 & 1.680 & 1.655 & 1.650 & 1.629 & 1.616 & 1.612\end{array}$

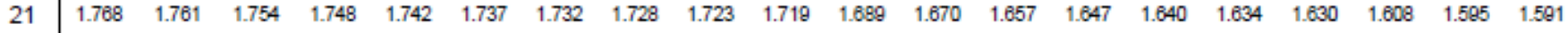

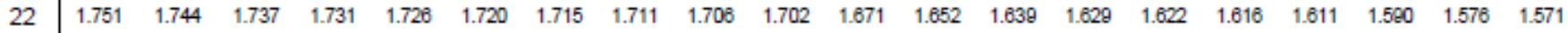

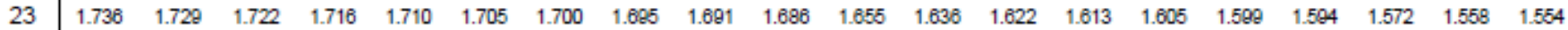

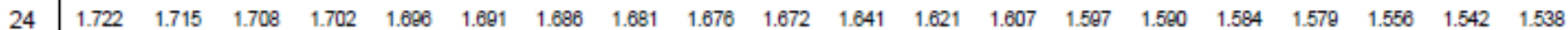

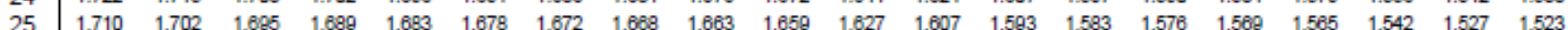

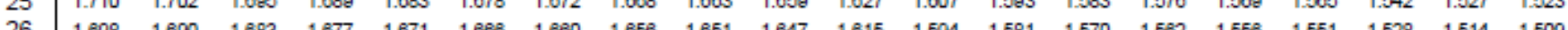

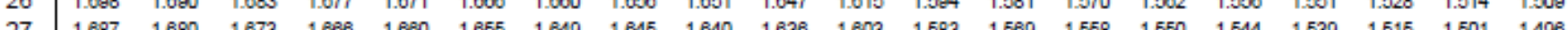
$\begin{array}{lllllllllllllllllllll}27 & 1.087 & 1.080 & 1.673 & 1.006 & 1.000 & 1.055 & 1.048 & 1.045 & 1.640 & 1.036 & 1.003 & 1.583 & 1.508 & 1.568 & 1.560 & 1.544 & 1.539 & 1.515 & 1.501 & 1.496\end{array}$

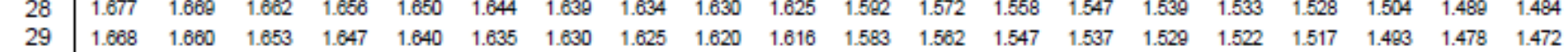

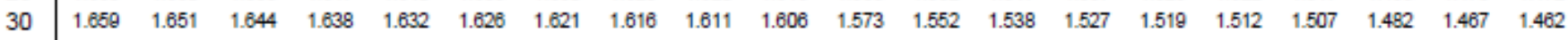

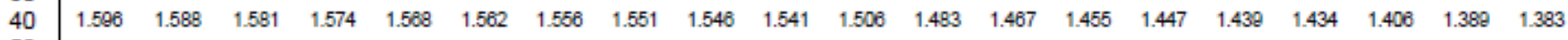

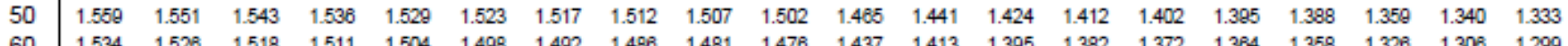

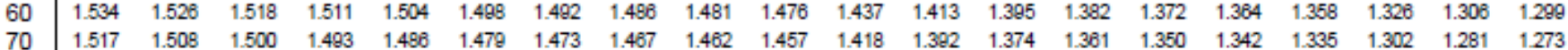

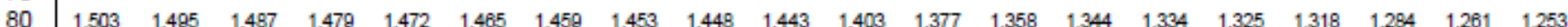

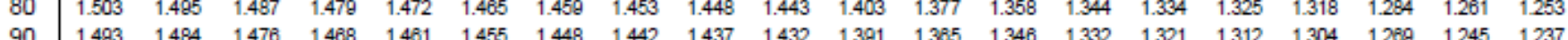

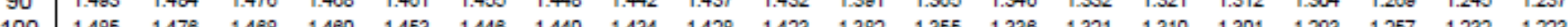

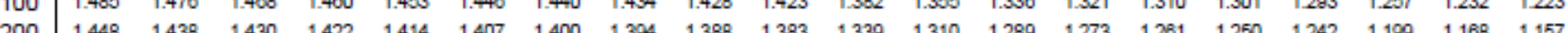

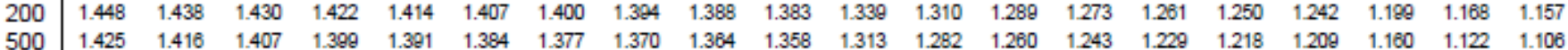

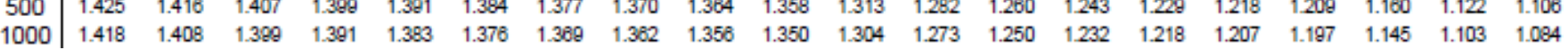




\section{Anexo 4 - Tabela de Distribuição F para: 1- $\alpha=95 \%$}

\begin{tabular}{|c|c|c|c|c|c|c|c|c|c|c|c|c|c|c|c|c|c|c|c|c|}
\hline 1 & 21 & 22 & 23 & 24 & 25 & 26 & 27 & 28 & 29 & 30 & 40 & 50 & 60 & 70 & 80 & 90 & 100 & 200 & 500 & 1000 \\
\hline 1 & 248.307 & 248.579 & 248.823 & 249.052 & 249.260 & 249.453 & 249.631 & 249.798 & 249.951 & 250.096 & 251.144 & 251.774 & 252.198 & 252498 & 252.723 & 252898 & 253.043 & 253.676 & 254.062 & 254.186 \\
\hline 2 & 19.448 & 19.450 & 19.452 & 18.454 & 19.456 & 18.457 & 18.458 & 12.480 & 18.481 & 19.463 & 18.471 & 18.476 & 18.479 & 19.481 & 18.483 & 18.485 & 18.486 & 18.481 & 12.494 & 19.485 \\
\hline 3 & 8.654 & 8.648 & 8.643 & 8.638 & 8.634 & 8.630 & 8.628 & 8.623 & 8.620 & 8.617 & 8.504 & 8.581 & 8.572 & 8.568 & 8.561 & 8.557 & 8.554 & 8.540 & 8.532 & 8.529 \\
\hline 4 & 5.725 & 5.787 & 5.781 & 5.774 & 5.780 & 5.763 & 5.750 & 5.754 & 5.750 & 5.746 & 5.717 & 5.680 & 5.688 & 5.679 & 5.673 & 5.688 & 5.664 & 5.646 & 5.635 & 5.632 \\
\hline 5 & 4.548 & 4.541 & 4.534 & 4.527 & 4.521 & 4.515 & 4.510 & 4.505 & 4.500 & 4.498 & 4.464 & 4.444 & 4.431 & 4.422 & 4.415 & 4.400 & 4.405 & 4.395 & 4.373 & 4.368 \\
\hline 6 & 3.865 & 3.856 & 3.849 & 3.841 & 3.835 & 3.828 & 3.823 & 3.818 & 3.813 & 3.808 & 3.774 & 3.754 & 3.740 & 3.730 & 3.722 & 3.716 & 3.712 & 3.600 & 3.678 & 3.673 \\
\hline 7 & 3.435 & 3.426 & 3.418 & 3.410 & 3.404 & 3.397 & 3.391 & 3.386 & 3.381 & 3.376 & 3.340 & 3.319 & 3.304 & 3.294 & 3.286 & 3.280 & 3.275 & 3252 & 3.239 & 3234 \\
\hline 8 & 3.140 & 3.131 & 3.123 & 3.115 & 3.108 & 3.102 & 3025 & 3.000 & 3.084 & 3.079 & 3.043 & 3.020 & 3.005 & 2.984 & 2.986 & 2.980 & 2.975 & 2851 & 2.837 & 2832 \\
\hline 9 & 2.928 & 2917 & 2.908 & 2.900 & 2.883 & 2.888 & 2880 & 2.874 & 2880 & 2.864 & 2826 & 2.803 & 2.787 & 2.776 & 2.768 & 2.761 & 2.756 & 2731 & 2.717 & 2712 \\
\hline 10 & 2.764 & 2754 & & & 2.730 & & & 2.710 & 2705 & 2.700 & 2081 & 2.637 & 121 & 2.600 & 2.601 & 2.504 & 2.588 & 2563 & 2.548 & 2543 \\
\hline 11 & 2.636 & 2626 & 2.617 & 2.600 & 2.601 & 2.504 & 2588 & 2.582 & 2576 & 2.570 & 2531 & 2.507 & 2.490 & 2.478 & 2.400 & 2.462 & 2.457 & 2431 & 2.415 & 2410 \\
\hline 12 & 2.533 & 2.523 & 2.514 & 2.505 & 2.488 & 2.491 & 2484 & 2.478 & 2472 & 2.466 & 2426 & 2.401 & 2.384 & 2.372 & 2.363 & 2.356 & 2.350 & 2323 & 2.307 & 2302 \\
\hline 13 & 2.448 & 2438 & & 420 & 412 & 2.405 & 2388 & 2.392 & 2386 & 2.380 & 2339 & 2.314 & 2297 & 2.284 & 2.275 & 2.267 & 2.261 & 2234 & 2.218 & 2212 \\
\hline 14 & 2.377 & 2367 & 357 & 349 & 341 & 2.333 & 2328 & 2.320 & 2314 & 2.308 & 2286 & 2.241 & 2223 & 2.210 & 2.201 & 2.183 & 2.187 & 2159 & 2.142 & 2136 \\
\hline 15 & 2.316 & 2306 & 2.297 & 2.288 & 2.280 & 2.272 & 2265 & 2.250 & 2253 & 2.247 & 2204 & 2.178 & 2.160 & 2.147 & 2.137 & 2.130 & 2.123 & 2005 & 2.078 & 2072 \\
\hline 16 & 2.264 & 2254 & 2.244 & 2.235 & 2.227 & 2.220 & 2211 & 2.208 & 2200 & 2.194 & 2.151 & 2.124 & 2.106 & 2.083 & 2.083 & 2.075 & 2.068 & 2039 & 2.022 & 2016 \\
\hline 17 & 2.219 & 2208 & 2.180 & 2.190 & 2.181 & 2.174 & 2167 & 2.160 & 2154 & 2.148 & 2,104 & 2.077 & 2.058 & 2.045 & 2.035 & 2.027 & 2.020 & 1.291 & 1.973 & 1.867 \\
\hline 18 & 179 & 2188 & 2.150 & 2.150 & 141 & 134 & 2128 & 2.111 & 2113 & 2.107 & 2003 & 2.035 & 2.017 & 2.003 & 1.993 & 1.985 & 1.978 & 1.248 & 1.928 & 1.823 \\
\hline 19 & 144 & 2,133 & 2.123 & 114 & 2.100 & 2.098 & 2020 & 2.084 & 2077 & 2.071 & 2026 & 1.920 & 1.880 & 1.986 & 1.965 & 1.947 & 1.240 & 1.810 & 1.891 & 1.824 \\
\hline 20 & 2.112 & 2102 & 2.0 & 2.082 & 2.074 & .068 & 2058 & 2.052 & 2045 & 2.038 & 1.204 & 1.988 & 1.946 & 1.932 & 1.922 & 1.913 & 1.907 & 1.875 & 1.856 & 1.850 \\
\hline 21 & 084 & 2073 & 2.083 & 2.054 & 2.045 & 2.037 & 2030 & 2.023 & 2016 & 2.010 & 1.866 & 1.238 & 1.816 & & 891 & 1.883 & 1.876 & 1.845 & 1.825 & 1.818 \\
\hline 22 & 2.058 & 048 & & & & & & & & & & & & 1.875 & 1.864 & & & & 1.797 & 1.790 \\
\hline 23 & 036 & 2025 & 2.014 & 2.0 & & & & 1.973 & 1.967 & 1.86 & 1.214 & & 1.885 & 1.850 & 1.839 & 1.830 & 1.823 & 1.791 & 1.771 & 1.764 \\
\hline 24 & & & & & & & & & & & & & & & & & & & 1.747 & $\begin{array}{l}1.740 \\
\end{array}$ \\
\hline 2 & 1.925 & 1.824 & 1.974 & 1.964 & 1.956 & 1.247 & 1.839 & 1.932 & 1.826 & 1.819 & 1.872 & 1.842 & 1.822 & 1.807 & 1.796 & 1.787 & 1.779 & 1.746 & 1.725 & 1.718 \\
\hline 2 & 1.978 & 1.968 & 1.056 & & 1.238 & 1.928 & 1.821 & 1.214 & 1.807 & 1.901 & 1.853 & 1.823 & 1.803 & 1.788 & 1.776 & 1.767 & 1.760 & 1.728 & 1.705 & 1.608 \\
\hline 2 & & 1.8 & & & & & & & & & & & & & & & & & 1.686 & \\
\hline 2 & 1.946 & 1.88 & 1.8 & & & & & 1.88 & 1.87 & 1.8 & 1.8 & 1.7 & 1.7 & 1.75 & 1.74 & 1.73 & 1.72 & 1.6 & 1.660 & 1.682 \\
\hline 29 & & 1.821 & & & & & & 1.86 & 1.861 & 1.8 & 1.806 & & & & & 1.717 & 1.710 & 1.6 & 1.6 & 1.645 \\
\hline 3 & & & & & & & & & & & & & & & & 1.70 & 1.8 & 1.6 & 1.8 & 1.630 \\
\hline 4 & 1. & & & & & & & 1.7 & 1.7 & 1.7 & 1.6 & 1.6 & & 1.62 & 1.60 & 1.56 & 1.5 & 1.561 & 1.5 & 1.517 \\
\hline 50 & 1.771 & 1.758 & 1.7 & & & & & & & & 1.6 & & & & 44 & 1.534 & 1.5 & 1.4 & 1.4 & 1.448 \\
\hline 60 & & & & & & & & & & & & & & & & & & & & 1.390 \\
\hline 7 & 1.708 & 1.896 & 1.685 & 1.874 & 1.684 & 1.854 & 1.646 & 1.637 & 1.629 & 1.622 & 1.586 & 1.530 & 1.505 & 1.486 & 1.471 & 1.450 & 1.450 & 1.404 & 1.374 & 1.384 \\
\hline 8 & & & & & & & & & & & & & & & & & & & & \\
\hline 9 & & & & & & & & & & & & & & & & 1.4 & 1.4 & 1.3 & $\begin{array}{l}1.326 \\
\end{array}$ & 1.314 \\
\hline 10 & 1.663 & 1.050 & 1.638 & 1.627 & 1.616 & 1.607 & 1.588 & 1.589 & 1.581 & 1.573 & 1.515 & 1.477 & 1.450 & 1.430 & 1.415 & 1.402 & 1.382 & 1.342 & 1.308 & 1.296 \\
\hline & & & & & & & & & & & & & & & & & & & 1.221 & 1.205 \\
\hline 500 & 1.577 & 1.563 & 1.551 & 1.539 & 1.528 & 1.518 & 1.508 & 1.48 & 1.480 & 1.482 & 1.419 & 1.378 & 1.344 & 1.322 & 1.303 & 1.288 & 1.275 & 1.210 & 1.150 & 1.138 \\
\hline 1000 & 568 & 1.563 & 1.540 & $\begin{array}{l}1.528 \\
\end{array}$ & 1.517 & $\begin{array}{l}1.507 \\
\end{array}$ & 1.497 & 1.488 & 1.478 & $\begin{array}{l}1.471 \\
\end{array}$ & 1.406 & 1.363 & $\begin{array}{l}1.332 \\
\end{array}$ & 1.308 & $\begin{array}{l}1.280 \\
\end{array}$ & 1.273 & 1.260 & 1.190 & $\begin{array}{l}1.134 \\
13\end{array}$ & 1.110 \\
\hline
\end{tabular}




\section{Anexo 5 - Tabela de Distribuição F para: 1- $\alpha=99 \%$}

\begin{tabular}{|c|c|c|c|c|c|c|c|c|c|c|c|c|c|c|c|c|c|c|c|c|}
\hline & 21 & 22 & 23 & 24 & 25 & 26 & 27 & 28 & 29 & 30 & 40 & 50 & 60 & 70 & 80 & 90 & 100 & 200 & 500 & 1000 \\
\hline & 6216.113 & 6223.097 & 6228.685 & 6234.273 & 6239.861 & 6244.518 & 6249.174 & 6252.900 & 6257.091 & 6260.350 & 6286.427 & 6302.260 & 6312.970 & 6320.866 & 6326.474 & 6330.665 & 6333.925 & 6349.757 & 6359.536 & 6362.796 \\
\hline 2 & 99.451 & 99.455 & 99.455 & 99.455 & 99.459 & 99.462 & 99.462 & 99.462 & 99.462 & 99.466 & 99.477 & 99.477 & 99.484 & 99.484 & 99.484 & 99.488 & 99.491 & 99.491 & 99.499 & 99.499 \\
\hline 3 & 26.664 & 26.639 & 26.617 & 26.597 & 26.579 & 26.562 & 26.546 & 26.531 & 26.517 & 26.504 & 26.411 & 26.354 & 26.316 & 26.289 & 26.269 & 26.253 & 26.241 & 26.183 & 26.148 & 26.137 \\
\hline 4 & 13.994 & 13.970 & 13.949 & 13.929 & 13.911 & 13.894 & 13.878 & 13.864 & 13.850 & 13.836 & 13.745 & 13.690 & 13.652 & 13.626 & 13.605 & 13.590 & 13.577 & 13.520 & 13.486 & 13.475 \\
\hline 5 & 9.528 & 9.506 & 9.485 & 9.466 & 9.449 & 9.433 & 9.418 & 9.404 & 9.391 & 9.379 & 9.291 & 9.238 & 9.202 & 9.176 & 9.157 & 9.142 & 9.130 & 9.075 & 9.042 & 9.032 \\
\hline 6 & 7.372 & 7.351 & 7.331 & 7.313 & 7.296 & 7.281 & 7.266 & 7.253 & 7.240 & 7.229 & 7.143 & 7.091 & 7.057 & 7.032 & 7.013 & 6.998 & 6.987 & 6.934 & 6.901 & 6.891 \\
\hline 7 & 6.132 & 6.111 & 6.092 & 6.074 & 6.058 & 6.043 & 6.029 & 6.016 & 6.003 & 5.992 & 5.908 & 5.858 & 5.824 & 5.799 & 5.781 & 5.766 & 5.755 & 5.702 & 5.671 & 5.660 \\
\hline 8 & 5.336 & 5.316 & 5.297 & 5.279 & 5.263 & 5.248 & 5.234 & 5.221 & 5.209 & 5.198 & 5.116 & 5.065 & 5.032 & 5.007 & 4.989 & 4.975 & 4.963 & 4.911 & 4.880 & 4.869 \\
\hline$\theta$ & 4.786 & 4.765 & 4.746 & 4.729 & 4.713 & 4.698 & 4.684 & 4.672 & 4.660 & 4.649 & 4.567 & 4.517 & 4.483 & 4.459 & 4.441 & 4.426 & 4.415 & 4.363 & 4.332 & 4.321 \\
\hline 10 & 4.393 & 4.363 & 4.344 & 4.327 & 4.311 & 4.296 & 4.283 & 4.270 & 4.258 & 4.247 & 4.165 & 4.115 & 4.082 & 4.058 & 4.039 & 4.025 & 4.014 & 3.962 & 3.930 & 3.920 \\
\hline 11 & 4.077 & 4.057 & 4.038 & 4.021 & 4.005 & 3.990 & 3.977 & 3.964 & 3.952 & 3.941 & 3.860 & 3.810 & 3.776 & 3.752 & 3.734 & 3.719 & 3.708 & 3.656 & 3.624 & 3.613 \\
\hline 12 & 3.836 & 3.816 & 3.798 & 3.780 & 3.765 & 3.750 & 3.736 & 3.724 & 3.712 & 3.701 & 3.619 & 3.569 & 3.535 & 3.511 & 3.493 & 3.478 & 3.467 & 3.414 & 3.382 & 3.372 \\
\hline 13 & $\begin{array}{l}3.640 \\
3.643\end{array}$ & 3.622 & $\begin{array}{l}3.1504 \\
3.604\end{array}$ & 3.587 & 3.571 & 3.556 & 3.543 & 3.530 & $\begin{array}{l}3.518 \\
3.518\end{array}$ & 3.507 & 3.425 & $\begin{array}{l}3.375 \\
3.375\end{array}$ & 3.341 & 3.317 & $\begin{array}{l}3.490 \\
3.298\end{array}$ & $\begin{array}{l}3.4784 \\
3.284\end{array}$ & 3.272 & 3.219 & $\begin{array}{l}3.302 \\
3.187\end{array}$ & $\begin{array}{l}3.312 \\
3.176\end{array}$ \\
\hline 14 & 3.483 & 3.463 & & 3.427 & 3.412 & & 3.383 & 3.371 & 3.359 & 3.348 & 3.266 & 3.215 & 3.181 & & & 3.124 & & 3.059 & 3.026 & 3.015 \\
\hline 15 & 3.350 & 3.330 & 3.3.311 & 3.294 & 3.278 & 3.264 & 3.250 & 3.237 & 3.225 & 3.214 & 3.132 & 3.081 & 3.047 & 3.022 & 3.004 & 2.989 & 2.977 & 2.923 & 2.891 & 2.880 \\
\hline 16 & 3.237 & 3.216 & 3.198 & 3.181 & 3.165 & 3.150 & 3.137 & 3.124 & 3.112 & 3.101 & 3.018 & 2.967 & 2.933 & 2.908 & 2.889 & 2.875 & 2.863 & 2.808 & 2.775 & 2.764 \\
\hline 17 & 3.139 & 3.119 & 3.101 & 3.083 & 3.066 & 3.053 & 3.039 & 3.026 & 3.014 & 3.003 & 2.920 & 2.869 & 2.835 & 2.810 & 2.791 & 2.776 & 2.764 & 2.709 & 2.676 & 2.664 \\
\hline 18 & 3.055 & 3.035 & 3.016 & 2.999 & 2.983 & 2.968 & 2.955 & 2.942 & 2.930 & 2.919 & 2.835 & 2.784 & 2.749 & 2.724 & 2.705 & 2.690 & 2.678 & 2.623 & 2.589 & 2.577 \\
\hline 18 & 2.991 & 2.961 & 2.942 & 2.925 & 2.909 & & & 2.868 & 2.855 & & 2.761 & 2.709 & & & & & 2.602 & 2.547 & 2.512 & 2.501 \\
\hline 20 & 2.916 & 2.895 & 2.877 & 2.859 & 2.843 & 2.829 & 2.815 & 2.802 & 2.790 & 2.778 & 2.695 & 2.643 & 2.608 & 2.582 & 2.563 & 2.548 & 2.535 & 2.479 & 2.445 & 2.433 \\
\hline 21 & 2.857 & 2.837 & 2.818 & 2.801 & 2.785 & 2.770 & 2.756 & 2.743 & 2.731 & 2.720 & 2.636 & 2.584 & 2.548 & 2.523 & 2.503 & 2.488 & 2.476 & 2.419 & 2.384 & 2.372 \\
\hline 22 & 2.805 & 2.785 & 2.766 & & 2.733 & 2.718 & 2.704 & 2.691 & 2.679 & 2.667 & 2.583 & 2.531 & & & & 2.434 & 2.422 & 2.365 & 2.329 & 2.317 \\
\hline 23 & $\begin{array}{l}2.7000 \\
2.758\end{array}$ & 2.738 & & 2.702 & 2.686 & 2.8 & & 2.644 & $\begin{array}{l}2.619 \\
2.632\end{array}$ & $\begin{array}{l}2.00 \\
2.62\end{array}$ & $\begin{array}{l}2.500 \\
2.536\end{array}$ & 2.48 & & & $\begin{array}{l}2.4001 \\
\end{array}$ & 2.386 & $\begin{array}{l}2.3422 \\
2.373\end{array}$ & $\begin{array}{l}2.300 \\
2.316\end{array}$ & 2.280 & 2.268 \\
\hline 24 & 2.716 & 2.695 & 2.676 & $\begin{array}{l}2.659 \\
\end{array}$ & $\begin{array}{l}2.640 \\
\end{array}$ & 2.628 & $\begin{array}{l}2.614 \\
\end{array}$ & 2.601 & $\begin{array}{l}2.5002 \\
\end{array}$ & $\begin{array}{l}2.52077 \\
\end{array}$ & 2.492 & $\begin{array}{l}2.4400 \\
2.440\end{array}$ & 2.403 & $\begin{array}{l}2.42137 \\
2.375\end{array}$ & 2.357 & $\begin{array}{l}2.3400 \\
2\end{array}$ & $\begin{array}{l}2.329 \\
\end{array}$ & 2.271 & 2.235 & $\begin{array}{l}2.2200 \\
\end{array}$ \\
\hline 25 & 2.677 & 2.657 & 2.638 & 2.620 & 2.604 & 2.589 & 2.575 & 2.562 & 2.550 & 2.538 & 2.453 & 2.400 & 2.364 & 2.337 & 2.317 & 2.302 & 2.289 & 2.230 & 2.194 & 2.182 \\
\hline 28 & 2.642 & 2.621 & 2.6 & 2.5 & 2.5 & 2.5 & 2.540 & 2.526 & 2.51 & 2.5 & 2.4 & 2.364 & 2.327 & 2.301 & 2.281 & 2.265 & 2.252 & 2.193 & 2.156 & 2.144 \\
\hline 27 & 2.609 & 2.589 & 2.570 & 2.552 & 2.536 & 2.521 & 2.507 & 2.494 & 2.481 & 2.470 & 2.384 & 2.330 & 2.294 & 2.267 & 2.247 & 2.231 & 2.218 & 2.159 & 2.122 & 2.109 \\
\hline 28 & 2.579 & 2.559 & 2.540 & 2.522 & 2.506 & 2.491 & 2.477 & 2.464 & 2.451 & 2.440 & 2.354 & 2.300 & $\begin{array}{l}2.264 \\
\end{array}$ & 2.236 & 2.216 & 2.200 & 2.187 & $\begin{array}{l}2.127 \\
\end{array}$ & $\begin{array}{l}2.122 \\
2.090\end{array}$ & $\begin{array}{l}2.077 \\
\end{array}$ \\
\hline 28 & 2.552 & 2.531 & 2.51 & 2.495 & 2.478 & 2.4 & & & 2.423 & 2.412 & & 2.27 & & & & 2. 1.171 & 2.158 & & 2.060 & 2.047 \\
\hline 30 & 2.526 & 2.50 & 2.48 & 2.46 & 2.45 & 2.4 & 2.423 & 2.410 & 2.398 & 2.3 & 2.2. & 2.2 & 2.26 & 2.1 & 2.160 & 2.14 & 2.131 & 2.070 & 2.032 & 2.019 \\
\hline 40 & 2.346 & 2.3 & 2.3 & 2.2 & 2.2 & 2.2 & 2.241 & 2.228 & 2.21 & 2.2 & 2.1 & 2.058 & 2.019 & 1.991 & 1.969 & 1.952 & 1.938 & 1.874 & 1.833 & 1.819 \\
\hline 5 & 2.242 & 2.221 & 2.202 & 2.183 & 2.167 & 2.151 & 2.136 & 2.123 & 2.110 & 2.098 & 2.007 & 1.949 & 1.909 & 1.880 & 1.857 & 1.839 & 1.825 & 1.757 & 1.713 & 1.698 \\
\hline 60 & 2.175 & 2.153 & 2.134 & 2.115 & 2.098 & 2.083 & 2.068 & 2.054 & 2.041 & 2.028 & 1.936 & 1.877 & 1.836 & 1.806 & 1.783 & 1.764 & 1.749 & 1.678 & 1.633 & 1.617 \\
\hline 76 & 2.127 & 2.106 & & 2.0 & 2.0 & & & & & & & & & & & & & & & 1.558 \\
\hline 80 & 2.092 & 2.070 & 2.0 & 20 & 2.0 & & & & 1.9 & & 1.8 & 1.7 & 1.7 & & 1.6 & 1.671 & 1.6 & 1.5 & 1.5 & 1.512 \\
\hline 90 & 2.065 & 2.043 & 2.023 & 2.004 & 1.987 & 1.971 & 1.956 & 1.942 & 1.928 & 1.916 & 1.82 & 1.759 & 1.716 & 1.684 & 1.659 & 1.639 & 1.623 & 1.546 & 1.494 & 1.476 \\
\hline 100 & 2.043 & 2.021 & 2.001 & 1.983 & 1.965 & 1.949 & 1.934 & 1.919 & 1.906 & 1.893 & 1.797 & 1.735 & 1.692 & 1.659 & 1.634 & 1.614 & 1.598 & 1.518 & 1.466 & 1.447 \\
\hline 200 & $\begin{array}{l}1.947 \\
\end{array}$ & $\begin{array}{l}1.925 \\
\end{array}$ & 1.905 & 1.886 & 1.868 & $\begin{array}{l}1.851 \\
\end{array}$ & 1.836 & $\begin{array}{l}1.821 \\
1.82\end{array}$ & $\begin{array}{l}1.807 \\
\end{array}$ & $\begin{array}{l}1.799 \\
\end{array}$ & 1.694 & $\begin{array}{l}1.629 \\
\end{array}$ & $\begin{array}{l}1.5853 \\
\end{array}$ & 1.548 & $\begin{array}{l}1.521 \\
1\end{array}$ & 1.499 & $\begin{array}{l}1.481 \\
\end{array}$ & 1.391 & 1.328 & 1.304 \\
\hline & 1.891 & 1.869 & & & & & & & & & & & & & & & & . & & \\
\hline 10 & $\begin{array}{l}1.8512 \\
\end{array}$ & 1.850 & & & & & & 43 & 1.729 & 1.716 & $\begin{array}{l}1.600 \\
1.613\end{array}$ & $\begin{array}{l}1.540 \\
\end{array}$ & 1.495 & 1.458 & $\begin{array}{l}1.428 \\
\end{array}$ & $\begin{array}{l}1.4204 \\
\end{array}$ & $\begin{array}{l}1.3803 \\
\end{array}$ & $\begin{array}{l}1.278 \\
\end{array}$ & $\begin{array}{l}1.202 \\
1.195\end{array}$ & $\begin{array}{l}1.159 \\
\end{array}$ \\
\hline
\end{tabular}




\section{Anexo 6 - Tabela Distribuição Normal (Área 0 a $+\infty$ )}

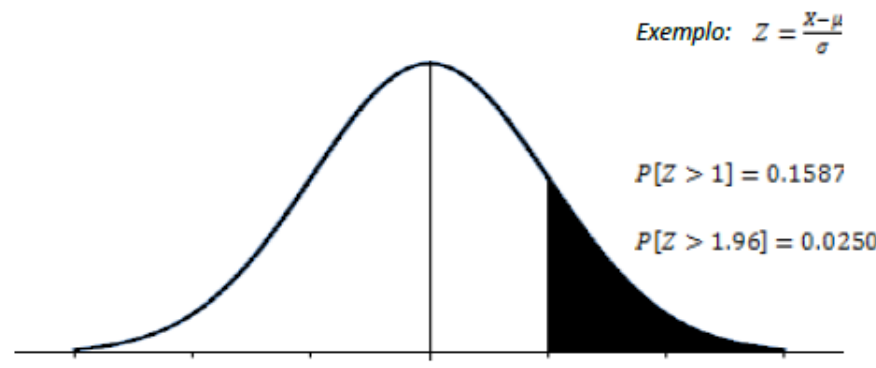

TABELA NORMAL

\begin{tabular}{|c|c|c|c|c|c|c|c|c|c|c|}
\hline $\begin{array}{l}\text { Desv. } \\
\text { Normal z }\end{array}$ & 0.00 & 0.01 & 0.02 & 0.03 & 0.04 & 0.05 & 0.06 & 0.07 & 0.08 & 0.09 \\
\hline 0.0 & 0.5000 & 0.4960 & 0.4920 & 0.4880 & 0.4840 & 0.4801 & 0.4761 & 0.4721 & 0.4681 & 0.4641 \\
\hline 0.1 & 0.4602 & 0.4562 & 0.4522 & 0.4483 & 0.4443 & 0.4404 & 0.4364 & 0.4325 & 0.4286 & 0.4247 \\
\hline 0.2 & 0.4207 & 0.4168 & 0.4129 & 0.4090 & 0.4052 & 0.4013 & 0.3974 & 0.3936 & 0.3897 & 0.3859 \\
\hline 0.3 & 0.3821 & 0.3783 & 0.3745 & 0.3707 & 0.3669 & 0.3632 & 0.3594 & 0.3557 & 0.3520 & 0.3483 \\
\hline 0.4 & 0.3446 & 0.3409 & 0.3372 & 0.3336 & 0.3300 & 0.3264 & 0.3228 & 0.3192 & 0.3156 & 0.3121 \\
\hline 0.5 & 0.3085 & 0.3050 & 0.3015 & 0.2981 & 0.2946 & 0.2912 & 0.2877 & 0.2843 & 0.2810 & 0.27776 \\
\hline 0.6 & 0.2743 & 0.2709 & 0.2676 & 0.2643 & 0.2611 & 0.2578 & 0.2546 & 0.2514 & 0.2483 & 0.2451 \\
\hline 0.7 & 0.2420 & 0.2389 & 0.2358 & 0.2327 & 0.2296 & 0.2266 & 0.2236 & 0.2206 & 0.2177 & 0.2148 \\
\hline 0.8 & 0.2119 & 0.2090 & 0.2061 & 0.2033 & 0.2005 & 0.1977 & 0.1949 & 0.1922 & 0.1894 & 0.1867 \\
\hline 0.9 & 0.1841 & 0.1814 & 0.1788 & 0.1762 & 0.1736 & 0.1711 & 0.1685 & 0.1660 & 0.1635 & 0.1611 \\
\hline 1.0 & 0.1587 & 0.1562 & 0.1539 & 0.1515 & 0.1492 & 0.1469 & 0.1446 & 0.1423 & 0.1401 & 0.1379 \\
\hline 1.1 & 0.1357 & 0.1335 & 0.1314 & 0.1292 & 0.1271 & 0.1251 & 0.1230 & 0.1210 & 0.1190 & 0.1170 \\
\hline 1.2 & 0.1151 & 0.1131 & 0.1112 & 0.1093 & 0.1075 & 0.1056 & 0.1038 & 0.1020 & 0.1003 & 0.0985 \\
\hline 1.3 & 0.0968 & 0.0951 & 0.0934 & 0.0918 & 0.0901 & 0.0885 & 0.0869 & 0.0853 & 0.0838 & 0.0823 \\
\hline 1.4 & 0.0808 & 0.0793 & 0.0778 & 0.0764 & 0.0749 & 0.0735 & 0.0721 & 0.0708 & 0.0694 & 0.0681 \\
\hline 1.5 & 0.0668 & 0.0655 & 0.0643 & 0.0630 & 0.0618 & 0.0606 & 0.0594 & 0.0582 & 0.0571 & 0.0559 \\
\hline 1.6 & 0.0548 & 0.0537 & 0.0526 & 0.0516 & 0.0505 & 0.0495 & 0.0485 & 0.0475 & 0.0465 & 0.0455 \\
\hline 1.7 & 0.0446 & 0.0436 & 0.0427 & 0.0418 & 0.0409 & 0.0401 & 0.0392 & 0.0384 & 0.0375 & 0.0367 \\
\hline 1.8 & 0.0359 & 0.0351 & 0.0344 & 0.0336 & 0.0329 & 0.0322 & 0.0314 & 0.0307 & 0.0301 & 0.0294 \\
\hline 1.9 & 0.0287 & 0.0281 & 0.0274 & 0.0268 & 0.0262 & 0.0256 & 0.0250 & 0.0244 & 0.0239 & 0.0233 \\
\hline 2.0 & 0.0228 & 0.0222 & 0.0217 & 0.0212 & 0.0207 & 0.0202 & 0.0197 & 0.0192 & 0.0188 & 0.0183 \\
\hline 2.1 & 0.0179 & 0.0174 & 0.0170 & 0.0166 & 0.0162 & 0.0158 & 0.0154 & 0.0150 & 0.0146 & 0.0143 \\
\hline 2.2 & 0.0139 & 0.0136 & 0.0132 & 0.0129 & 0.0125 & 0.0122 & 0.0119 & 0.0116 & 0.0113 & 0.0110 \\
\hline 2.3 & 0.0107 & 0.0104 & 0.0102 & 0.0099 & 0.0096 & 0.0094 & 0.0091 & 0.0089 & 0.0087 & 0.0084 \\
\hline 2.4 & 0.0082 & 0.0080 & 0.0078 & 0.0075 & 0.0073 & 0.0071 & 0.0069 & 0.0068 & 0.0066 & 0.0064 \\
\hline 2.5 & 0.0062 & 0.0060 & 0.0059 & 0.0057 & 0.0055 & 0.0054 & 0.0052 & 0.0051 & 0.0049 & 0.0048 \\
\hline 2.6 & 0.0047 & 0.0045 & 0.0044 & 0.0043 & 0.0041 & 0.0040 & 0.0039 & 0.0038 & 0.0037 & 0.0036 \\
\hline 2.7 & 0.0035 & 0.0034 & 0.0033 & 0.0032 & 0.0031 & 0.0030 & 0.0029 & 0.0028 & 0.0027 & 0.0026 \\
\hline 2.8 & 0.0026 & 0.0025 & 0.0024 & 0.0023 & 0.0023 & 0.0022 & 0.0021 & 0.0021 & 0.0020 & 0.0019 \\
\hline 2.9 & 0.0019 & 0.0018 & 0.0018 & 0.0017 & 0.0016 & 0.0016 & 0.0015 & 0.0015 & 0.0014 & 0.0014 \\
\hline 3.0 & 0.0013 & 0.0013 & 0.0013 & 0.0012 & 0.0012 & 0.0011 & 0.0011 & 0.0011 & 0.0010 & 0.0010 \\
\hline
\end{tabular}




\section{Anexo 7 - Tabela Distribuição Normal (Área - $\infty$ a 0)}

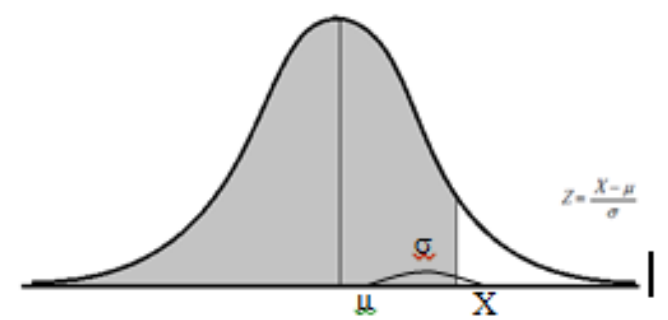

\begin{tabular}{|c|c|c|c|c|c|c|c|}
\hline$z$ & $\phi(\mathrm{z})$ & $\mathrm{z}$ & $(\mathrm{z})$ & $z$ & $\phi(\mathrm{z})$ & $z$ & $\phi(\mathrm{z})$ \\
\hline 0.00 & 0.5000 & 0.62 & 0.7324 & 1.24 & 0.8925 & $\overline{1.86}$ & 0.9686 \\
\hline 0.02 & 0.5080 & 0.64 & 0.7389 & 1.26 & 0.8962 & 1.88 & 0.9699 \\
\hline 0.04 & 0.5160 & 0.66 & 0.7454 & 1.28 & 0.8997 & 1.90 & 0.9713 \\
\hline 0.06 & 0.5239 & 0.68 & 0.7517 & 1.30 & 0.9032 & 1.92 & 0.9726 \\
\hline 0.08 & 0.5319 & 0.70 & 0.7580 & 1.32 & 0.9066 & 1.94 & 0.9738 \\
\hline 0.10 & 0.5398 & 0.72 & 0.7642 & 1.34 & 0.9099 & 1.96 & 0.9750 \\
\hline 0.12 & 0.5478 & 0.74 & 0.7704 & 1.36 & 0.9131 & 1.98 & 0.9761 \\
\hline 0.14 & 0.5557 & 0.76 & 0.7764 & 1.38 & 0.9162 & 2.00 & 0.9772 \\
\hline 0.16 & 0.5636 & 0.78 & 0.7823 & 1.40 & 0.9192 & 2.02 & 0.9783 \\
\hline 0.18 & 0.5714 & 0.80 & 0.7881 & 1.42 & 0.9222 & 2.04 & 0.9793 \\
\hline 0.20 & 0.5793 & 0.82 & 0.7939 & 1.44 & 0.9251 & 2.06 & 0.9803 \\
\hline 0.22 & 0.5871 & 0.84 & 0.7995 & 1.46 & 0.9279 & 2.08 & 0.9812 \\
\hline 0.24 & 0.5948 & 0.86 & 0.8051 & 1.48 & 0.9306 & 2.10 & 0.9821 \\
\hline 0.26 & 0.6026 & 0.88 & 0.8106 & 1.50 & 0.9332 & 2.12 & 0.9830 \\
\hline 0.28 & 0.6103 & 0.90 & 0.8159 & 1.52 & 0.9357 & 2.14 & 0.9838 \\
\hline 0.30 & 0.6179 & 0.92 & 0.8212 & 1.54 & 0.9382 & 2.16 & 0.9846 \\
\hline 0.32 & 0.6255 & 0.94 & 0.8264 & 1.56 & 0.9406 & 2.18 & 0.9854 \\
\hline 0.34 & 0.6331 & 0.96 & 0.8315 & 1.58 & 0.9429 & 2.20 & 0.9861 \\
\hline 0.36 & 0.6406 & 0.98 & 0.8365 & 1.60 & 0.9452 & 2.22 & 0.9868 \\
\hline 0.38 & 0.6480 & 1.00 & 0.8413 & 1.62 & 0.9474 & 2.24 & 0.9875 \\
\hline 0.40 & 0.6554 & 1.02 & 0.8461 & 1.64 & 0.9495 & 2.26 & 0.9881 \\
\hline 0.42 & 0.6628 & 1.04 & 0.8508 & 1.66 & 0.9515 & 2.28 & 0.9887 \\
\hline 0.44 & 0.6700 & 1.06 & 0.8554 & 1.68 & 0.9535 & 2.30 & 0.9893 \\
\hline 0.46 & 0.6772 & 1.08 & 0.8599 & 1.70 & 0.9554 & 2.32 & 0.9898 \\
\hline 0.48 & 0.6844 & 1.10 & 0.8643 & 1.72 & 0.9573 & 2.34 & 0.9904 \\
\hline 0.50 & 0.6915 & 1.12 & 0.8686 & 1.74 & 0.9591 & 2.36 & 0.9909 \\
\hline 0.52 & 0.6985 & 1.14 & 0.8729 & 1.76 & 0.9608 & 2.38 & 0.9913 \\
\hline 0.54 & 0.7054 & 1.16 & 0.8770 & 1.78 & 0.9625 & 2.40 & 0.9918 \\
\hline 0.56 & 0.7123 & 1.18 & 0.8810 & 1.80 & 0.9641 & 2.42 & 0.9922 \\
\hline 0.58 & 0.7190 & 1.20 & 0.8849 & 1.82 & 0.9656 & 2.44 & 0.9927 \\
\hline 0.60 & 0.7257 & 1.22 & 0.8888 & 1.84 & 0.9671 & 2.46 & 0.9931 \\
\hline
\end{tabular}

